Florida International University FIU Digital Commons

\title{
Endogenous Risk Perception, Geospatial Characteristics and Temporal Variation in Hurricane Evacuation Behavior
}

Subrina Tahsin

stahs002@fiu.edu

DOI: $10.25148 /$ etd.FI14071166

Follow this and additional works at: https://digitalcommons.fiu.edu/etd

\section{Recommended Citation}

Tahsin, Subrina, "Endogenous Risk Perception, Geospatial Characteristics and Temporal Variation in Hurricane Evacuation Behavior" (2014). FIU Electronic Theses and Dissertations. 1513.

https://digitalcommons.fiu.edu/etd/1513 


\section{FLORIDA INTERNATIONAL UNIVERSITY \\ Miami, Florida}

ENDOGENOUS RISK PERCEPTION, GEOSPATIAL CHARACTERISTICS AND TEMPORAL VARIATION IN HURRICANE EVACUATION BEHAVIOR

A thesis submitted in partial fulfillment of

the requirements for the degree of

MASTER OF SCIENCE

in

ENVIRONMENTAL STUDIES

by

Subrina Tahsin 
To: Interim Dean Michael R. Heithaus

College of Arts and Sciences

This thesis, written by Subrina Tahsin, and entitled Endogenous Risk Perception, Geospatial Characteristics and Temporal Variation in Hurricane Evacuation Behavior, having been approved in respect to style and intellectual content, is referred to you for judgment.

We have read this thesis and recommend that it be approved.

$\begin{array}{r}\hline \text { Keqi Zhang } \\ \hline \text { Hugh Gladwin } \\ \hline \text { B. M. Golam Kibria } \\ \hline \text { Pallab Mozumder, Major Professor }\end{array}$

Date of Defense: June 13, 2014

The thesis of Subrina Tahsin is approved.

Interim Dean Michael R. Heithaus
College of Arts and Sciences

Dean Lakshmi N. Reddi

University Graduate School

Florida International University, 2014 
(C) Copyright 2014 by Subrina Tahsin

All rights reserved. 


\section{DEDICATION}

I dedicate this thesis to my parents, siblings and spouse. Without their patience, understanding, support, and most of all love, the completion of this work would not have been possible. 


\section{ACKNOWLEDGMENTS}

I would like to thank my thesis committee members for their support, patience, and guidance. Dr. Keqi Zhang was very helpful in clarifying relevant concepts and directing towards correct data sources. Dr. Hugh Gladwin provided me a very rich dataset which gave me the opportunity to materialize the unique concept of my research. I received comments from Dr. Golam Kibria time to time while writing my thesis. Finally, I would like to thank my major professor, Dr. Pallab Mozumder. From the beginning, he had accelerated my ability by his clear and inspiring comments. His confidence on my ability and my thirst for research was an excellent match throughout the entire period of my thesis. He was especially helpful in identifying innovative and very important topic in disaster management field. I am also thankful to my classmates who helped me in reviewing my writings.

Finally I would like to thank the National Science Foundation for their funding for the original survey. Without the informative survey, this research would not have been possible. 


\begin{abstract}
OF THE THESIS
ENDOGENOUS RISK PERCEPTION, GEOSPATIAL CHARACTERISTICS AND

TEMPORAL VARIATION IN HURRICANE EVACUATION BEHAVIOR
\end{abstract}

by

Subrina Tahsin

Florida International University, 2013

Miami, Florida

\title{
Professor Pallab Mozumder, Major Professor
}

The main focus of this thesis was to gain a better understanding about the dynamics of risk perception and its influence on people's evacuation behavior. Another major focus was to improve our knowledge regarding geo-spatial and temporal variations of risk perception and hurricane evacuation behavior. A longitudinal dataset of more than eight hundred households were collected following two major hurricane events, Ivan and Katrina. The longitudinal survey data was geocoded and a geo-spatial database was integrated to it. The geospatial database was composed of distance, elevation and hazard parameters with respect to the respondent's household location. A set of Bivariate Probit (BP) model suggests that geospatial variables have had significant influences in explaining hurricane risk perception and evacuation behavior during both hurricanes. The findings also indicated that people made their evacuation decision in coherence with their risk perception. In addition, people updated their hurricane evacuation decision in a subsequent similar event. 


\section{TABLE OF CONTENTS}

CHAPTER

PAGE

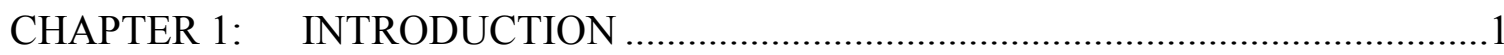

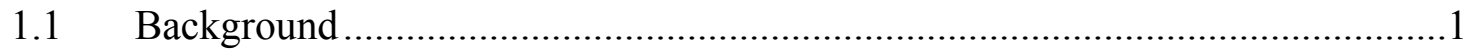

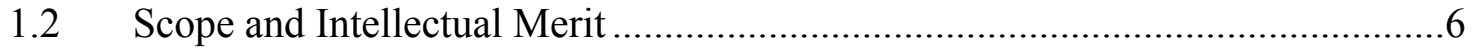

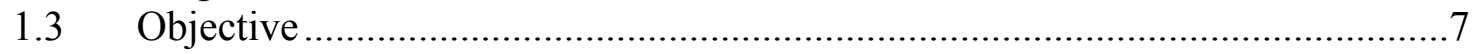

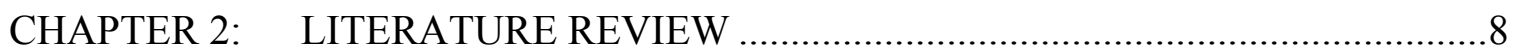

2.1 Past Research on Determinants of Hurricane Evacuation ..................................

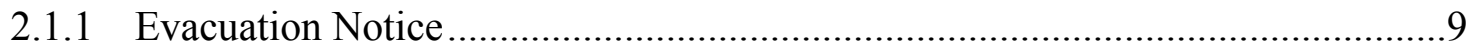

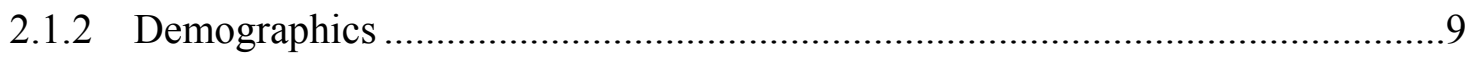

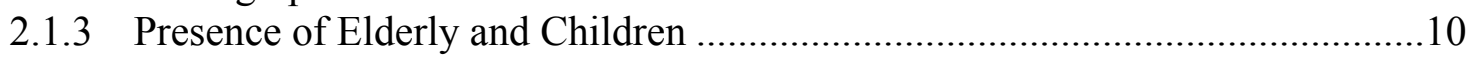

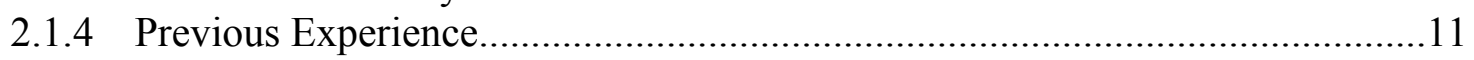

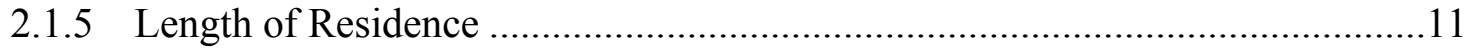

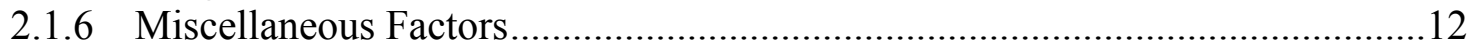

2.2 Past Research on Determinants of Hazard Risk Perception ..............................12

2.3 Role of Geographical Factors on Hazard Risk Perception and

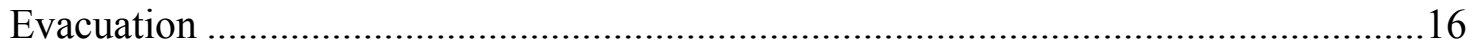

2.4 Human Behavior Adjustment at Extreme Weather Condition: Panel

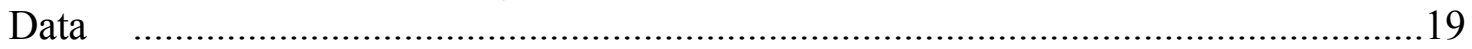

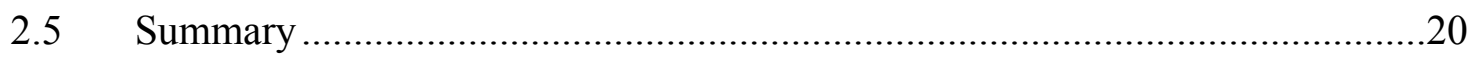

CHAPTER 3: SURVEY DATA COLLECTION AND DATA DESCRIPTION..........21

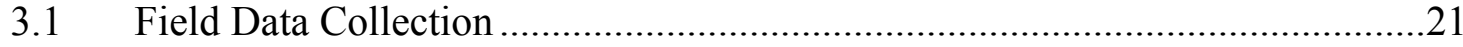

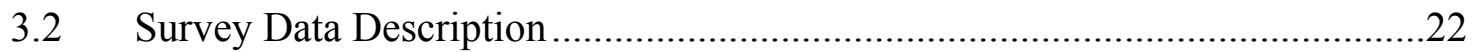

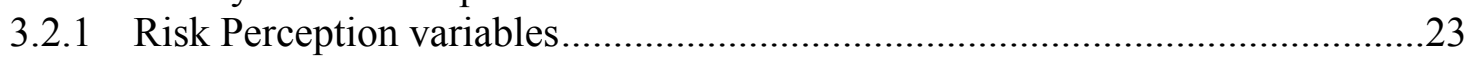

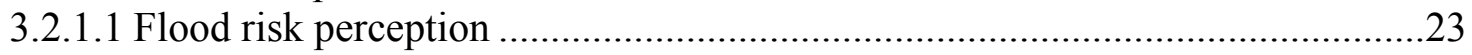

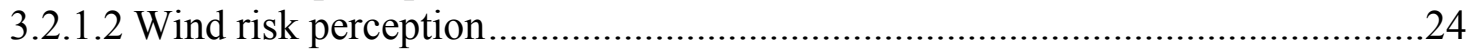

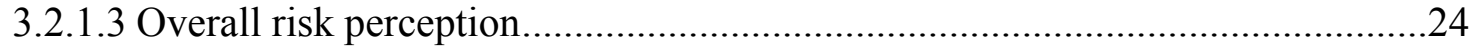

3.2.2 Evacuation Behavior in Terms of Risk Measures............................................25

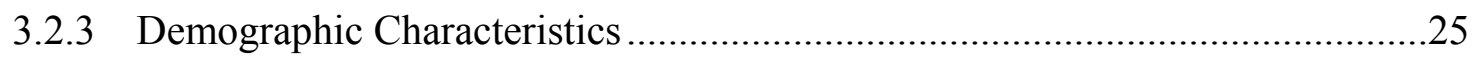

3.2.4 Socio-Economic Characteristics of the Household........................................25

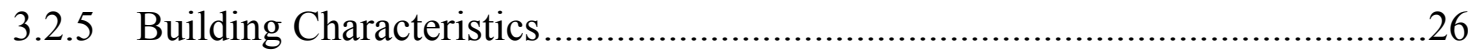

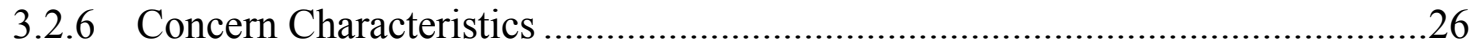

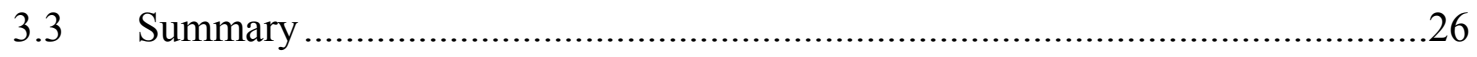

CHAPTER 4: DATA AND METHODS: GEO-SPATIAL DATABASE ......................27

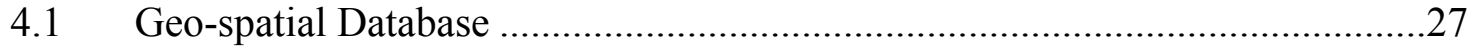

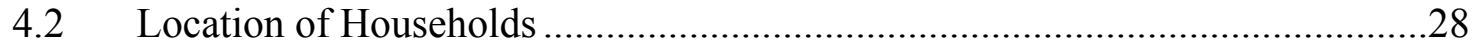

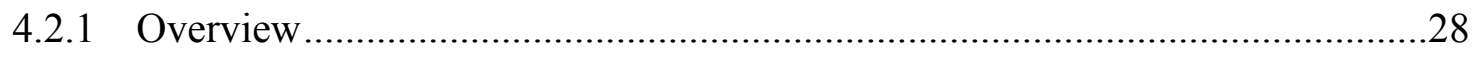

4.2.2 Theory of Map Projection and Geocoding .....................................................28

4.2.3 Implication of Map Projection and Geocoding ...............................................29

4.3 Elevation of Household Location .................................................................30 


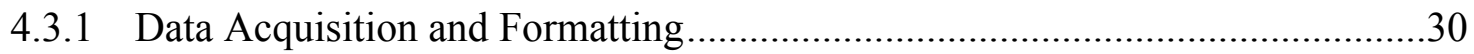

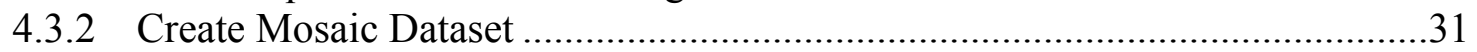

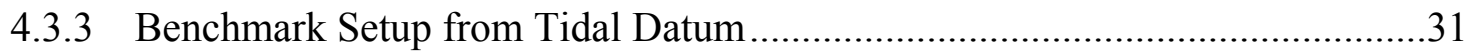

4.3.4 Tidal Station Surface Interpolation ..................................................................

4.3.5 Household Elevation Derivation from Mean Sea Level .......................................33

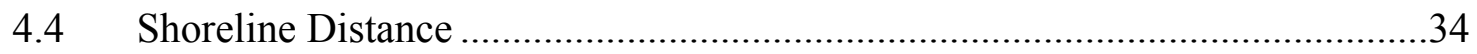

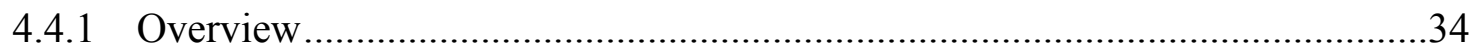

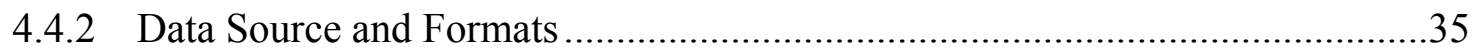

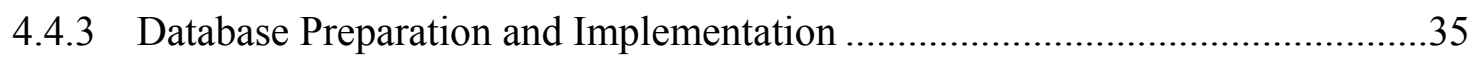

4.5 Distance from Hurricane Tract ..................................................................

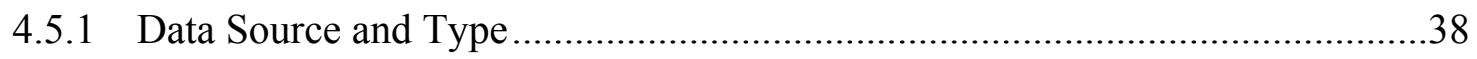

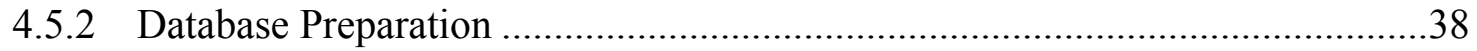

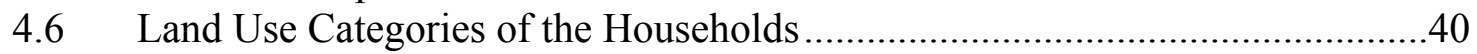

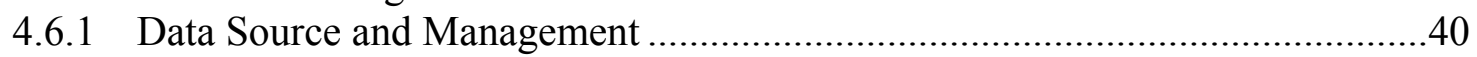

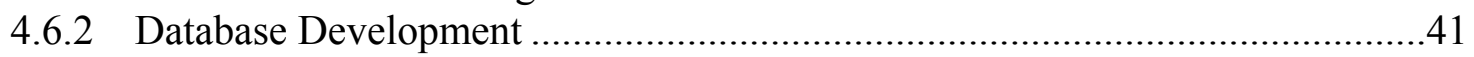

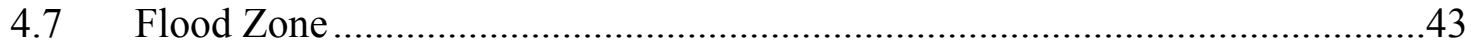

4.7.1 Data Acquisition, Management and Database Development ………………....43

4.8 Wind Profile of the Study Area during Hurricane Events ..................................45

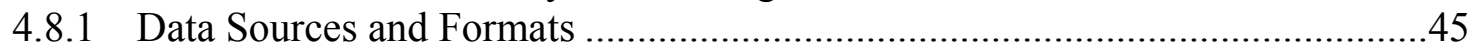

4.8.2 Wind Database Development Using Geo-statistical Kriging ...........................46

4.8.3 Maximum Sustained Wind (MSW) Database Development .............................47

4.8.4 Theory of Ordinary Kriging and Its Components............................................47

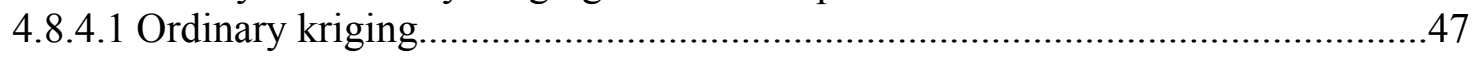

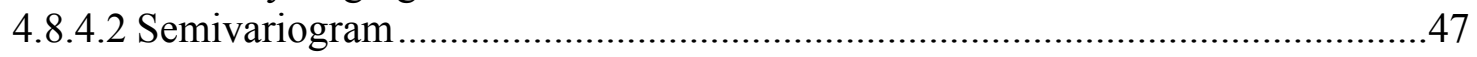

4.8.5 Hurricane Ivan MSW Database Development..............................................48

4.8.6 Hurricane Katrina MSW Database Development ..........................................50

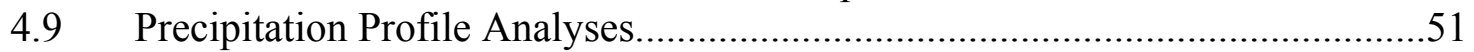

4.9.1 Hurricane Katrina Precipitation Database ...................................................52

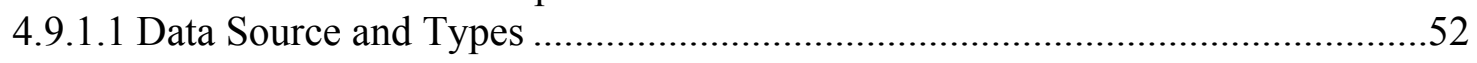

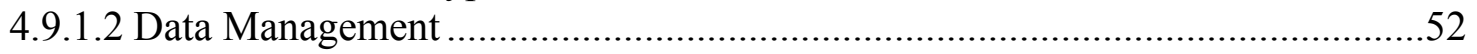

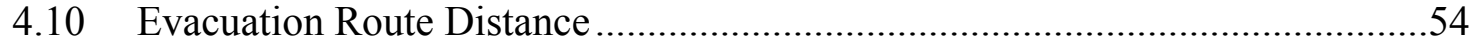

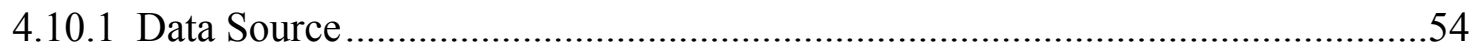

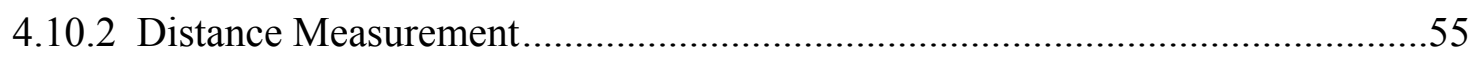

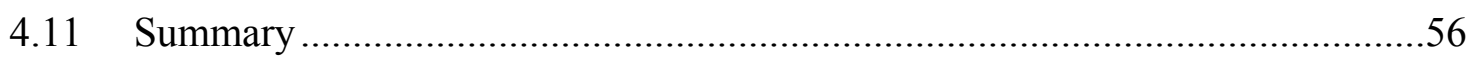

CHAPTER 5: EMPIRICAL SPECIFICATIONS ………………….....................57

5.1 Model Specification (Bivariate Probit Model) ……........................................58

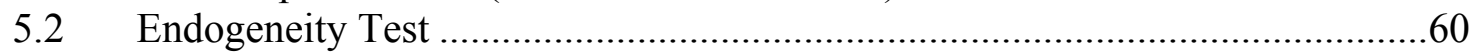

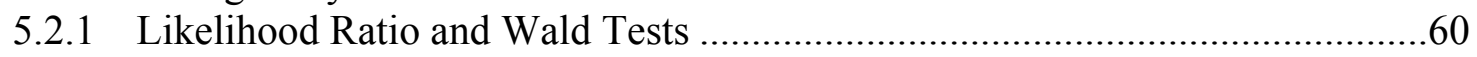

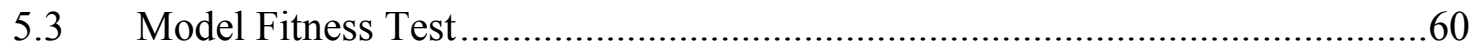

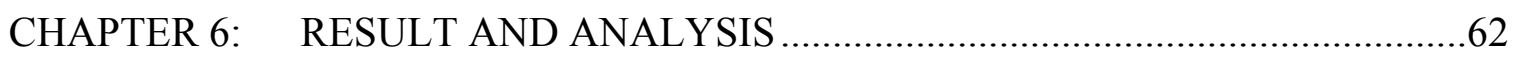

6.1 Bivariate Probit Model of Household Overall Risk Perception..........................62

6.1.1 Role of Socio-Economic and Context Specific Factors on Risk Perception . 
6.1.2 Geographical Dimensions of Risk Perception

6.1.3 Geospatial and Social Dimension of Evacuation Decision in Response

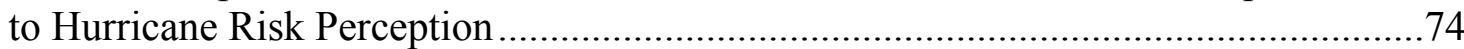

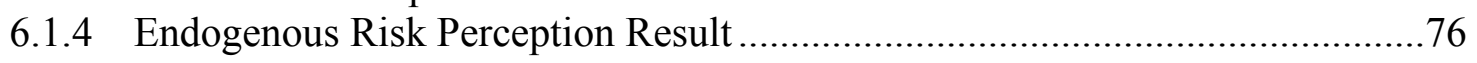

6.2 Influence of Flood and Wind Risk Perception on Evacuation Decision ...........76

6.3 Geospatial and Social Dimension of Household Flood Risk Perception...........79

6.3.1 Endogenous Flood Risk Perception Result.................................................84

6.4 Geospatial and Social Dimension of Household Wind Risk Perception ...........85

6.4.1 Endogenous Wind Risk Perception Result .....................................................90

6.5 Hurricane Katrina: Evidence of Near-Miss Phenomena .................................90

6.5.1 Modeling Hurricane Katrina ...................................................................90

6.5.2 Socio-Economic Factors Influencing Evacuation Decision ..........................93

6.6 Near-Miss Evidence from Hurricane Katrina ............................................... 101

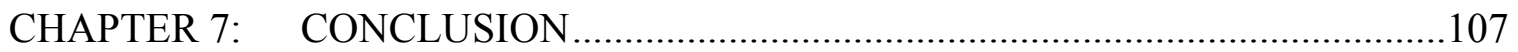

7.1 Implications of Results on Emergency Management Practices.......................109

Future Research ................................................................................ 110

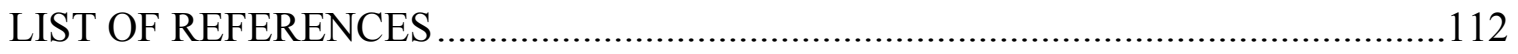




\section{LIST OF TABLES}

TABLE

PAGE

Table 4-1: Summary statistics of elevation of households in the three states .................. 33

Table 4-2: Distance from hurricane Ivan tract (in meter) .......................................... 38

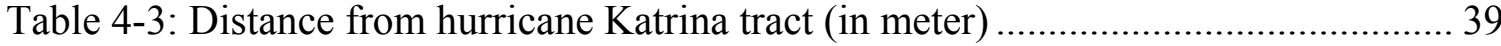

Table 4-4: Statistical description of route distance from household.............................. 55

Table 6-1: Variable definitions and descriptive statistics of hurricane Ivan ................... 64

Table 6-2: Probability of risk perception on evacuation decision, Bivariate Probit specification and marginal effects

Table 6-3: Probability of flood risk perception on evacuation decision during hurricane

Ivan, Bivariate Probit specification and marginal effects....

Table 6-4: Probability of wind risk perception on evacuation decision during hurricane

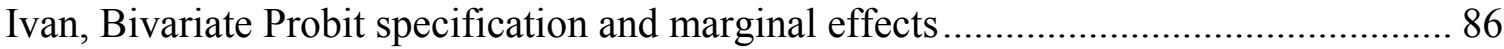

Table 6-5: Evacuation decision during hurricane Ivan and hurricane Katrina ................ 91

Table 6-6: Descriptive statistics of the variables during hurricane Katrina..................... 92

Table 6-7: Determinants of evacuation decision during hurricane Katrina..................... 96

Table 6-8: Contingency Tables: Timing of Evacuation during Ivan or Timing of

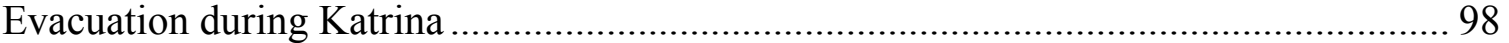

Table 6-9: Correlation matrix between geospatial variables ....................................... 100 


\section{LIST OF FIGURES}

FIGURE

PAGE

Figure 3-1: Perceived vulnerability from flooding (flood) at different storm levels........ 24

Figure 3-2: Perceived vulnerability from wind (wind) at different storm levels .............. 24

Figure 4-1: Geocoded households in the study area …………………....................... 29

Figure 4-2: Flow chart for the methodology to measure elevation of households (MSL) 30

Figure 4-3: Hypothetical tidal datum showing relation with MSL and NAVD88 ........... 32

Figure 4-4: Surface interpolation from the difference between MSL and NAVD88 at

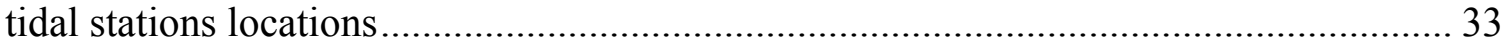

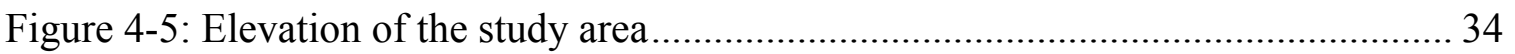

Figure 4-6: Flow chart for the methodology to shoreline distance measurement............. 35

Figure 4-7: Distance from a point to a polyline .......................................................... 36

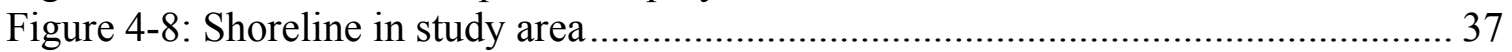

Figure 4-9: Flow chart for the methodology to tract distance measurement .................... 37

Figure 4-10: Distance from hurricane Ivan tract to household ........................................ 39

Figure 4-11: Flowchart of land use database construction ............................................. 41

Figure 4-12: Land use pattern in the study area............................................................ 42

Figure 4-13: Flowchart of flood zone database construction for both hurricane Ivan and

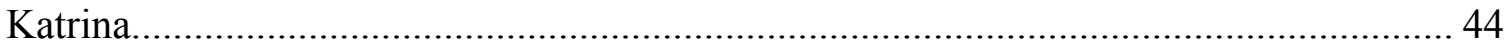

Figure 4-14: Floodplain Map of the Study Area............................................................ 44

Figure 4-15: Flowchart of wind database construction for hurricane Ivan and Katrina... 45

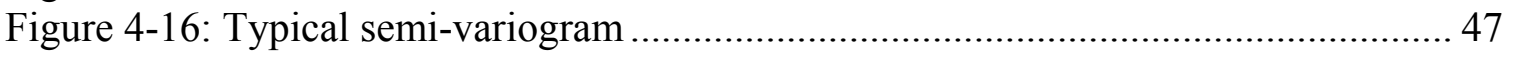

Figure 4-17: Semivariogram of the maximum sustained wind (in knots) ........................ 48

Figure 4-18: Cross validation for error in predicted wind value ………………............ 48

Figure 4-19: Variogram analysis for predicted wind value ......................................... 48

Figure 4-20: Wind profile during Ivan......................................................................... 49

Figure 4-21: Cross validation for predicted wind value ………………………............ 50

Figure 4-22: Variogram analysis of Ivan wind profile mapping ..................................... 50

Figure 4-23: Wind profile during hurricane Katrina........................................................ 51

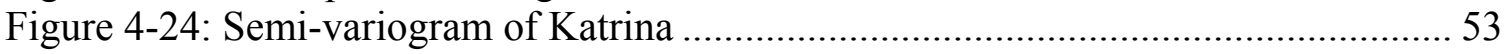

Figure 4-25: Cross-validation of Katrina precipitation profile ......................................... 53

Figure 4-26: Hurricane Ivan precipitation profile...................................................... 53

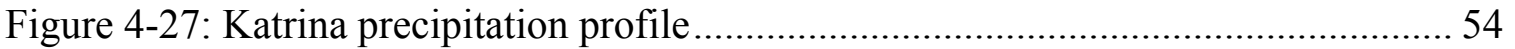

Figure 4-28: Evacuation route and decision during hurricane Ivan.................................. 55

Figure 4-29: Evacuation route and decision during hurricane Katrina.............................. 56

Figure 6-1: Mapping risk perception and shoreline distance.......................................... 69

Figure 6-2: Geographic pattern of overall risk perception (wind and flood)................... 73

Figure 6-3: Evacuation decision and risk perception....................................................... 74

Figure 6-4: Total percentage of wind and flood risk perception ...................................... 77

Figure 6-5: Variability in risk perception for flood and wind .......................................... 78 
Figure 6-6: Comparison of evacuation timing during hurricane Ivan and hurricane

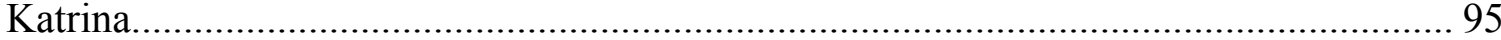




\section{CHAPTER 1: $\quad$ INTRODUCTION}

\subsection{Background}

Coastal communities in the U.S. and around the world are continuously threatened by hurricanes, floods and storm surges under current climatic conditions. Hurricanes are affecting human lives and damaging properties and critical infrastructures regularly in coastal areas. While storm surge and heavy winds are major concerns along the coastline, people located inland are also vulnerable to flooding from rainfall, wind force or tornadoes (Rappaport 2000). Over the 80 years of record from 1926 to 2005, the average annual normalized damage of hurricanes in the continental U.S. is estimated to be about $\$ 10$ billion (Pielke et. al, 2008). These storms have become the costliest natural disasters in the USA (Hasan et. al, 2010). With the changing pattern of climate, the hurricanes and related impacts are getting stronger. Examination of a 30 year hurricane trend found that Atlantic tropical cyclones are getting stronger which is related to an increase in ocean temperatures over the Atlantic Ocean (Elsner, Kossin and Jagger, 2008, Emanuel, 2005). Even though these coastal areas are vulnerable, more and more people increasingly inhabit these coastal locations due to favorable amenities. Without strict regulation on the growing population in coastal areas, damage will increase day by day (Pielke et. al, 2008). The 2005 Atlantic hurricane season was one of the most active and harmful hurricane seasons in recorded history. During that time, hurricane Katrina killed approximately 2,300 people and damaged more than $\$ 130$ billion (NHC, 2006).

Natural disasters associated with extreme weather such as hurricanes pose broad challenges for both emergency officials and responders. The immediate challenge comes from the extreme weather itself, destruction of built environment, and the cost it poses 
on exposed populations. The next challenge arises from how general people respond to the extreme weather events in terms of taking the decision to evacuate to avoid the risk. However, substantial risk is associated with the evacuation process itself. Mass evacuation in anticipation of storms brings the possibility of a significant portion of evacuees trapped in congested roadways when the hurricane strikes (Stein, Dueñas, Osorio and Subramanian, 2010). For instance, large numbers of evacuees were trapped in a traffic jam in New Orleans during Hurricane Katrina and in Houston during Hurricane Rita. It is also threatening for people who were waiting in traffic jams for a longer period on evacuation routes which were located parallel to surge-prone bays. A landfall in this type of situation can bring massive loss of lives while thousands of people were waiting inside risk zones close to storm surges (Lindell et al. 2005).

Given that hurricanes can cause widespread destruction and there are enormous management challenges associated with the emergency evacuation process, people can become demotivated after experiencing problems with evacuation. Therefore an efficient evacuation strategy is critical for saving their lives. A new level of urgency among researchers and emergency management agencies have arisen after reviewing the critical role of evacuation in saving lives, especially after the 2005 Atlantic hurricane season. To manage the evacuation process, it is important to note that evacuation is not an individual decision but a household aggregate decision. A thorough and careful understanding of the determinants of evacuation behavior is therefore needed for emergency managers to protect the loss of lives in vulnerable communities (Hasan et. al, 2010). Therefore, understanding the evacuation behavior would help to develop effective community evacuation plans (Fischer et al. 1995). A planned evacuation can help to 
reduce loss of lives, properties and emergency management costs. Information regarding people's needs during evacuation is also very useful in any disaster risk management plan. Despite growing hurricane risk in the Gulf of Mexico and in the Southeast U.S., there are not many studies that have investigated hurricane evacuation of the same group of people for multiple hurricanes. Hurricane evacuation study gives the opportunity to understand the evolution of risk preference over time.

Another complexity added in the evacuation process is households' understanding about their risk exposure. In spite of similar education and income status, some households tend to evacuate while some do not. The variety of responses indicates that all households do not perceive the risk in the same way. Another potential risk for evacuees from zones under an evacuation advisory is to be trapped in congested traffic caused by evacuees from zones not under an evacuation advisory. These people who evacuated unnecessarily are referred to as shadow evacuees (Dash and Gladwin, 2007; Henk et al., 2007). Shadow evacuation is the consequence of the fact that a household's decision making process under such situation is not only influenced by people's preparation and arrangement but also people's own perception which is influenced by many factors (Gladwin et al., 2007). It is evident that a significant amount of research has been done on the character of evacuees and non-evacuees, compared to the amount of research conducted on household evacuation decision and relating that evacuation decision with household risk perception.

Therefore, an emerging challenge for emergency officials is how to best inform and organize public responses to these emergency events. One of the persistent problems for emergency officials is obtaining public compliance to evacuation orders. The failure 
to comply with evacuation advisories has often resulted in a greater incidence of bodily harm, loss of property, and inconvenience (Dash \& Gladwin, 2007; Henk et al., 2007; Stein, Dueñas-Osorio, \& Subramanian, 2010).

In the light of above discussion, the present study focuses on analyzing two particular hurricane evacuation processes and people's risk perception about those events at the time the storms were moving towards land. The central idea of this study is to rigorously understand people's evacuation behavior using longitudinal data gathered from hurricane Ivan and hurricane Katrina. The present study is investigating people's risk perception and its influence on the household evacuation decision making process. Availability of longitudinal data is rare in studying natural disasters, and a careful investigation of longitudinal data can enlighten us with temporal dynamics of evacuation behavior.

The recent two major hurricanes, Ivan and Katrina left a traumatic impact on many people's lives. Both of these hurricanes hit almost the same areas in two consecutive years. The first hurricane, Ivan, made landfall on the night of September 1516, 2004 near the Alabama-Florida state line. It was a category 5 hurricane on the SaffirSimpson scale when it was in the southern Gulf of Mexico (Douglass et al., 2004). It pushed storm surges as high as 20 feet in some places into Lake Pontchartrain and flooded several miles in Louisiana. Up to 80 percent of the homes and properties in Louisiana were flooded and severely damaged by wind and water (Laska, 2008). The official estimate is that up to 600,000 persons evacuated from metropolitan New Orleans between September 13 and September 15 (the last three days before landfall). Because of the high volume of evacuees, emergency management officials had to face major 
evacuation challenges including long traffic jams which made the evacuation time up to eleven hours to go the distance usually traveled in less than one and a half hour (Laska, 2008).

Just after one year, the second hurricane Katrina made landfall on the Gulf Coast between the major cities of New Orleans (Louisiana) to the west and Mobile (Alabama) to the east. On the morning of August 29, 2005, in the swath of the storm along the Gulf Coast and inland, hurricane Katrina displaced hundreds of thousands of families in three states (Louisiana, Mississippi, and Alabama) and killed more than 1,000 people (Gabe et al, 2005). Congressional Research Service (CRS) estimated that more than 700,000 people may have been severely impacted by hurricane Katrina, as a result of residing in areas that were flooded or sustained significant structural damages (Gabe et al, 2005). The total property damage was estimated at $\$ 81$ billion (Knabb et al., 2005).

The significant loss of lives and properties in addition to evacuation problems indicates that better evacuation planning is necessary to reduce the casualties. A large number of residents who evacuated during hurricane Ivan reported long traffic delays (Laska, 2008). But hurricane Ivan eventually did not hit the area. Such experiences can be seen as a precursor of the 'cry wolf' phenomenon that may have negatively affected evacuation behavior in the wake of hurricane Katrina in 2005. However, survey evidence from hurricane Katrina does not tend to provide much support for the "cry wolf' effect. In spite of many constraints, more people evacuated during Katrina than during Ivan. It seems that other context-specific factors such as forecast information, timing of the information received, and time available to evacuate and relevant geospatial factors such as shoreline distance, wind gust exposure before hurricane landfall, 
and elevation of household property may explain people's risk perception and evacuation behavior during these two hurricanes. Therefore, the current research analyzes the influence of geospatial factors on people's risk perception and how the risk perception influences evacuation behavior. People's risk perception refers to the subjective belief structure regarding the vulnerability of a disaster event which can be influenced by physical and objective risk factors. To cover the complex process of risk perception, both subjective and objective phenomena were included (e.g., wind gust, household elevation, distance from shoreline etc.).

\subsection{Scope and Intellectual Merit}

The focus of the research is to improve our understanding of the role of geospatial factors on risk perception which drives evacuation behavior during disaster events from several new perspectives. Firstly, current study addresses the gap in the hazards literature and provides improved understanding of the role of locational or geospatial phenomena on evacuation behavior. Secondly, the study examines a longitudinal dataset which allows conducting temporal changes in evacuation behavior. It is assumed that some people may exhibit change in evacuation behavior in a positive way, while some others may not change evacuation behavior. Thirdly, the dataset allows analyzing people's actual evacuation decision and not just their intention for future events.

Finally, current study takes into account endogeneity of risk perception which eventually drives evacuation behavior. The consideration of endogeneity of risk perception has improved the analysis of the evacuation behavior. Under this proposition, factors that are salient to risk perception (e.g., geographic variables, demographics and 
socio-economic variables) should be included in explaining risk perception which eventually explains the evacuation behavior as well.

\subsection{Objective}

The overall objective of the research can be summarized as follows.

1. To explore the influence of geo-spatial factors in respondent's endogenous risk perception about hurricane impacts;

2. To explore the influence of risk perception and geo-spatial factors in respondent's evacuation decision;

3. To analyze the influence of flood and wind risk perceptions on evacuation behavior;

4. To investigate change in respondent's evacuation behavior over time from hurricane Ivan to Katrina. 


\section{CHAPTER 2: $\quad$ LITERATURE REVIEW}

The current chapter provides a review of the literature pertaining to the hurricane risk perception and evacuation process. The first section of the chapter presents a review of the hazards literature which addresses the determinants of evacuation behavior, particularly during hurricanes. In other words, it focuses on the characteristics of evacuees or non-evacuees in past hurricanes. The second section discusses the determinants of risk perception in different hazard contexts. This third section of this chapter reviews literature on the role of geographical factors in risk perception that may influence the evacuation decision. The final section of this chapter reviews literature on longitudinal analyses of human behavior in past hurricane events.

\subsection{Past Research on Determinants of Hurricane Evacuation}

Understanding evacuation behavior, that is who evacuates and who does not, has been one of the major focuses of natural hazard research. Evacuation process needs to move large numbers of threatened population into safer areas. Understanding evacuation intention is a part of the planning puzzle (Pfister, 2002). While mass evacuation is always preferable, some residents prefer to stay at home during a disaster event. Such individual choice is a protected right as long as people do not interfere with the evacuation process. There are considerable debates and some evidence that suggests that staying may be a reasonable response for people who are well-prepared and that evacuating later rather than earlier, or not at all, may increase risks in some circumstances (Lindell et al., 2006). A significant number of earlier studies investigated the influence of various socio-economic and demographic factors in evacuation behavior. 


\subsubsection{Evacuation Notice}

Letson et al. (2007) present an assessment of the economic theory concerning individual's behavior with respect to hurricane forecasts and evacuation choices. They emphasized the importance of considering hurricane forecasts in studying evacuation behavior under hurricane threat, since this information may act as a decision aid to reduce uncertainty. Some other researchers provided evidence supporting that evacuation order increases evacuation probability (Baker, 1991; Lindell, Lu and Prater, 2005; Whiteheat et. al., 2000). However, Dow and Cutter (1998) suggested inaccurate forecasts may reduce household reliance on forecast information and reduce their perception of a hurricane threat and consequently, reduce evacuation rates. The dual influence of evacuation notice on user motivation in different hurricanes suggests more investigation into this matter is needed.

\subsubsection{Demographics}

A good part of other literature has focused on effects of household demography on evacuation decision. Whitehead et al. (2000) found that gender had significant effects in the decision to evacuate. There are differences in perceiving risk about natural disaster between men and women. While women feel "risky" and believe that the disaster will become worse, men feel "in control" in the same situation (Riad et al., 1998). Eckel (2007) used Bayesian network to develop risk preferences of hurricane evacuees on the basis of different hurricanes exposure level and found that women preferred evacuation over men at higher extent of hurricane risk exposure. Lindell, Lu, and Prater (2005), Riad, Norris and Ruback (1999) and Bateman \& Edwards (2002) suggested that being female increased the probability of evacuation. 
High income groups were more likely to evacuate during hurricane events than low income groups (Elliott and Pais, 2006). Few studies explored the influence of education and household size on evacuation tendencies. Education is typically not associated with evacuation tendency (Whitehead, 2003; Smith, 1999), nor is occupation, marital status, presence of pets in the home, or whether the occupant owns or rents the dwelling (Baker, 1991). Recent studies found different scenarios regarding marital status. Wilmot and Meri (2004) found unmarried residents more likely to evacuate than married residents.

Gladwin and Peacock (1997) focused on contextual indicators on evacuation behavior. They found that household size has a negative impact on evacuation decision. Solís, Thomas, and Letson, (2010) showed that family size did not significantly correlate with evacuation. Lindell et al. (2005) found no correlation with ethnicity, but others found that Whites/Caucasians were more likely to evacuate than were Blacks/AfricanAmericans (Riad, Norrisand and Ruback, 1999; Elliott and Pais, 2006; Perry and Lindell, 1991).

\subsubsection{Presence of Elderly and Children}

Researchers agree to a greater extent that factors associated with not evacuating include work obligations and age-related mobility restrictions such as households with elderly members (Peacock, Morrow, and Gladwin, 1997). Factors increasing the likelihood of evacuation include having children in the home (Lindell, Lu and Prater, 2005; Solís, Thomas and Letson, 2010). The commonly held view that children increase evacuation likelihood was refuted in the work of Riad, Norris and Ruback (1999). For the same hurricane though, Gladwin and Peacock found the consideration between presence 
of children and evacuation to be significant (Gladwind and Peacock, 1999). However, child-related logistical issues may inhibit evacuation (Dash and Gladwin, 2007).

\subsubsection{Previous Experience}

The conventional wisdom seems to be that people in communities which have recently experienced major hurricanes will evacuate in greater numbers compared to the people in communities which have not experienced a major hurricane. The similar hurricane can bring a different mindset to those communities which have not had a direct hit from a major hurricane recently but have been on the peripheries of a severe storm or experienced a lesser hurricane. Those people are supposed to have "false experience". Windham et al. (1977) believes that newcomers to coastal areas for the same reason would actually be more likely to evacuate than old timers because the newer residents had not yet experienced the "false experience". Experience might have influence the evacuation behavior that contributes to awareness of the hazard. Awareness can affect different ways, some of which might lead to a greater concern about evacuation than experience (Baker, 1999). Some other research indicates that previous experience of a household is a substantial predictor of evacuation behavior which may influence evacuation behavior positively (Dash \& Gladwin, 2007; Adeola, 2008; Solis et al., 2010). Baker (1991) also reported that people living in areas previously affected by a major hurricane are more willing to evacuate in a similar future event.

\subsubsection{Length of Residence}

There is no consistent evidence found regarding the effect of length of residence, although it has been measured and tested against evacuation in several hurricane 
studies. Length of residence has a close connection with previous experience hypothesis. There are two types of ideas: (1) Newcomers realized the destructive potential of hurricanes less than long time stayers. Therefore they are less likely to evacuate. (2) There are large numbers of coastal residents who have experienced big storms and found them not so dangerous, while new comers heard about the destruction but never faced it. Therefore, newer residents are more likely than older residents to evacuate (Baker, 1991).

\subsubsection{Miscellaneous Factors}

Factors increasing the likelihood of evacuation include greater storm severity (Baker, 1991; Whitehead et. al, 2000). The medical needs and other special needs of people often affect the evacuation decision. Disabled, sick and elderly people may need special care during and after a hurricane. The presence of disabled people in a household reduces the intention to evacuate (Petrolia \& Bhattacharjee, 2010). Smith (1999) and Whitehead et al. (2000) found that pet owners were less likely to evacuate than non- pet owners. Alexander (2005) also found that pet owners often had to leave their animals behind, as many of the motels or shelters would not accept them. Encouragement from family and friends (Baker, 1991) and consultation with others, especially family and friends outside the household may also influence the evacuation decision (Dow and Cutter, 2000, 2002; Mileti and Darlington 1997).

\subsection{Past Research on Determinants of Hazard Risk Perception}

A recurring challenge for personnel, who are responsible for managing evacuations during natural disasters and hurricanes, is how to best inform and direct people's response to these incoming emergencies. One of the persistent problems for 
emergency personnel is to obtain public compliance with evacuation order. The failure to comply (either willingly or non-willingly) with evacuation orders often results in bodily injury, damage of property, and inconvenience for the respondents (Dash and Gladwin, 2007; Henk et al., 2007; Stein, Dueñas-Osorio, \& Subramanian, 2010). Stein et al. (2013) strongly suggests that people's perceived risk about hurricane threat can be compiled to a single score by including different risk types induced by hurricanes. They found that compliance to official advisories relies on whether one perceives high hazard related risk or not. Kim \& Kang (2010); Burnside et al. (2007); Lindell et al.( 2005); Peacock et al. (2005) have also agreed on the fact that risk perception is likely to have major influence on people's subjective risk. Along the same line, Whitehead (2003) and Smith (1999) found that people living in vulnerable structures, such as those living in weak structures like mobile homes or in areas frequently affected by flooding, showed greater tendency to evacuate. The possible reason is answered by Gladwin, Gladwin and Peacock (2001) that feeling unsafe at home increases the likelihood of evacuation.

Often gender variation exhibits difference in risk perception related to natural hazards. In general, literature shows that women generally exhibit higher risk aversion than men (Eckel \& Grossman 2002, 2008a, b, c). Holt and Laury (2002) and Whitehead et al. (2000) found that gender significantly explains varying levels of risk perception which eventually drives the evacuation decision.

Over the years, a number of research have been devoted to understand people's risk perception and its role in shaping evacuation behavior (Aguirre, 1991; Baker, 1991; Bouyer, Bagdassarian, Chaabanne, \& Mullet, 2001; Dash \& Gladwin, 2007; Lindell \& Perry, 2004; Perry, 1994; Peters \& Slovic, 1996; Riad \& Norris, 2012; Stein et al., 2010; 
Whitehead, 2005; Whitehead et al., 2000). Basically, when individuals consider themselves at risk from hurricane-related hazards, they are more willing to evacuate and reduce the risk of hazard.

Living in high-risk areas or evacuation zones is one of the factors influencing risk perception and evacuation behavior. Individuals living close to the shoreline are subject to the highest risk of storm surge and strongest winds for all hurricane categories. However, inland areas can also be at high risk for some hurricane hazards because of intense winds and rain-induced flooding in strong hurricane events. Therefore, emergency planners define geographic risk zones to educate the public about their risk exposures and recommended actions to be taken in the event of a storm (Zhang, Prater, \& Lindell, 2004). People in the Houston area experienced shadow evacuation which generated traffic congestion in the last two hurricane events, hurricane Rita in 2005 and hurricane Ike in 2008 (State of Texas, 2010). A significant portion of the population in zones not under evacuation advisory evacuated. For Hurricane Rita, about $33 \%$ of the Harris County residents were shadow evacuees, and for Hurricane Ike, about $16 \%$ of the populations were shadow evacuees. Despite the reduction in percentage of shadow evacuees during Hurricane Ike, the number of shadow evacuees was comparable to the number of coastal residents that needed to be evacuated. As a result, major roadways experienced significant traffic congestion because of the evacuation prior to the hurricane's landfall (State of Texas, 2010). Stein et al. (2010) argued that shadow evacuations are related to the lack of agreement between individual risk perceptions and the risk criteria used by the officials for defining evacuation areas, which is mostly determined by storm surge hazard. If risk perceptions of individuals are not in agreement 
with the officially designated risk areas, it is generally assumed that those individuals lack necessary information about their expected risks and the degree of compliance with official directives is affected (Baker et al., 2009; Baker, Shaw, Riddel, \& Woodward, 2009; Dow \& Cutter, 1998, 2001; Horney, MacDonald, Van Willigen, Berke, \& Kaufman, 2010). However, it is possible that some of the individuals who live in nonevacuation areas indeed face property loss or personal injury risks from other hurricanerelated hazards (e.g., wind damage, rainfall flooding) that may motivate them to evacuate despite official warnings to shelter in place. Rather than simply advising all coastal residents to evacuate and all non-evacuation zone residents to shelter in place, it might be more effective to communicate messages regarding the location-specific estimates of risk whether they are related to wind damage, power loss, or flooding. When the warning messages are specific and clear, they are more likely to produce the desired responses (Dash \& Gladwin, 2007; Mileti \& Beck, 1975).

Empirical results on flood hazards about the effects of experience on risk perceptions across studies are not entirely consistent. For example, Peacock et al. (2005) find that earlier experience with a disaster can even lower the perceived risk associated with future events. A possible explanation of the later phenomenon is that some people think that as they already have experienced one disaster, therefore there is less chance that they will face another hurricane in the future. The specific nature of the experiences is likely to be important in shaping risk perceptions. For example, all residents may claim that they have experienced a flood in a region where flooding has occurred. However, it is not necessary that all of them have actually suffered from flood water while in their home. Research has shown that more intense personal experiences, such as 
suffering from damage by hurricane, result in elevated perceptions of risk (Windham et al., 1977; Perry and Lindell, 1990; Norris et al.1999; Riad et al., 1999).

Risk perceptions for individual hurricane-related hazards have been the subject of a number of earlier studies. Zhang et al. (2007) examined risk perceptions of Hurricane Rita evacuees relative to four hurricane-related hazards, including storm surge, flooding, wind, and tornadoes. They did not find significant differences in the level of concern for these four hazards with regard to property damage and personal injury. Brommer and Senkbeil (2010) also divided hurricane hazards into the same four meteorological factors to study which hazards were most influential in evacuation decisions. They found that different types of hazards motivated residents in various parts of the study region to evacuate (coastal Louisiana residents were motivated by storm surge whereas inland residents were motivated by hurricane force winds). On the other hand, Horney et al. (2010) found that hazard-specific risk perceptions (flooding or wind damage) alone were not sufficient to motivate evacuation; however, perceived severity of the risks was effective in determining evacuation decisions.

\subsection{Role of Geographical Factors on Hazard Risk Perception and Evacuation}

Very few studies were done regarding geographical dimensions of either natural hazard risk perception or evacuation decision. Hasan et al. (2010) tried to capture the heterogeneity in hurricane evacuation behavior, explained by the unobserved factors, such as category of the risk zone that a household is living in and distance between the house and the center of the storm track. They included the spatial variable "state", which represented location of respondent in a particular state, to understand the regional 
variation in risk perception and evacuation. A connection could be established regarding hazard risk exposure in terms of the distance from track and being in an evacuation zone.

Some earlier research provided efforts in understanding the role of the evacuation zone as the key to understanding evacuation behavior. The evacuation zone is one of the geographical factors which received a lot of attention in past research. One study in Florida showed that a significant portion of residents were not fully aware of their location regarding living inside or outside an evacuation area (Lazo, J.K., and B.H. Morrow, 2013). By comparing seven hurricanes, another study indicated that evacuation from high-risk areas is usually higher (83\%) compared to that of nearby low-risk areas (37\%). These two evacuation rates are notably different. The reason might be that in high-risk areas residents are aware of their risk exposure and also because public officials make greater efforts to evacuate the residents out of these areas. It was clear that the most vulnerable group of people towards hurricane risk were most willing to evacuate. Also from a policy standpoint, emergency management agencies have traditionally been understandably preoccupied with maximizing evacuation rates from high-risk areas. It appears that moderate-risk areas deserve more attention than they have normally received in the past, given their vulnerability to flooding and their relatively low response rates (Baker 1991). Another empirical study, using results from a survey of 1,355 households in Florida, suggests that households living in risky environments (mobile home and flood zones) are more likely to evacuate (Solís, Thomas, and Letson, 2010). Another factor that increases the likelihood of evacuation is living inside storm surge zones (Baker, 1991; Solís, D., M. Thomas, and D. Letson, 2010; Whitehead et. al, 2000). 
Among very few studies in this area, Siebeneck (2010) focused on the geographical dimensions of the evacuation and return-entry process for a flood hazard. Risk perception varied throughout the disaster event and evacuees experienced similar levels of risk perception during the evacuation return entry process (EREP). A distancedecay effect was observed during the flood event. The greater distance a household evacuates, the less likely they will receive the clear message to return home. The results also indicated that socio-demographic factors could not predict return compliance after the event. However, several factors influenced evacuation behavior such as age, education, family size, and socio-economic status. Cutter et al. (2011) investigated that $58 \%$ of residents who lived in category 1 and 2 surge zones and 55\% of residents who lived in category 2 surge zones evacuated, while only $47 \%$ of residents evacuated who lived outside storm surge zone. Interestingly, $41 \%$ of residents, living outside the designated storm surge areas (shadow evacuation zone), have also evacuated. In another study, evacuees from the path of Hurricane Gustav were surveyed to determine which meteorological hazards most influenced their decision to leave. The survey analysis suggests that there were geographical variations in perceiving risk from different meteorological hazards. Analyses revealed that evacuees in and around New Orleans evacuated as a result of the perceived threat from a storm surge. Residents in the Houma, Louisiana region evacuated with similar perception; and residents in Lafayette and the surrounding areas were concerned with the threats posed by hurricane-force winds (Brommer and Senkbeil, 2010). 


\subsection{Human Behavior Adjustment at Extreme Weather Condition: Panel Data}

Kelly et al. (2009) argue that single event studies ignore the possibility that households may learn from their own experience. They compared two distinct regions in Florida for four separate hurricane events during the 2005 season. By doing so, two new dimensions were added to that study of the determinants of evacuation choices; namely, regional variability and within season variability (Solís, Thomas and Letson, 2010).

Whitehead (2005) performed a predictive validity test on evacuation behavior using a panel survey data. That hurricane evacuations behavior data was initially collected after Hurricane Bonnie in 1998. Respondents were asked about their intended evacuation for an incoming hurricane. A follow-up survey was performed in the next year after hurricanes Dennis and Floyd in 1999. Respondents were asked about their real evacuation decision to examine if they behaved according to their stated intended behavior. The joint analysis found that stated behavior data has some degree of predictive validity.

Tuite et. al (2012) also conducted joint analysis regarding evacuation route choice for both hurricanes Ivan and Katrina. They found that respondents chose similar evacuation route in the subsequent hurricane.

Review of numerous literatures indicated that a number of studies have considered the influence of socio-economic factors on evacuation behavior thoroughly. But a large gap remains in the literature to explicitly analyze the role of geo-spatial factors (e.g., shoreline distance, elevation of property, wind gust exposure before landfall) in influencing the evacuation behavior. Very few studies looked into assessing the role of spatial variation on risk perception except one has been done for flood risk 
perception (Siebeneck \& Cova, 2012). Little has been done to investigate the role of geospatial factors affecting hurricane risk perception and evacuation behavior. Against this backdrop, current research focuses on analyzing the role of potential geo-spatial factors that might have influenced the risk perception and evacuation decision during hurricane Katrina and hurricane Ivan. The geocoded survey samples have provided the opportunity to create and analyze the influence of relevant geo-spatial variables. The longitudinal dataset is based on survey responses from same household in two consecutive years after two hurricane events. This type of data is quite unique in hurricane evacuation behavior research. Current research will provide useful insight into the understanding of the role of geo-spatial factors affecting people's risk perception and evacuation behavior for more effective evacuation planning.

\subsection{Summary}

This chapter described prevailing literatures on hurricane evacuation behavior. It focused on four areas of evacuation behavior- determinants of evacuation, role of risk perception in evacuation behavior, role of geographical factors on risk perception and evacuation decision, and human behavior adjustment in the face of extreme weather condition using longitudinal data. The next chapter will briefly discuss about survey data collection and data description. 


\section{CHAPTER 3: $\quad$ SURVEY DATA COLLECTION AND DATA DESCRIPTION}

\subsection{Field Data Collection}

To analyze evacuation behavior, the present study used a longitudinal dataset utilizing a geo-coded sample of householders in Florida, Alabama, Mississippi and Louisiana. The households were first interviewed after Hurricane Ivan (in 2005) and reinterviewed after hurricane Katrina (in 2006) to understand their knowledge, attitudes and behavior about those two hurricanes.

The first phase of the household survey was conducted as part of the post-storm impact assessment of Hurricane Ivan. The survey households were located in Florida, Alabama, Mississippi and Louisiana (Morrow and Gladwin, 2005) and the survey year was 2005 which was one year after hurricane Ivan. Hurricane Ivan was the third and most disastrous storm to hit Gulf Shores in 2004 (Stewart, 2004). Hurricane Ivan impacted a large portion of the survey area. All the three states, Alabama, Louisiana and Mississippi had experienced the hit of the hurricane. A household survey was conducted one year later to this incident to understand the extent of damage to the area. The major part of the data collection consisted of Computer Assisted Telephone Interview to a sample of 3200 households. Survey language was English and Spanish to represent the diverse nature of the population living in the above mentioned three states. Data were collected on hurricane forecast message and risk communication; time issues and decision constraints during evacuation; transportation constraints; and high-risk populations. These are the areas which are essential considerations in any comprehensive evacuation behavior model. The dataset also provided household demographic information and socioeconomic condition, among others. Other necessary information related to evacuation 
studies such as previous hurricane experience, evacuation notice type (mandatory or voluntary), media of evacuation order, evacuation day were also included in the data.

The second phase of the survey took place in 2006, just one year after the first phase of the survey. Again, 2006 was just a year after hurricane Katrina. The temporal and spatial nature of these consecutive storms allowed conducting the time-series survey by interviewing same respondents. Hurricane Katrina was the most costly natural disaster in the history of the United States. The hurricane made three landfalls from $25^{\text {th }}$ to $29^{\text {th }}$ August in 2005. The first landfall took place at Florida; second one at Louisiana; and final one at Louisiana/Mississippi border (Knabb et. al, 2005). The Katrina survey was conducted to determine the influence of previous experience on subsequent evacuations and consisted of 1200 respondents. Variables used in these two surveys pertain to similar questions, although some refinements were made to the subsequent questionnaire.

Longitudinal studies that use panel data are relatively rare in disaster research. The current dataset provided unique information about the role of previous experiences on subsequent hurricane evacuation behavior by the same respondents. In addition to their reported experience, the geocoded locations provided the opportunity to geographically locate each household in relation to subsequent storms. Among these two sets of survey data, we were able to match 811 respondents who responded both hurricane Ivan and Katrina surveys. The present study focused on analyzing the behavior of these 811 people.

\subsection{Survey Data Description}

The variables used in this study belong to three categories: socio-demographic information, housing and location characteristics, and other evacuation related features. 
Variables used in the evacuation behavior analysis are discussed under some broad headings in the current section.

\subsubsection{Risk Perception variables}

Risk perception characteristics included responses from survey that reflect household risk sensitivity specific to hurricane Ivan. In previous literature, there was evidence of low risk perception for flood events (Botzen et al., 2009). Therefore, current study modeled the flood and wind risk perception separately to understand its influence on evacuation behavior. However, this analysis was by modeling the influence of combined risk perception of flood and wind on evacuation behavior.

\subsubsection{Flood risk perception}

As part of the survey, respondents were asked three sequential questions about how much flood risk do they perceive under three different categories of hurricanes. The category 5 hurricane (155 MPH sustained winds) risk perception question reads as follows:

Q: "If a category 5 (strongest hurricane which is called very dangerous by meteorologist) hurricane with sustained wind over $155 \mathrm{MPH}$ made landfall near your location with sustained winds of $155 \mathrm{MPH}$ and then passed directly over your home, do you believe that your home would be flooded by storm surge, wave action, or river flooding severe enough to pose a threat to your safety if you stayed in your home?" Answer: "Yes; No; Do not Know". To avoid compliancy in survey data analysis, responses were stored in binary format ( 0 for all no and 1 for all yes) and at the same time, recorded all "do not know" responses as missing cases. 
This question was followed by similar question for two other categories of hurricanes (category 3 and category 2). We combined the responses from these three survey questions to understand household flood risk perception for different categories of hurricanes. In that way, we created a new variable which represents flood risk perception (flood). We recoded the new variable in the following manner.

Figure 3-1: Perceived vulnerability from flooding (flood) at different storm levels

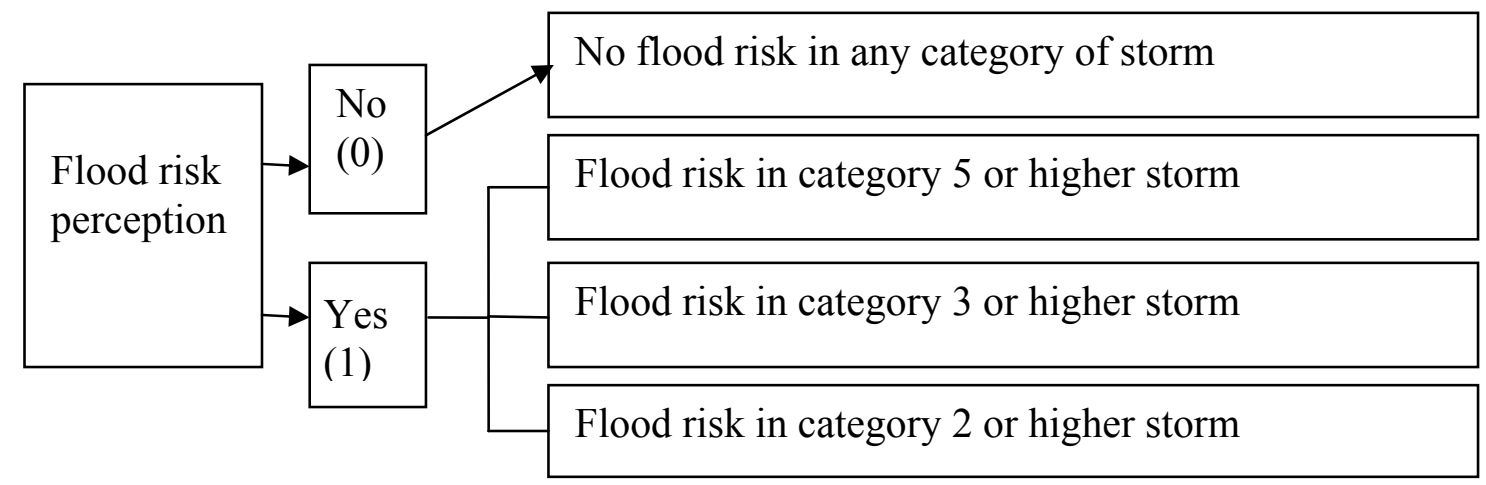

\subsubsection{Wind risk perception}

Wind risk perception (wind) was developed in the similar way combining three questions regarding peoples wind risk perception for different categories of hurricanes.

Figure 3-2: Perceived vulnerability from wind (wind) at different storm levels

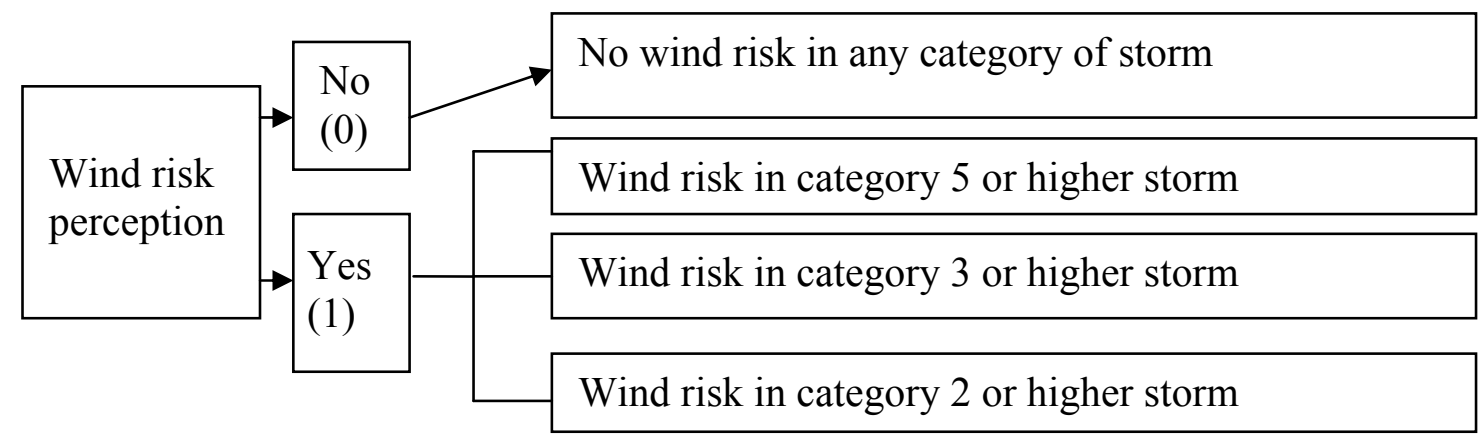

\subsubsection{Overall risk perception}

We combined both flood risk perception and wind risk perception and created another new variable called overall risk perception (Risk). 


\section{Figure 3-3: Perceived vulnerability for any kind of risk (risk)}

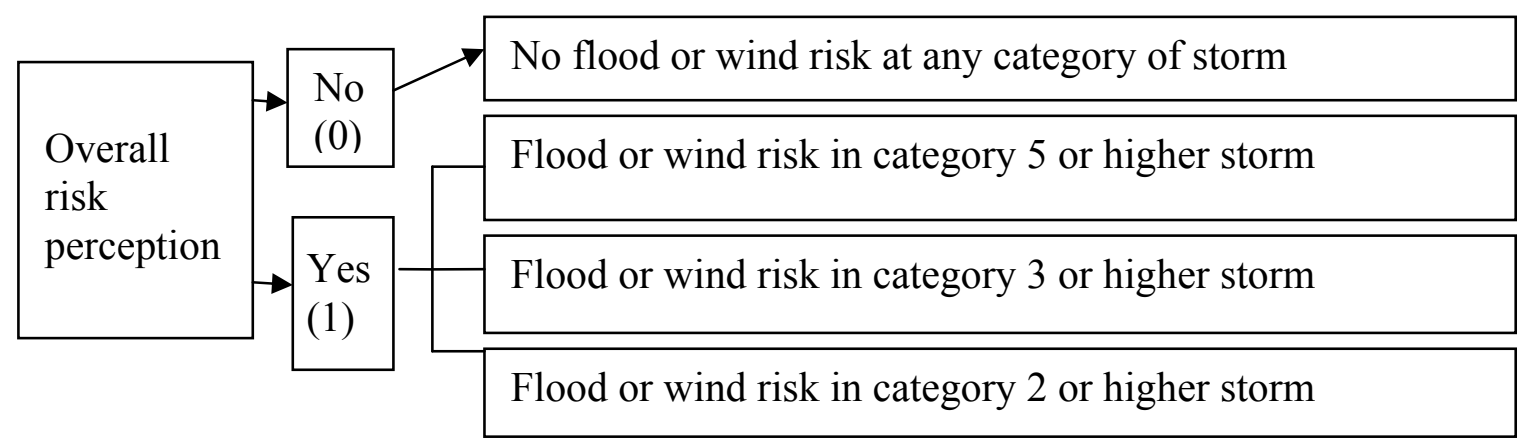

\subsubsection{Evacuation Behavior in Terms of Risk Measures}

Respondent's evacuation behavior consisted of two types of responses- either "Evacuated" or "Did not evacuate". The binary response was coded by 0 for "did not evacuate" and 1 for "Evacuated". The basic hypothesis of current research is that evacuation behavior is significantly influenced by people's subjective risk perception.

\subsubsection{Demographic Characteristics}

The present study used demographic characteristics of the household which were found relevant to predict subjective risk perception in the previous literatures (Botzen et. al, 2009; Stein, 2011). Independent variables such as education, household size, duration of stay in home, presence of elderly/ children/ pet and ownership pattern were included in analysis. These variables were included to control for heterogeneity at the household level. The descriptions of these variables are given in table 6-1 and table 6-6 in chapter 6 .

\subsubsection{Socio-Economic Characteristics of the Household}

The present study used some context specific socio-economic variables which were assumed to influence household's subjective risk perception. Questions were asked to collect information about household income, if the households were required to stay 
for job purpose during evacuation time, if they followed hurricane forecast, if they were inside or outside evacuation zone and if they got evacuation notice.

\subsubsection{Building Characteristics}

The current study also used some context specific variables representing household vulnerability in the face of a hurricane. Therefore we asked specific question regarding availability of any kind of home protection, and if the households raised their dwelling structure above a platform or not. It was assumed that building characteristics may influence household's subjective risk perception.

\subsubsection{Concern Characteristics}

Questions were also asked regarding household specific concern during the hurricane Ivan event. Investigation were done to understand if household had traffic related concern or any logistics issues or shelter related concern. Any such constraints can negatively influence evacuation decision.

\subsection{Summary}

This chapter described the survey data collection process. It provided description of the survey variables that will be used for further analysis. In the next chapter, the thesis explains the development of the spatial dataset with reference to the household locations obtained from the survey. 


\section{CHAPTER 4: $\quad$ DATA AND METHODS: GEO-SPATIAL DATABASE}

The present chapter describes the methodology used to develop a geo-spatial database to analyze hurricane evacuation behavior. The focus is to construct potential geo-spatial variables that might influence people's risk perception about storm surge and may eventually influence evacuation behavior during a hurricane event. Related theory behind formulation of each geospatial variable was explained briefly.

\subsection{Geo-spatial Database}

Geo-spatial database was developed to analyze people's hurricane risk perception and evacuation behavior with reference to geographic locations of their households. The geo-spatial database also identifies relationship between selected geo-spatial variables and household socio-economic factors. Hypothesis was formed regarding geo-spatial influence on household risk perception and evacuation decision during hurricane Ivan and hurricane Katrina. Most geo-spatial databases allow representing simple geometric objects such as points, lines and polygons. The current geo-spatial database composed of both vector and raster based features. Considering the convenience of analysis, some of the raster features were converted to vector based features for further analysis and vice versa. Because some statistical analysis works better on continuous data while some other works better on vector data. Two types of spatial variables were developed in present study. One is time invariant spatial variables and another one is time variant spatial variables. The geo-spatial database consisted of nine different variables.

1. Time invariant variables: Some spatial phenomena are constant and do not change over time. For example distances from one fixed object to another fixed object do not change across time (or at least, not over the time-period studied), so the current study 
considers such objects as time invariant variables. In this particular study, the time invariant variables are: (i) Distance from shoreline, (ii) elevation of household property, (iii) types of household according to land use (iv) distance from evacuation route, (v) location in flood zone (vi) location in evacuation zone.

2. Time variant variables: A geo-spatial phenomenon that changes across time period is considered as time variant variable. The time variant variables are: (i) Distance from tract (ii) maximum sustained wind exposure on household (iii) Precipitation exposure on household.

\subsection{Location of Households}

\subsubsection{Overview}

The survey respondents were located in three states, Louisiana (LA), Mississippi (MS) and Alabama (AL). The telephone survey conducted for each household was geocoded in a manner that made it possible to enter household location information into a GIS based platform for mapping and geo-spatial analysis. The geo-coded locations were projected to a uniform equidistance projection system to get best result of distance measurement. According to Snyder (1997), "equidistance projection has the useful properties that all points on the map are at proportionately correct distances from the center point". The projection used for all geo-spatial layers and household locations were kept similar in the study.

\subsubsection{Theory of Map Projection and Geocoding}

Map projection is an important operation in this study because much of the geospatial analysis is done based on distance and elevation measurements. According to Snyder (1989), "A map projection is a systematic transformation of the latitudes and 
longitudes of locations on the surface of a sphere or an ellipsoid into locations on a plane". All geographic datasets used in ArcGIS was assigned a coordinate system that enabled them to be located in relation to the earth's surface.

\subsubsection{Implication of Map Projection and Geocoding}

The study used geographic co-ordinate system, WGS 1984 and datum, NAD 1983. Also it used 3 State Plane Coordinate System (SPCS) projection. Because the study area consists of three SPCS zones- Alabama West, Mississippi East and Louisianan South.

Figure 4-1: Geocoded households in the study area

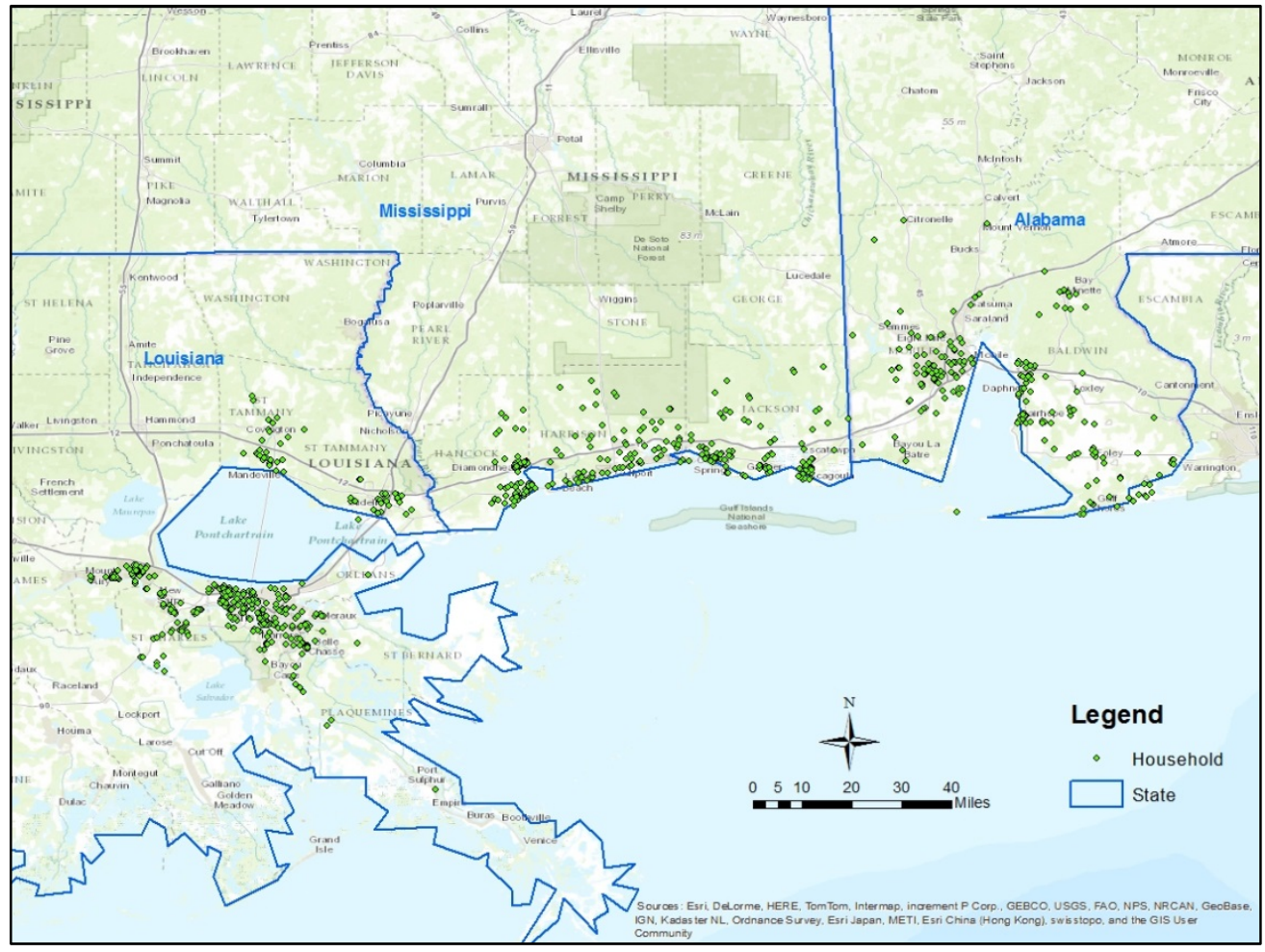

The households were geocoded based on the pair of coordinates which was collected during survey. The resulting locations are output as geographic features. Other useful information collected from survey were demographic information, income, ownership 
pattern etc. were used as attributes. Above figure 4.1 is showing the location of households in the study area.

\subsection{Elevation of Household Location}

Elevation of each household location was derived based on their $\mathrm{x}, \mathrm{y}$ co-ordinates. The following flowchart (Figure 4-2) describes the methodology to derive elevation in each household.

Figure 4-2: Flow chart for the methodology to measure elevation of households (MSL)
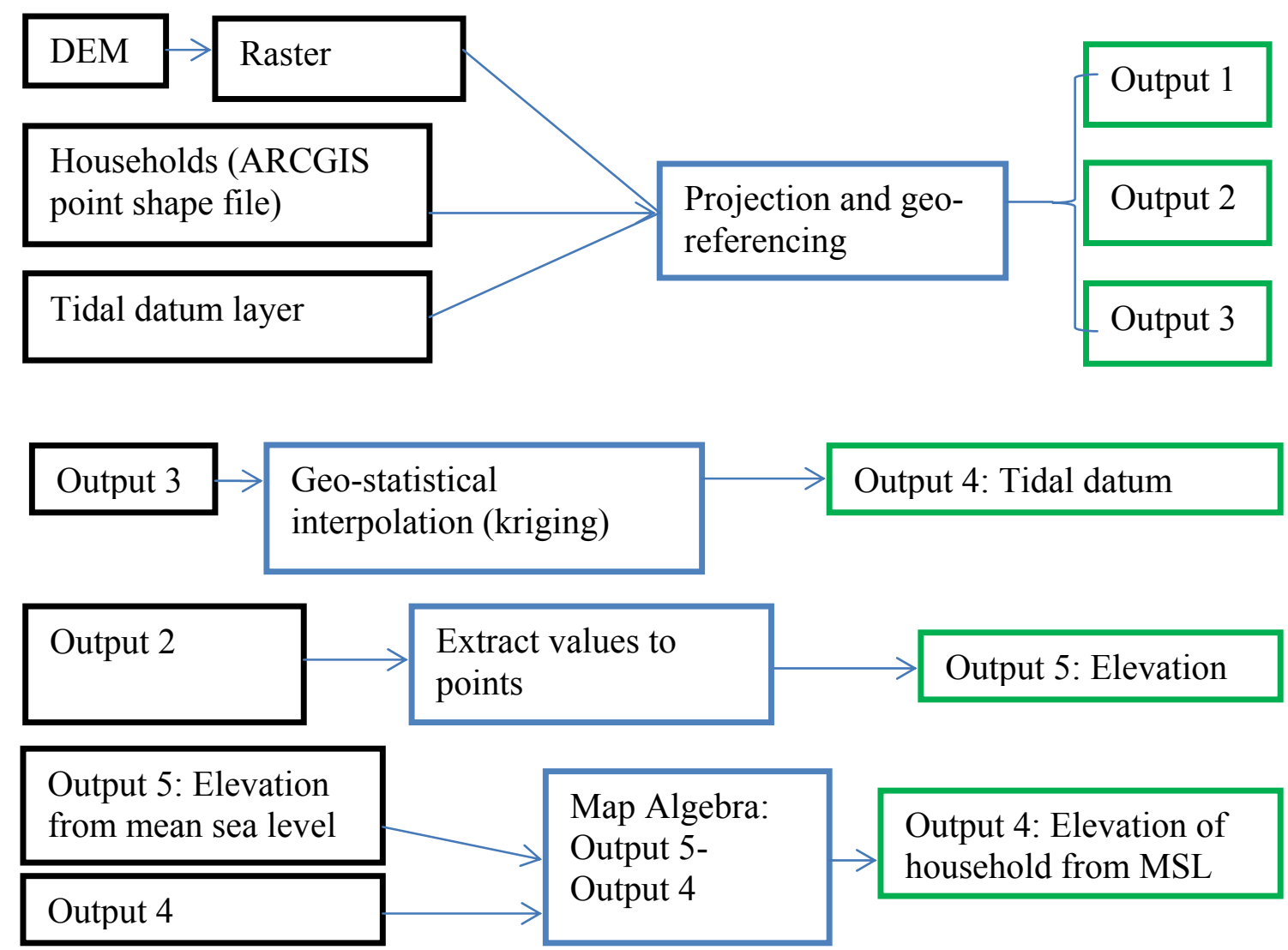

\subsubsection{Data Acquisition and Formatting}

Elevation dataset was collected from U.S. Geological Survey (USGS). In 2009, USGS published a seamless database on Alabama, Louisiana, and Mississippi coastal 
area for pre-Katrina period. The dataset for the study area were found in 1/9-Arc second (approx. 3 meters) in digital raster format. The units of measurement in the dataset was meters, and were referenced to the North American Vertical Datum of 1988 (NAVD 88) over the study area.

The elevation dataset was projected to correct SPSC's as discussed in section 4.2.3. DEMs in Louisiana were projected as Louisiana south state plane, DEMs in Mississippi were projected as Mississippi west state plane and DEMs in Alabama were projected in Alabama south state plane.

\subsubsection{Create Mosaic Dataset}

Elevation dataset were collected in raster format and in multiple tiles. In the next step, the multiple tiles were integrated to make a continuous surface. ARCGIS spatial analyst tools were used to perform the task of developing continuous surface.

\subsubsection{Benchmark Setup from Tidal Datum}

The elevation dataset of the study area was referenced to the North American Vertical Datum of 1988 (NAVD 88). NAVD 88 is not the same as the mean sea level (MSL). Therefore they cannot be used without proper datum adjustment. In different parts of the study area, MSL and NAVD 88 is not located parallel. In some region, NAVD 88 level is higher than MSL and in some region NAVD88 is lower than MSL level. The tidal stations are the benchmark to identify elevations with reference to a fixed

point (see figure 4-3) such as mean sea level (MSL), mean high water (MHW), mean high high water (MHHW), Mean low low water (MLLW), NAVD88, NAVD29 etc. Not all the tidal stations have the record of elevation with reference to all these parameters. In the current study, elevation of the study area was converted to mean sea level from 
NAVD88. The reason is that all the raster Digital Elevation Model (DEM) files were referenced with NAVD88. In the study area, there are 17 tidal stations that have record for elevation both in terms of MSL and NAVD88. Those stations are the basis of tidal station elevation surface. From this tidal station surface, elevation of the study area was derived with reference to MSL.

\section{Figure 4-3: Hypothetical tidal datum showing relation with MSL and NAVD88}

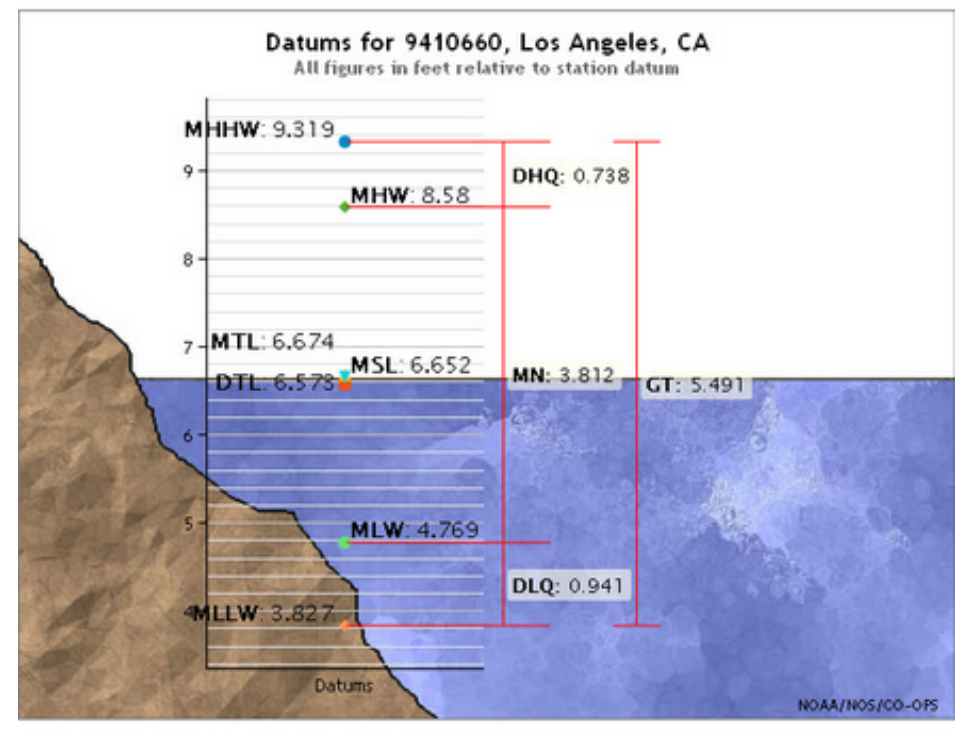

\subsubsection{Tidal Station Surface Interpolation}

Based on the 17 tidal stations, a continuous surface was interpolated using ArcGIS geo-spatial analyst. Using ArcGIS geo-statistical analyst, the tidal datum surface was developed. The surface was a statistically valid prediction surface, along with prediction uncertainties, from a limited number of data measurements. Figure 4-4 is showing the continuous surface of elevation difference between MSL and NAVD88. 
Figure 4-4: Surface interpolation from the difference between MSL and NAVD88 at tidal stations locations

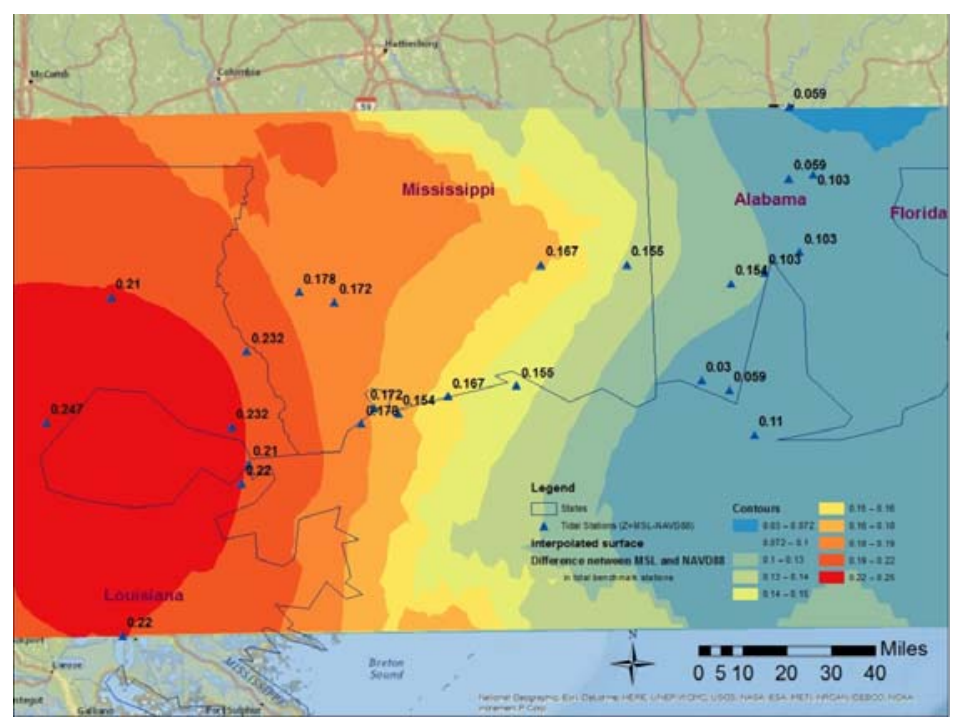

\subsubsection{Household Elevation Derivation from Mean Sea Level}

The next step was to determine household level elevation from mean sea level. Elevation measurements were extracted exactly at household locations. The following Figure 4-5 is showing how the evacuation decisions during hurricane Katrina and Ivan were affected by the elevation of the household properties. Table 4.1 shows the summery statistics of elevation of household properties.

Table 4-1: Summary statistics of elevation of households in the three states

\begin{tabular}{|c|c|c|c|}
\hline \multicolumn{4}{|c|}{$\begin{array}{l}\text { LA/MS/AL Elevation of household Summary } \\
\text { (meter) }\end{array}$} \\
\hline & LA & MS & $\mathrm{AL}$ \\
\hline Minimum & -2.03067 & 0.356504 & 1.143202 \\
\hline Maximum & 19.80479 & 56.46015 & 104.526 \\
\hline Average & 1.604392 & 9.889357 & 29.85307 \\
\hline
\end{tabular}


Figure 4-5: Elevation of the study area

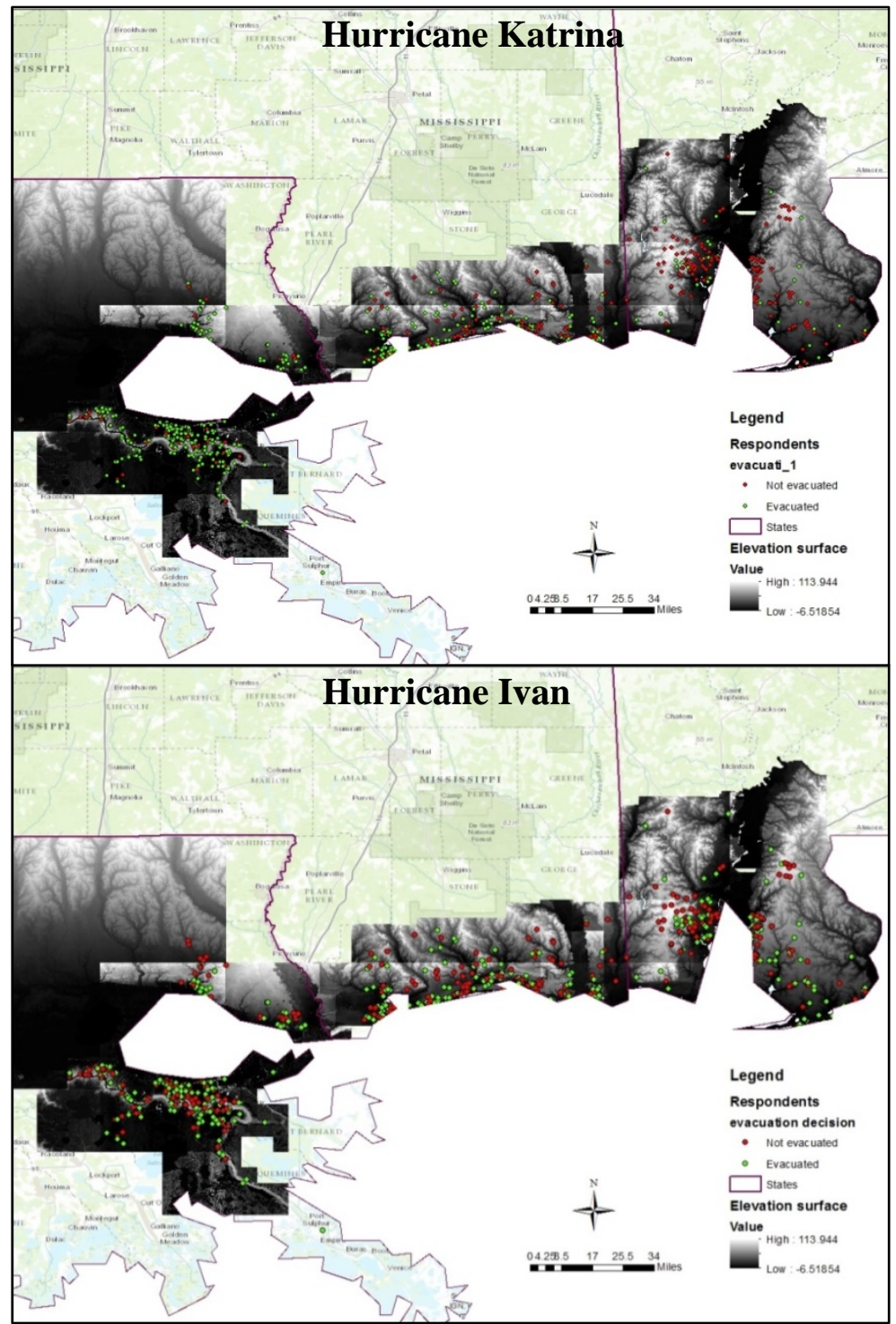

\subsection{Shoreline Distance}

\subsubsection{Overview}

Current study assumed that that shoreline distance from household location is an important determinant in household risk perception about storm surge risk. It is also assumed that the closer the household to the shoreline, the higher chance to be exposed by storm surge or coastal flooding, and consequently a higher chance of evacuation. The 
following flowchart, figure 4-6 describes the method used to obtain shoreline distance from household location.

Figure 4-6: Flow chart for the methodology to shoreline distance measurement

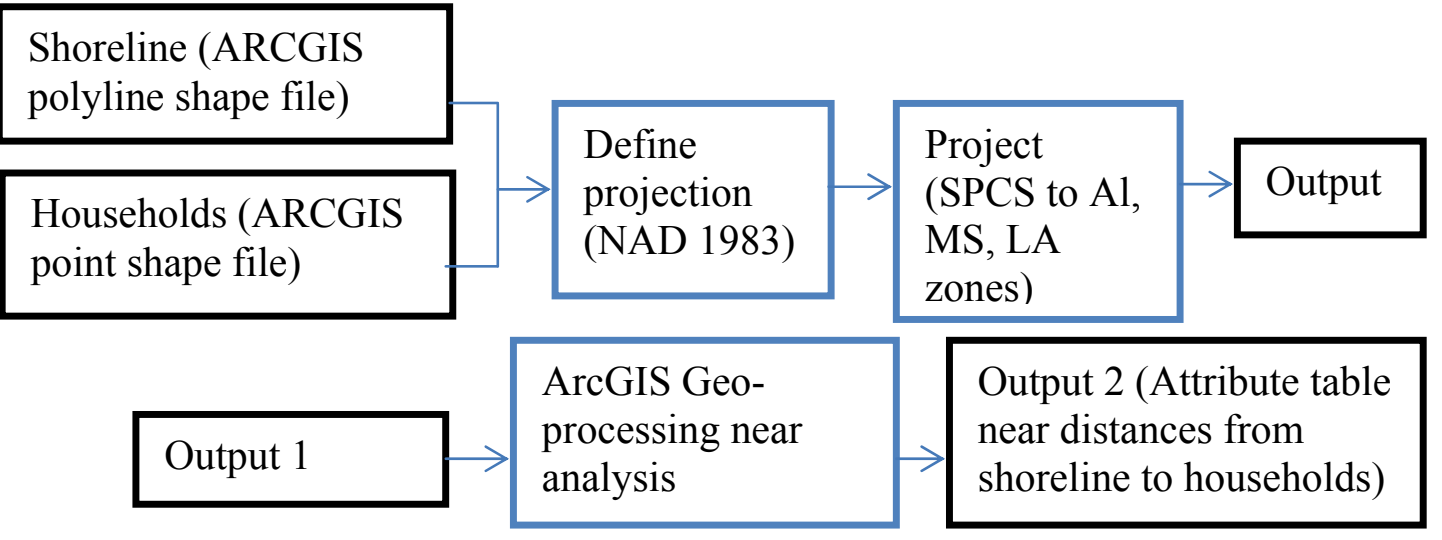

\subsubsection{Data Source and Formats}

The shoreline dataset was collected from National Oceanic and Atmospheric Administration (NOAA) National Geodetic Survey (NGS). The format of the data is ESRI shape file in seamless polyline format and it covers the whole study area. The layer is created from various sources including Lidar, imagery and shoreline vectors. The dataset has a geographic coordinate system (decimal degrees) and horizontal datum of North American Datum of 1983 (NAD83).

\subsubsection{Database Preparation and Implementation}

After the ArcGIS layer was added in the database, the layer was being defined a geographic co-ordinate system and Datum (NAD 1983). Then the layer was projected as mentioned in section 4.2.3. An equidistant projection system was used to get best result of distance measurement. Again, the unit of distance was calculated by applying the specific tool "near" in ArcGIS. Unit is the same unit as the input feature (ESRI, 2011). 
The input features are the layer containing shoreline and household data in polyline and point format.

The distance between any two features is calculated as the shortest separation between them. This logic is applied by any geo-processing tool that calculates distance, including tools such as "Near" tool in ArcGIS. However the basic rule to measure distance from a point to a line is either the perpendicular or the closest vertex which is shown in Figure 4-7.

\section{Figure 4-7: Distance from a point to a polyline}

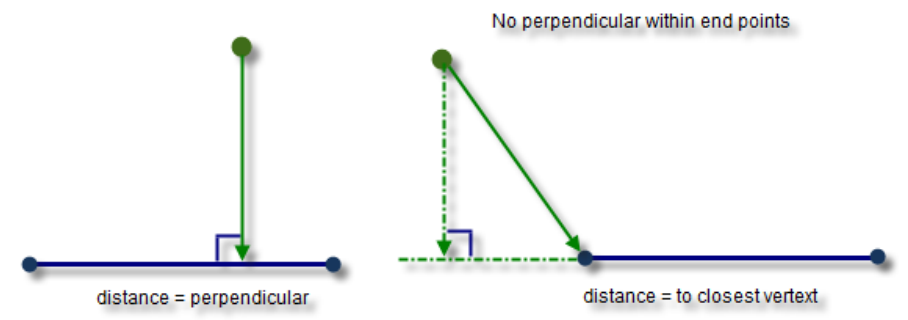

Next the distance from each household location to the nearest shoreline is measured. The shoreline data is extracted and then the minimum distance between the shoreline and household location was derived. In case multiple features are located at equal distance from one another, one is randomly selected as the closest. The following map is showing households risk perception in terms of the shoreline. 
Figure 4-8: Shoreline in study area

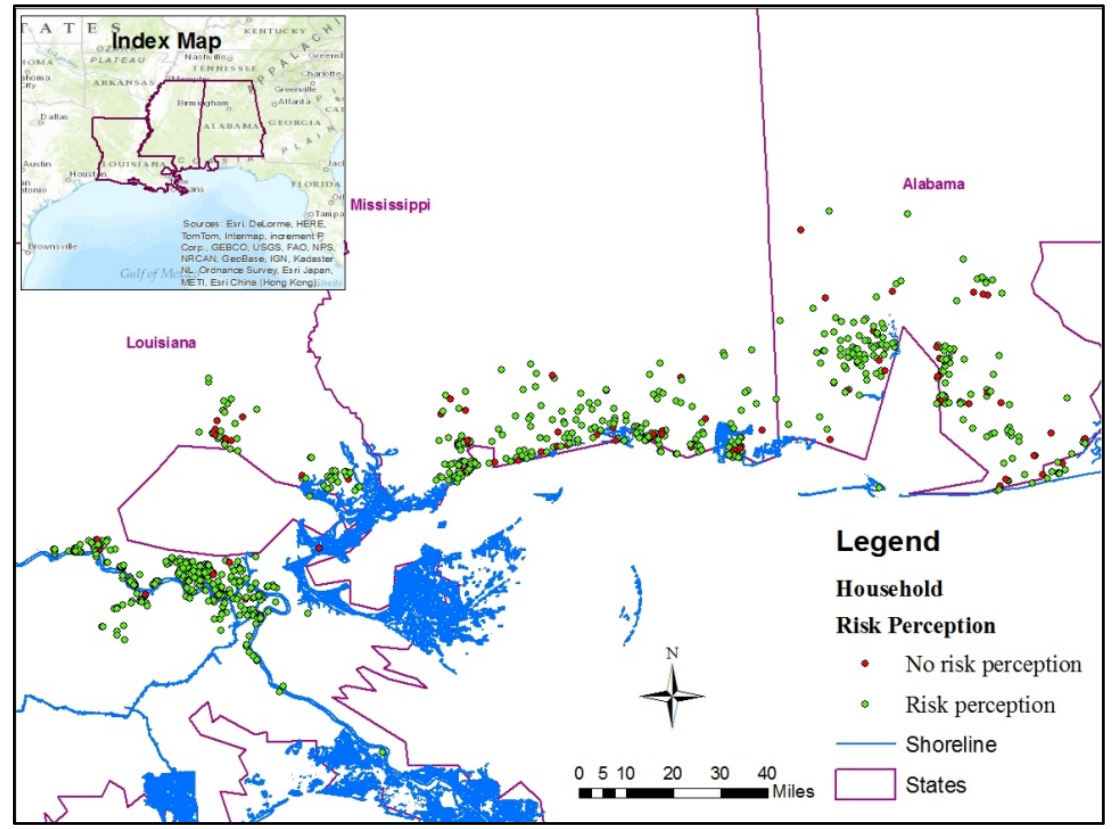

\subsection{Distance from Hurricane Tract}

It is assumed that the distance from tract is an important determinant in household risk perception about storm surge risk. It is also assumed that the closer a household to hurricane tract, the higher chance of impact by intense wind, storm surge or coastal flooding. The following flowchart (Figure 4-9) describes the method used to obtain distance from tract to household locations.

Figure 4-9: Flow chart for the methodology to tract distance measurement

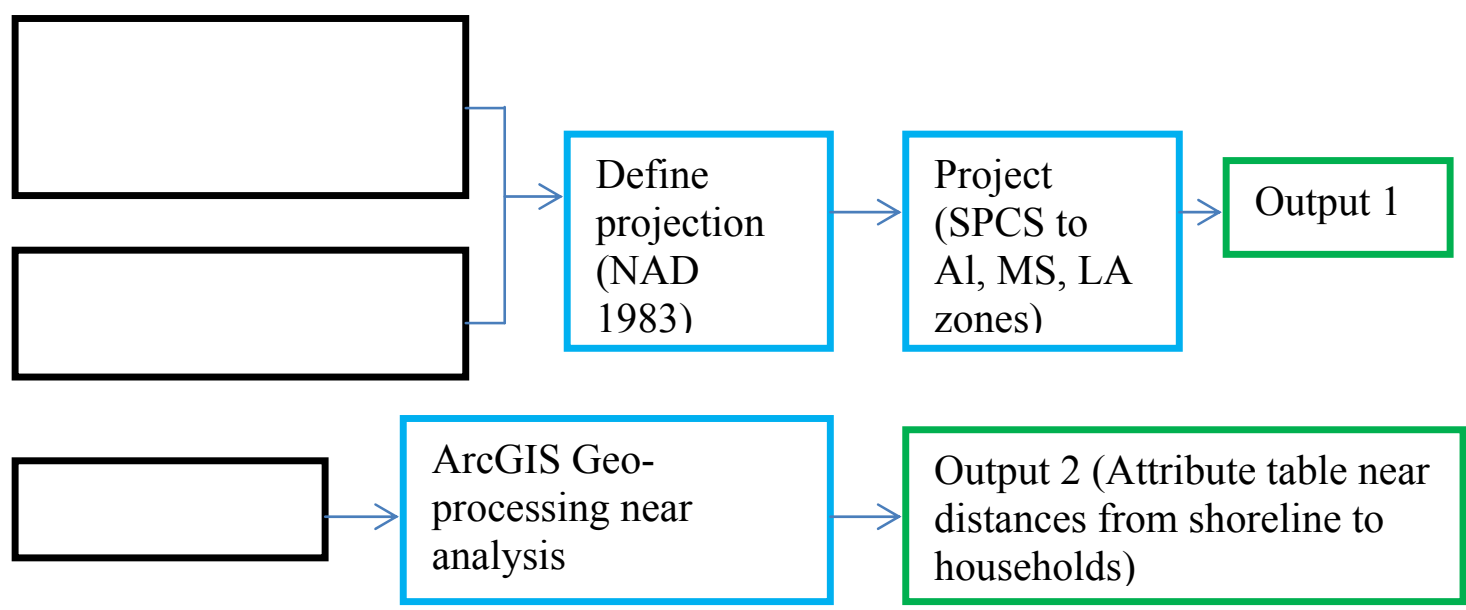




\subsubsection{Data Source and Type}

National hurricane center maintains a historic archive of best hurricane tract data. Atlantic hurricane database (HURDAT2) contains best tract data from 1851-2012. This dataset is stored in text format and comma-delimited. It contains forecast information with six-hour sequence about the location and maximum winds data.

\subsubsection{Database Preparation}

After the ArcGIS layer was added in the database, the layer was defined as a geographic co-ordinate system and Datum (NAD 1983). Then it was projected to the same SPCS as mentioned in section 4.2.3 for Alabama, Mississippi and Louisiana. The first input features in this section are the layer containing hurricane Ivan tract in polyline format and household location data in point format. The second input features are the layer containing hurricane Katrina tract in polyline format and household data in point format. The method and logic behind the distance measurement is same as described in section 4.4.

Table 4-2 and 4-3 are showing summary statistics of tract distance for both hurricane Ivan and Katrina.

\section{Table 4-2: Distance from hurricane Ivan tract (in meter)}

\begin{tabular}{|c|c|c|c|}
\hline \multicolumn{4}{|c|}{ Summary of Distances from Ivan Tract } \\
\hline & $\mathrm{AL}$ & LA & MS \\
\hline Minimum & 0.00 & 1.50 & 0.58 \\
\hline Maximum & 0.60 & 2.64 & 1.59 \\
\hline Average & 0.23 & 2.21 & 1.140 \\
\hline
\end{tabular}


Table 4-3: Distance from hurricane Katrina tract (in meter)

\begin{tabular}{|c|c|c|c|}
\hline \multicolumn{4}{|c|}{ Summary of Distances from Katrina Tract } \\
\hline & $\mathrm{AL}$ & LA & MS \\
\hline Minimum & 1.20 & 0.01 & 0.15 \\
\hline Maximum & 2.14 & 1.02 & 1.19 \\
\hline Average & 1.65 & 0.58 & 0.60 \\
\hline
\end{tabular}

It has been found that hurricane Ivan tract was more close to Alabama than Mississippi and Louisiana. Therefore it is assumed that respondents from Alabama will have higher risk perception than Mississippi and Louisiana during hurricane Ivan.

Figure 4-10: Distance from hurricane Ivan tract to household

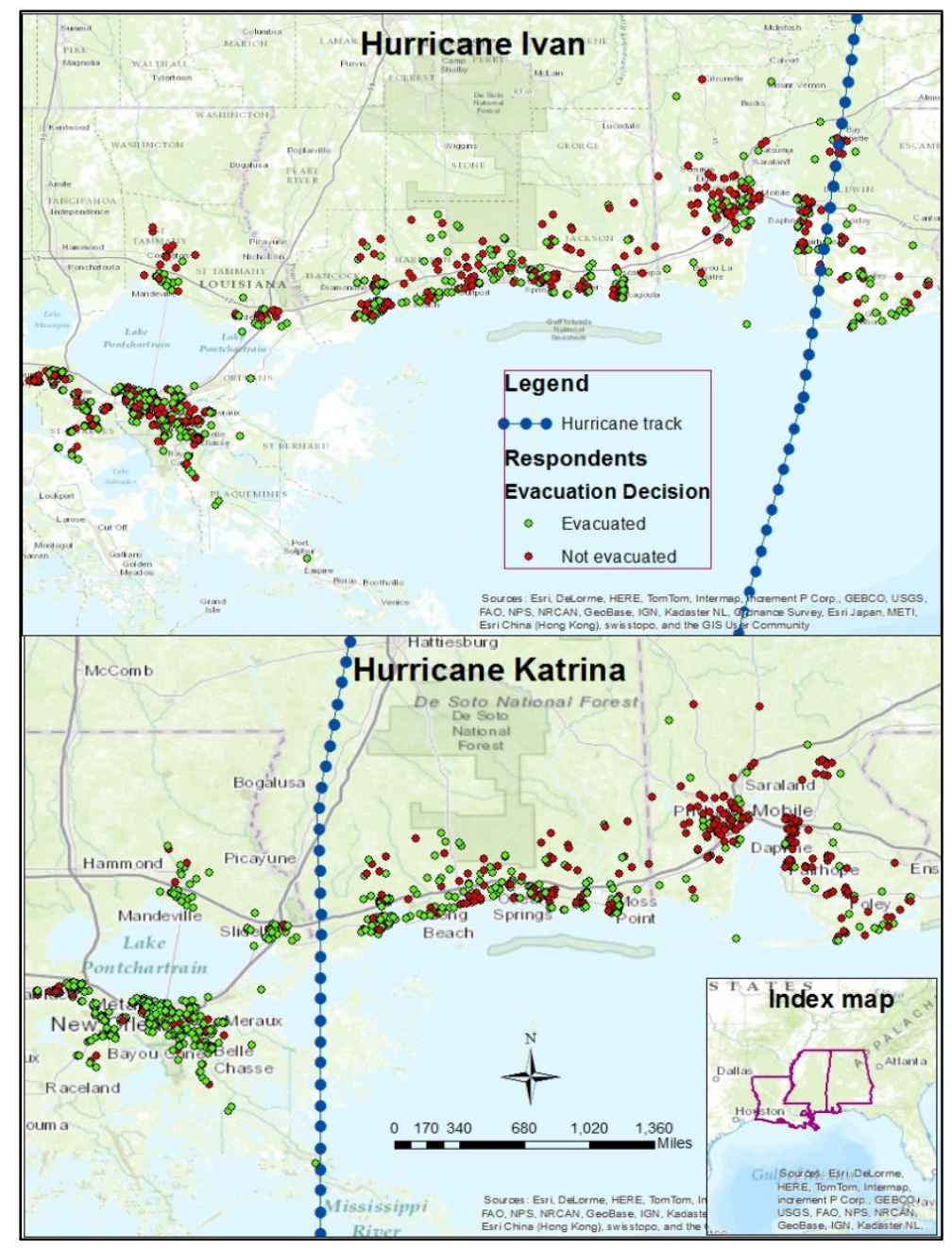


The above figure 4-10 is showing how evacuation decisions during hurricane Ivan and Katrina were affected by hurricane tracts. Figure 4-10 indicates that number of evacuees increased substantially during hurricane Katrina around the tract. Table 4-2 and 4-3 recorded the summary of distances from tract in the study area.

\subsection{Land Use Categories of the Households}

It is assumed that the location vulnerability depends on land use types of an area. For example, open land has high chance of being impacted by wind gust, low lying areas have high chance of being impacted by flood water. Therefore, different types of natural disasters can impact different types of land uses. Therefore, it is assumed that a reasonable relationship can be established between land use and risk perception or evacuation decision. To test this assumption, land use types were identified in respondent's household locations.

\subsubsection{Data Source and Management}

Data set from pre-hurricane Katrina 2006-era classification was derived for the National Oceanic and Atmospheric Administration (NOAA), Coastal Services Center (CSC). This data set was used in the Coastal Change Analysis Program (C-CAP) in order to define land cover in coastal areas. This classification includes total 25 classes of land including- unclassified (cloud, shadow, etc.), high intensity developed, medium intensity developed, low intensity developed, pen spaces developed, cultivated land, pasture, grassland, deciduous forest, evergreen forest, mixed forest, shrub, palustrine forested wetland, palustrine shrub wetland, palustrine emergent wetland, estuarine forested wetland, estuarine scrub/shrub wetland, estuarine emergent wetland, unconsolidated shore, bare land, water, palustrine aquatic bed, estuarine aquatic bed, tundra and snow. 


\subsubsection{Database Development}

The land use database was obtained in ERDAS Imagine image file (.img) format. The format is GIS compatible. The image is brought into GIS and projected into appropriate co-ordinate system. Next, the complex 25 classes map was converted to a binary (0/1) format using reclassify tool in ARCGIS software (see Figure 4-12).

Figure 4-11: Flowchart of land use database construction

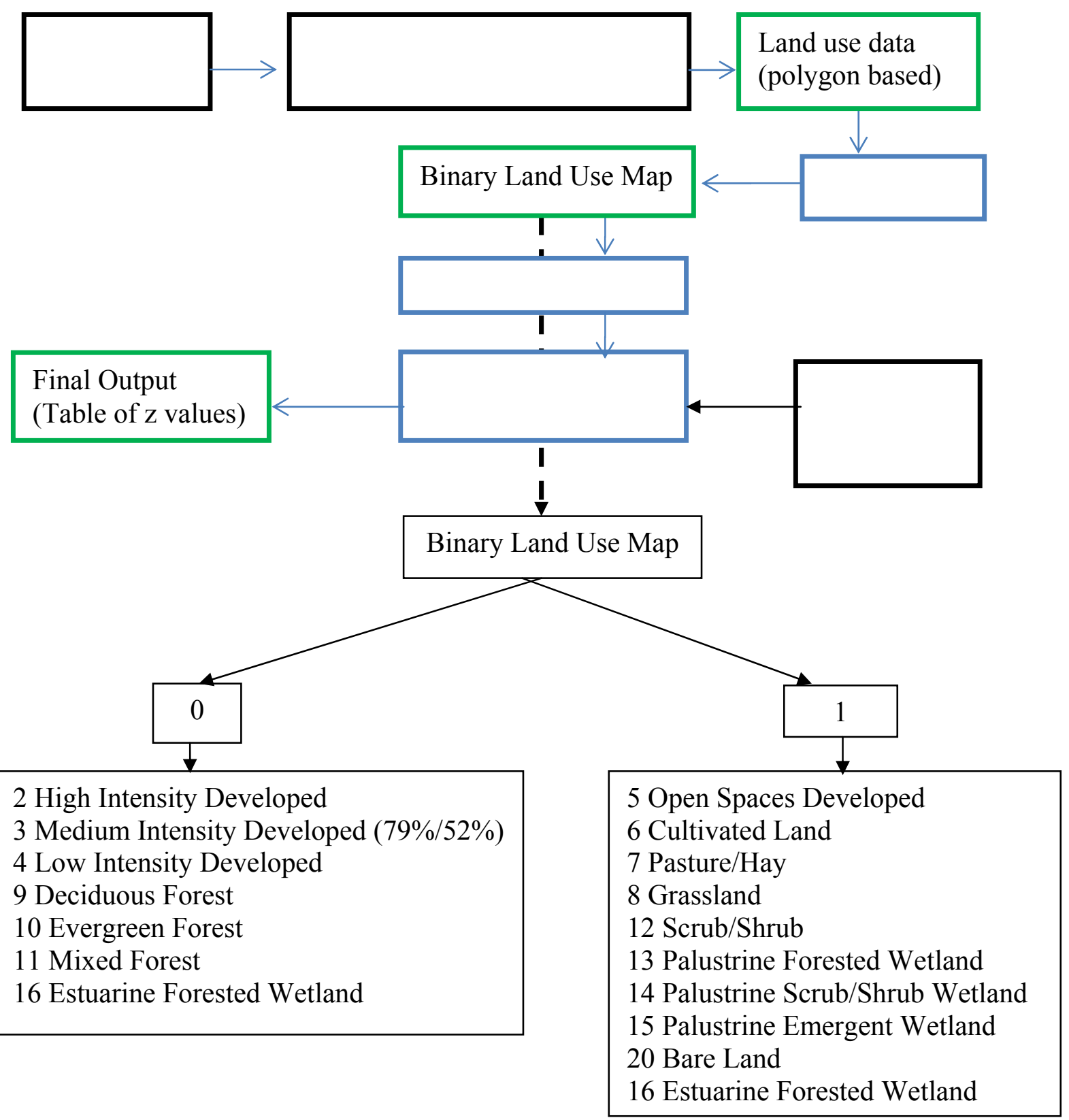


Figure 4-12: Land use pattern in the study area

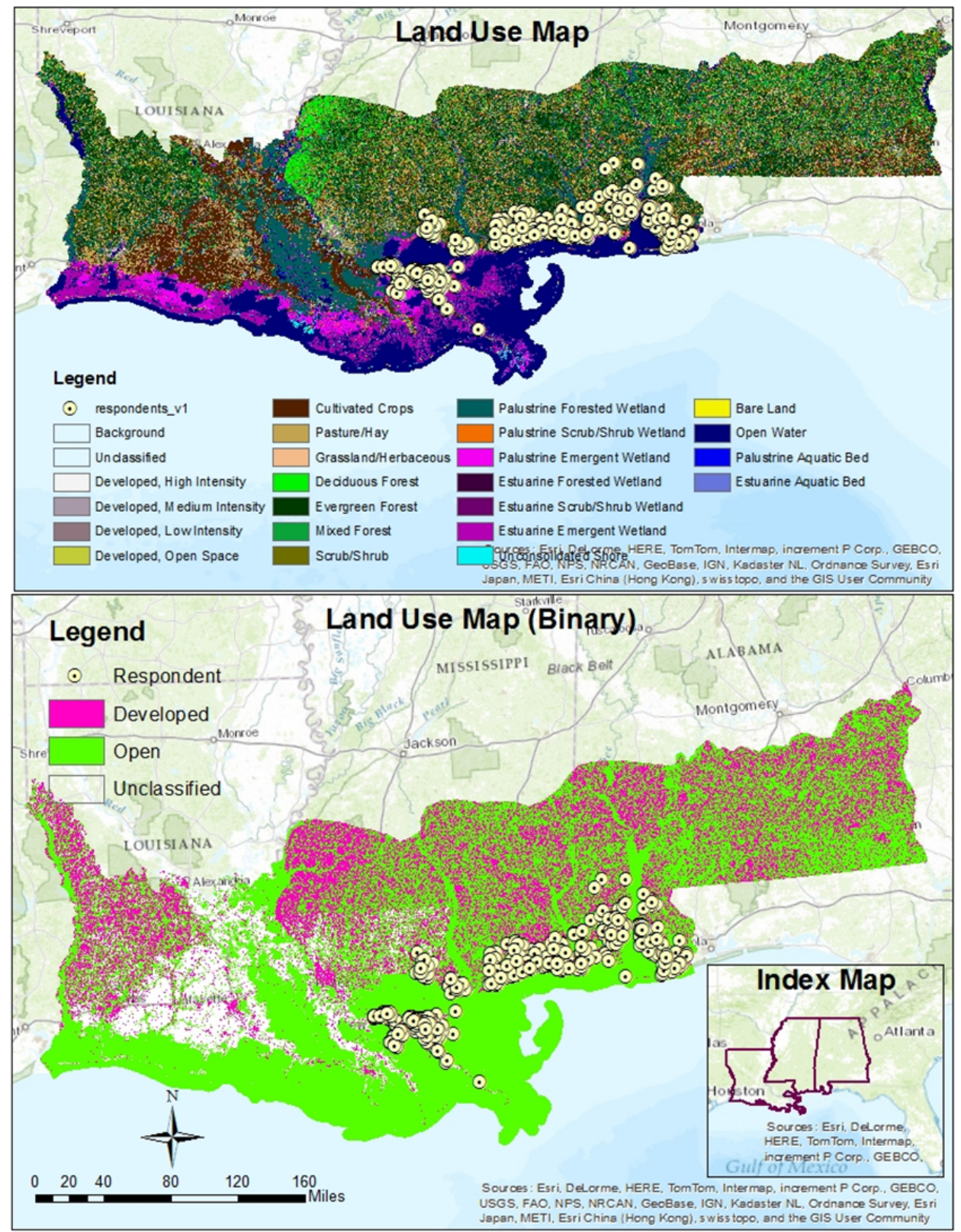

In the final GIS map, green represents natural and open land use (open land, bare land, grass land etc.) and magenda represents dense and developed land use (high intensity developed, medium intensity developed, low intensity developed etc.). 


\subsection{Flood Zone}

A floodplain is commonly understood an area that can be flooded from a river, stream or other waterways by overflow. The overflow can arise during common floods or from coastal flooding caused by tropical storms or hurricane induced storm surge. Flood zones are delineated by Federal Emergency Management Agency's (FEMA) according to hazard type. These zones are called Special Flood Hazard Area (SFHAs). The zones are defined as Zone A, Zone AE, Zone AO, Zone AH, Zones A1-A30, Zone AR, Zone AE, Zone V, Zone VE, and Zones V1-V30. Zone B or Zone X (shaded) are defined as moderate flood hazard areas. Zone C or Zone X (unshaded) are defined as minimal flood hazard area. Structures in a category "A" flood zone has around 26 percent chance of flooding and category " $\mathrm{B}$ " flood zone has around 6 percent chance of flooding during a 30 -year period of time. If the structure is not elevated, then the risk for flooding increases according to proximity of a structure to a river or streamline or shoreline (FEMA, 2013).

\subsubsection{Data Acquisition, Management and Database Development}

Data for three different counties were acquired from different organizations. Floodplain for South Louisiana was collected from Louisiana Recovery Authority. Floodplain for Mississippi and Alabama were collected from Federal Emergency Management Agency. For the convenience of analysis, flood zone map were recoded into a binary map showing household within flood zone or not (see Figure 4-14). All the 'A' or ' $\mathrm{B}$ ' zone refers flood zone and all else are non-flood zone. 
Figure 4-13: Flowchart of flood zone database construction for both hurricane Ivan and Katrina

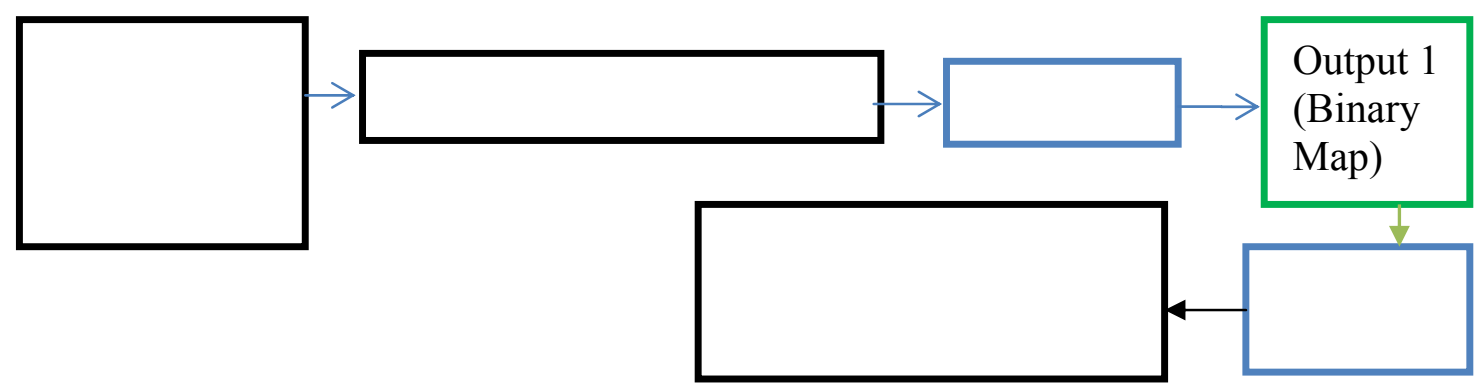

Figure 4-14: Floodplain Map of the Study Area

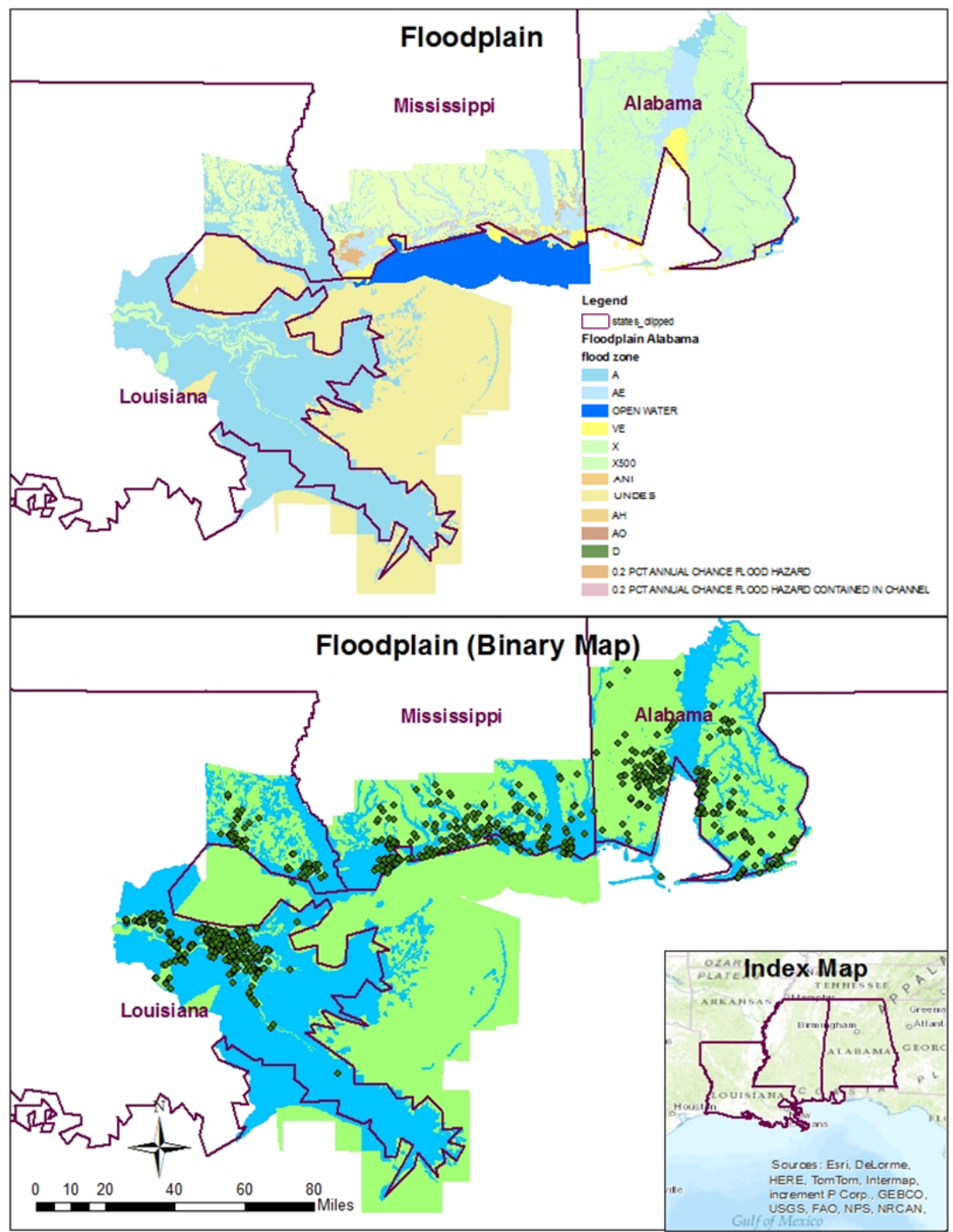




\subsection{Wind Profile of the Study Area during Hurricane Events}

The wind intensity may increase household risk perception which can positively affect evacuation decision. The following flow-chart is showing the methodology of the wind database development.

Figure 4-15: Flowchart of wind database construction for both hurricane Ivan and Katrina

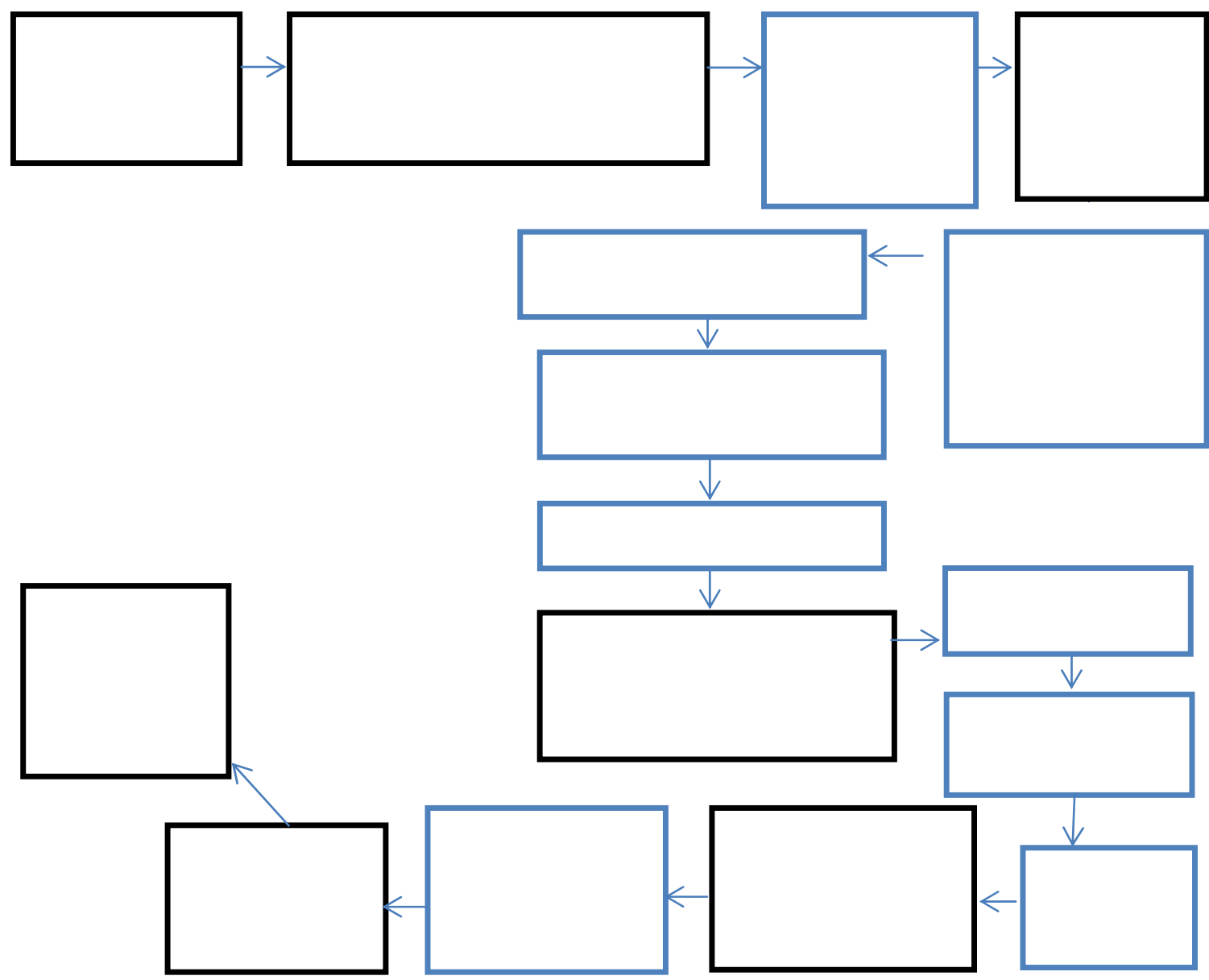

\subsubsection{Data Sources and Formats}

The hurricane research division (HRD) at the National Hurricane center (NHC) maintains an archive for hurricane wind database for historic hurricanes. It preserves 
maximum sustained wind (MSW) data which is used in this study because MSW is a common indicator of the intensity of the storm. The wind database was stored in gridded image and shape file format and had been used for the current research.

\subsubsection{Wind Database Development Using Geo-statistical Kriging}

Maximum sustained wind (MSW) data was collected for hurricane Ivan and hurricane Katrina. The distance between wind data points were found at least 12 meter. Therefore, a continuous wind surface was developed by using ArcGIS geo-statistical kriging method. Kriging interpolation works best when the data points are normally distributed and located closely (ESRI, 2011). This method gives standard errors associated corresponding to each predicted values. The continuous raster surface was used in further analysis.

The NHC wind dataset had more than 25000 data points in the study area. The large data points give good results with more certainty. There are several components of geo-statistical models. The most important component was to examine the data through exploratory spatial data analysis (ESDA) and variography (by creating empirical semi variogram and fitting a model to the empirical semi variogram). The next part was to build a desired output surface to suit the study needs. The method also performed cross validation and compared from alternate models to pick the best one. The distribution of the data was found normal. Spatial autocorrelation of the data points were examined by developing semi variogram/covariance cloud. Highly clustered data points indicated a good spatial autocorrelation among data points.

The same kriging method was done for all the 12 raster datasets ( 4 raster dataset for each day which starts from 3 days before landfall). The raster files were then merged 
so that the output raster file considered the average of all MSW data 3 days before landfall. Next, from the raster data layer, MSW data were extracted for each household location.

\subsubsection{Maximum Sustained Wind (MSW) Database Development}

Based on the vector point file of MSW data in the study area, I operated ordinary kriging interpolation. Before the kriging, the study examined the spatial auto co-relation among those 40,000 points.

\subsubsection{Theory of Ordinary Kriging and Its Components}

\subsubsection{Ordinary kriging}

Ordinary kriging assumes the following model, $Z(s)=\mu+\varepsilon(s)$, where $\mu$ is an unknown constant. Mean is assumed to be constant in ordinary kriging method.

\subsubsection{Semivariogram}

The semivariogram is defined as $\gamma\left(\mathrm{s}_{\mathrm{i}}, \mathrm{s}_{\mathrm{j}}\right)=1 / 2 \operatorname{var}\left(\mathrm{Z}\left(\mathrm{s}_{\mathrm{i}}\right)-\mathrm{Z}\left(\mathrm{s}_{\mathrm{j}}\right)\right)$, where "var" stands for variance. As distance gets farther apart, they become less similar, so the differences in their values become larger. This can be seen in the following figure, which shows the anatomy of a typical semi-variogram. It is to be noted that with the increase in distance, the variance increases as well. Therefore, semi-variogram expresses a dissimilarity function.

\section{Figure 4-16: Typical semi-variogram}

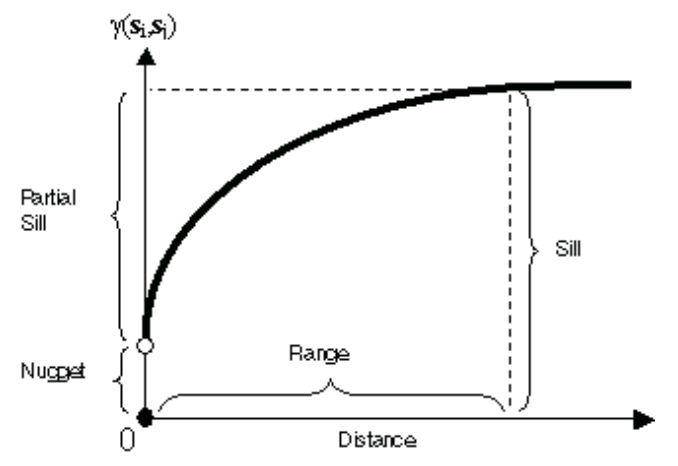




\subsubsection{Hurricane Ivan MSW Database Development}

Based on the point based vector file containing 40000 points of MSW data in the study area, exploratory data analysis was done. A semi-variogram model is fitted using available data points.

Figure 4-17: Semivariogram of the maximum sustained wind (in knots)

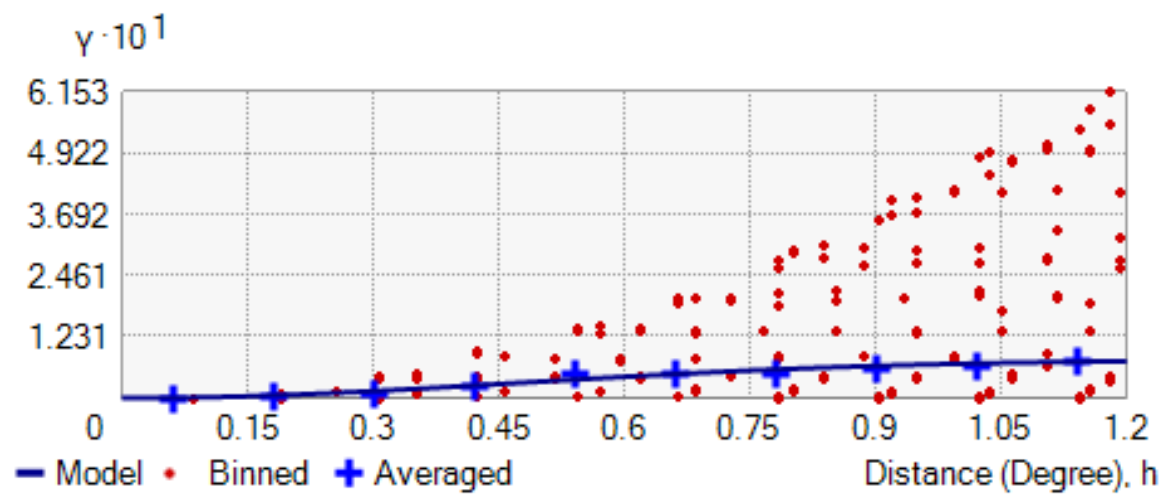

Figure 4-17 explains the spatial autocorrelation within the wind dataset. The binned value (blue plus sign) and the model values were clustered in a similar pattern indicating a good model with appropriate value.

Figure 4-19: Variogram analysis for predicted wind value

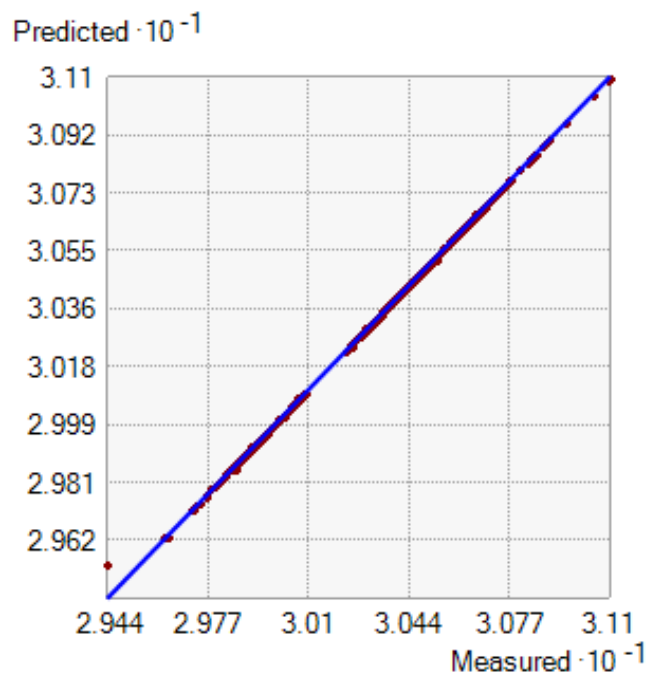

Figure 4-18: Cross validation for error in predicted wind value

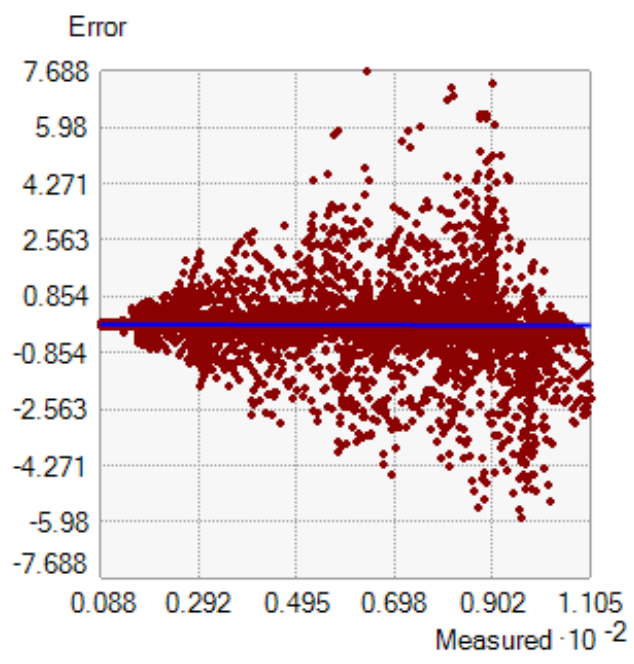


Figure 4-18 is showing a scatterplot of normal measured values versus error values. Besides making predictions, it estimates the variability of the predictions from the true values. It is important to get the correct variability. Figure 4-18 explains that the error values are randomly distributed and there is no outlier. From the context of kriging prediction error statistics, it is known that if the average standard errors are close to the root mean squared prediction errors, the model is correctly assessing the variability in prediction. The prediction surface has low and close root-mean-square predicted errors and average standard errors. In addition, mean standardized error is close to zero. Therefore, the model fit is good. Based on the interpolated wind map, wind exposure on each household is measured and Figure 4-20 shows the distribution of MSW exposure on each household.

Figure 4-20: Wind profile during Ivan

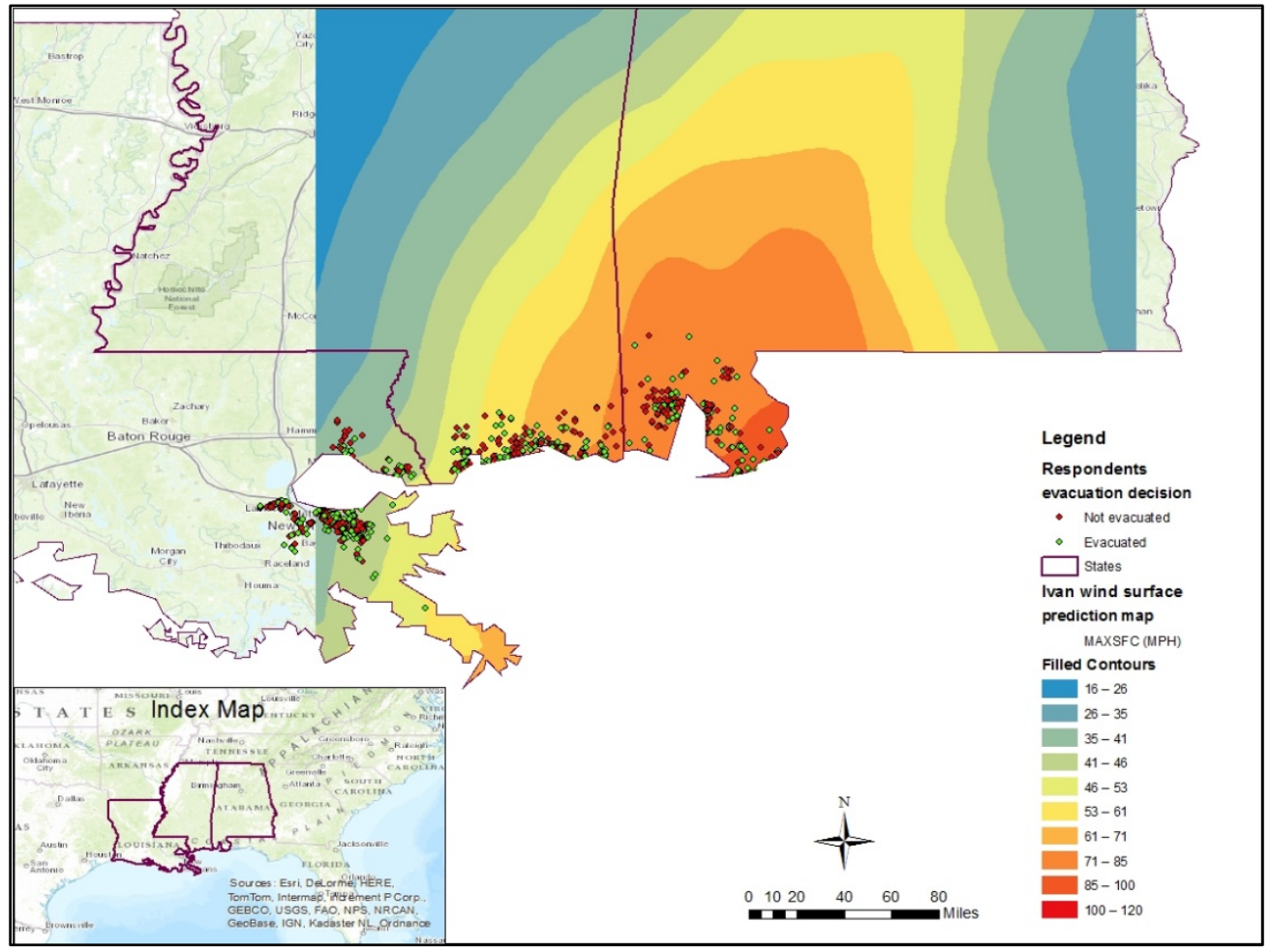




\subsubsection{Hurricane Katrina MSW Database Development}

Based on total 33489 points for hurricane Katrina wind data, a similar wind profile is developed (see figure 4-23) based on previously described methodology in section 4.7 .

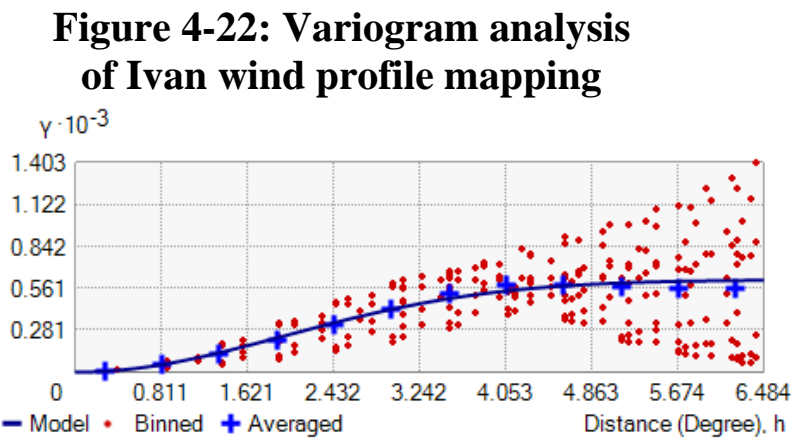

Figure 4-21: Cross validation for predicted wind value

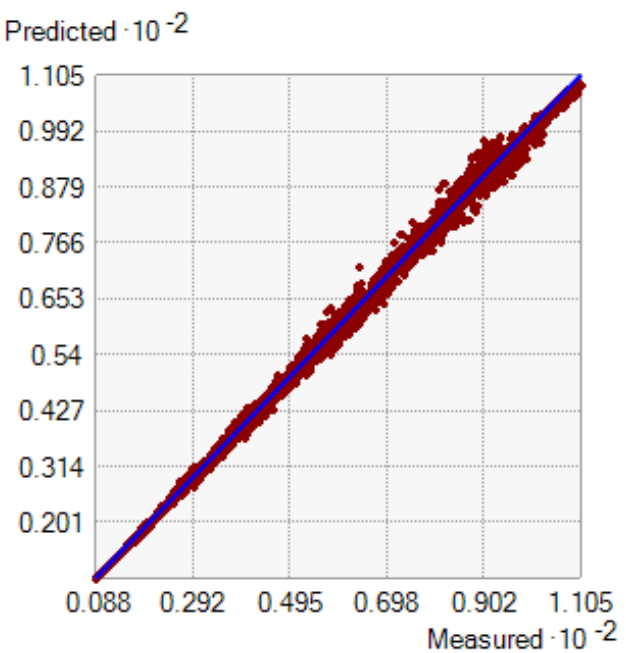

The above semi-variogram (Figure 4-22) cloud explains the local characteristics of spatial autocorrelation within the dataset and checks for local outliers. The binned value and the model merge almost perfectly indicating the goodness of model fit. Even though the model is underestimating initially and it is again overestimating in later part, but in terms of the area, the model fit is good. 
Figure 4-23: Wind profile during hurricane Katrina

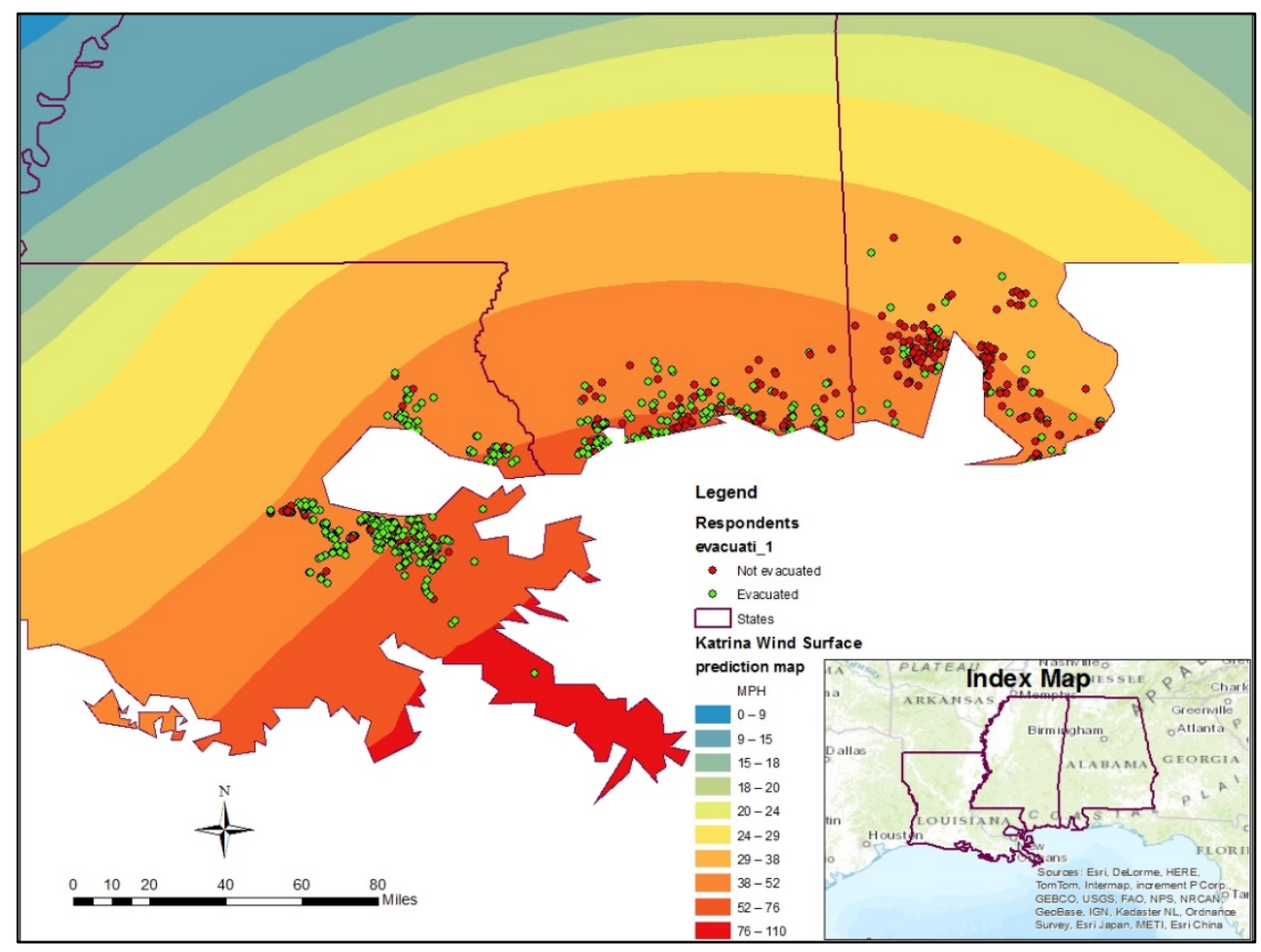

The cross validation in figure 4-21 indicates strong auto-correlation between predicted and observed data points. The following figure (Figure 4-23) is showing MSW exposure on household locations in the study area during Katrina.

\subsection{Precipitation Profile Analyses}

National weather service (NWS) climate data center maintains an archive of historic precipitation data. Precipitation data for the study area is collected from the website of NWS both for hurricane Ivan and Katrina. We used rainfall data from 3 days before landfall. As majority of survey respondent's evacuated within the 3 day time span, therefore rainfall amount is measured for that time.

Using satellite image to predict rainfall is common. After collection of the images for 4 specific dates, images were geo-referenced and bring into ArcGIS format. Using ArcGIS point value extraction tool, rainfall amount is measured for the household 
locations. Rainfall values were finally measured by averaging the total rainfall over the four days.

\subsubsection{Hurricane Katrina Precipitation Database}

Present study collected precipitation data from National weather service for both hurricane Ivan and Katrina.

\subsubsection{Data Source and Types}

Data were obtained from National Weather Service (NWS) River Forecast Centers (RFCs). Data were stored in vector format. Precipitation data were collected for 3 days starting from three days before landfall. Each of the vector files consisted of more than 4500 points.

\subsubsection{Data Management}

Based on the available data points, semi-variogram was constructed to fit a model of predicted values. Cross validation was performed after that to see the variance in the data. The semi-variogram (Figure 4-24) indicates that the model is predicting the surface accurately with a slight overestimating at the end of the model. Also the cross-validation (Figure 4-25) indicates variability in predicted and observed data. Both of these kriging tools indicate strong fit of model and observed data point. Again, average standard errors were very close and also mean standardized error was close to zero. The precipitation exposure on each household is extracted next from the continuous raster dataset. 
Figure 4-25: Cross-validation of Katrina precipitation profile

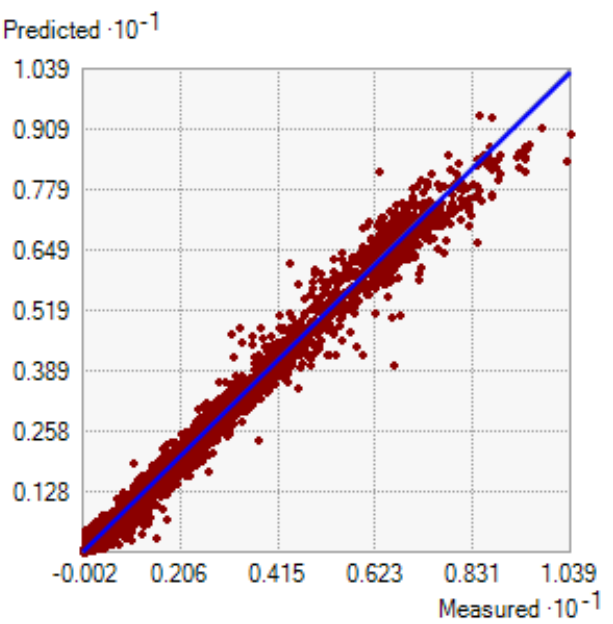

Figure 4-24: Semi-variogram of Katrina

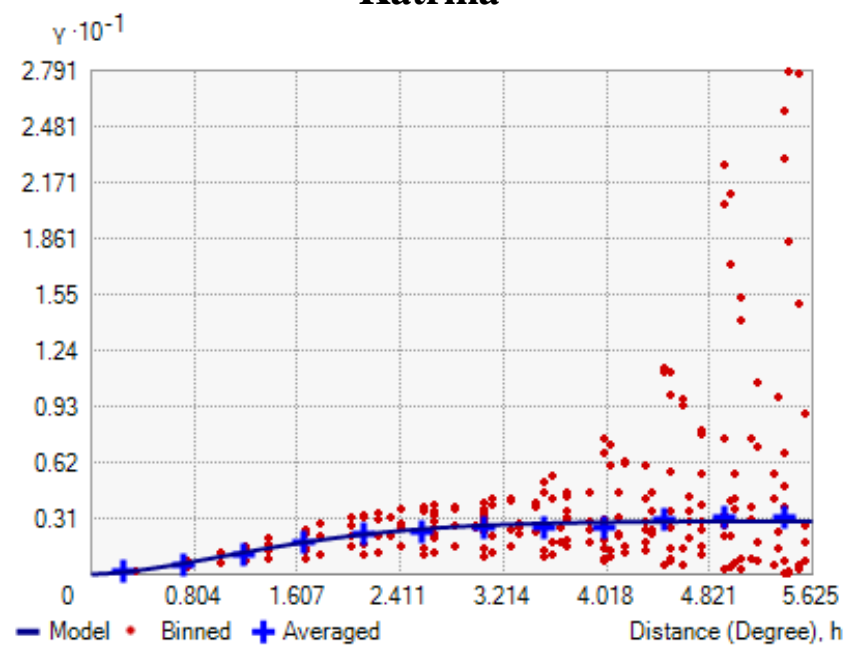

Figure 4-26 and 4-27 are showing precipitation exposure for each household during hurricane Ivan and Katrina. The figures are representing precipitation exposure for all the four days from 3 days before landfall. For the analysis purpose, averages of the four day precipitation data were taken.

Figure 4-26: Hurricane Ivan precipitation profile

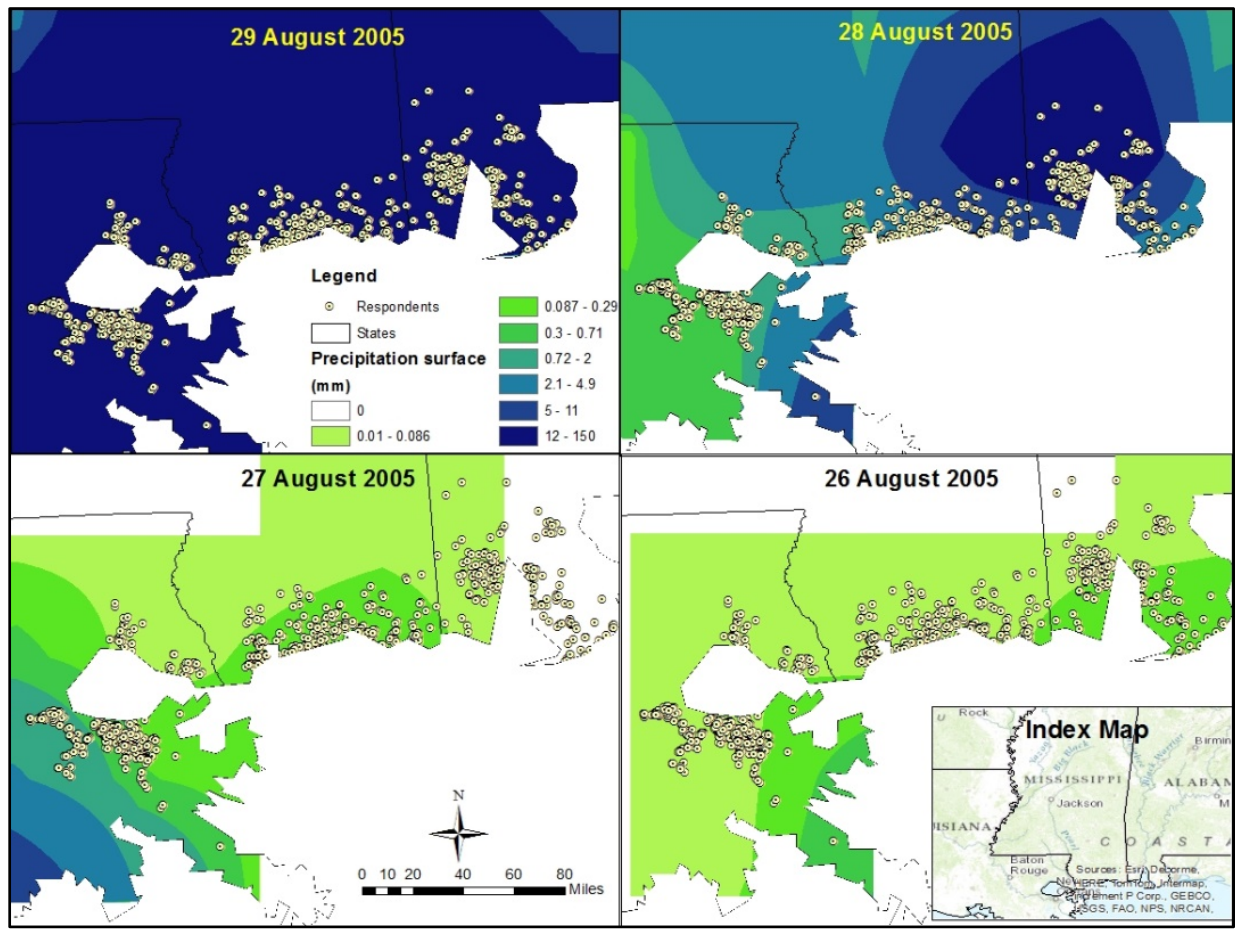


Figure 4-27: Katrina precipitation profile

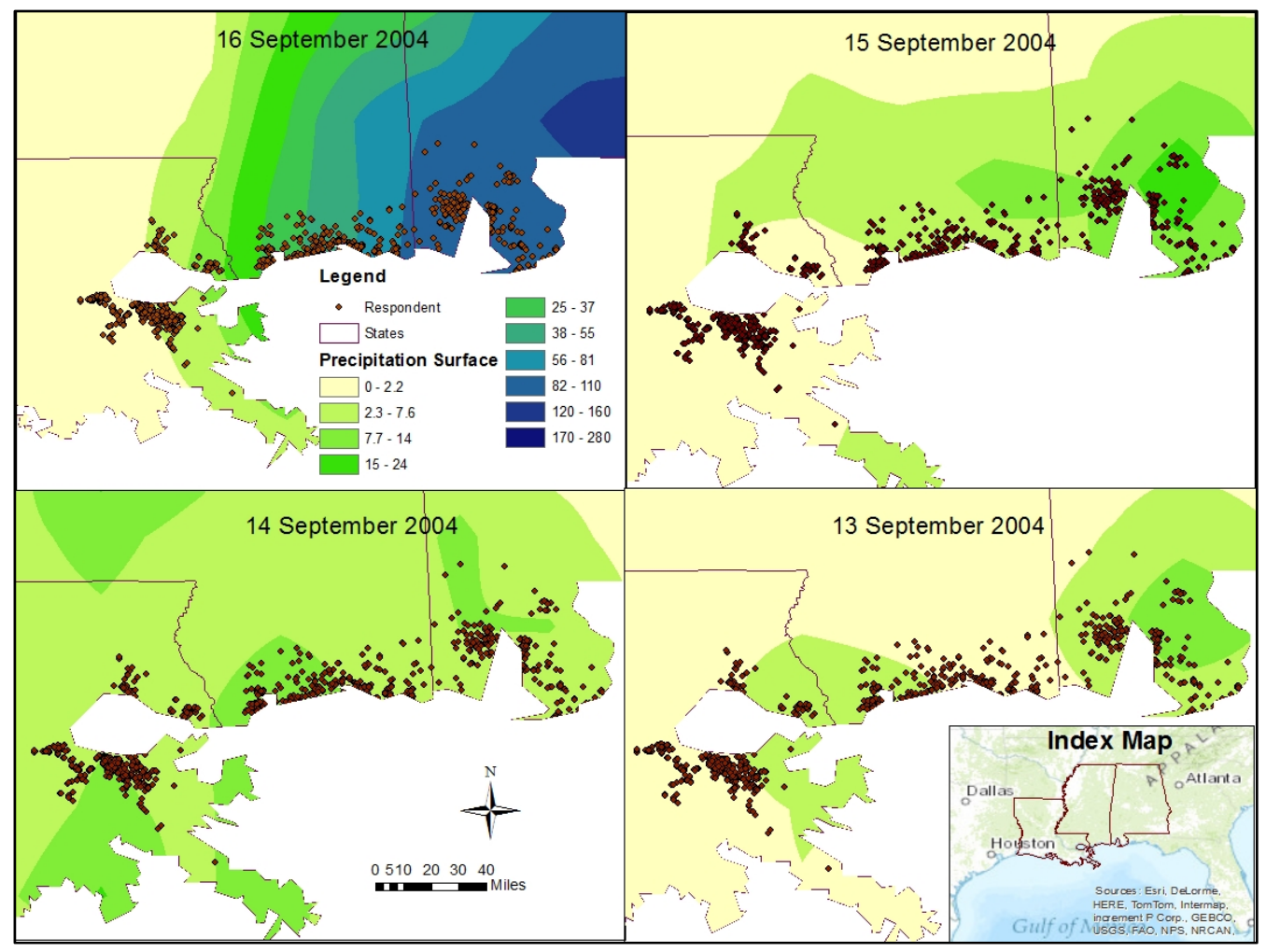

\subsection{Evacuation Route Distance}

It is also assumed that evacuation route distance from household is an important determinant in household risk perception for hurricane threat. People were concerned about traffic jam and road condition. Therefore, location farther or close to the evacuation route can potentially make a difference in risk perception. For example, households far from the evacuation route may have higher risk perception as it may take longer travel time to evacuate in the face of congestion and traffic jams.

\subsubsection{Data Source}

Hurricane evacuation routes are designated route used to direct traffic to safer places in case of a hurricane event. The evacuation route is based on data supplied by gulf coast and Atlantic seaboard states. Mainly primary hurricane evacuation routes were 
identified as evacuation route. Some counties designated secondary hurricane evacuation routes and therefore included in the GIS map. The publication date of the data set was 2007. Since the study is explaining evacuation during 2004 and 2005, this dataset provided credible route information during those two hurricanes.

\subsubsection{Distance Measurement}

The distance is measured using the same logic and method explained in section 4.4. Table 4-4 describes statistical summary of distances between evacuation route and household locations.

Table 4-4: Statistical description of route distance from household

\begin{tabular}{|llll|}
\hline $\begin{array}{l}\text { Statistical } \\
\text { Properties }\end{array}$ & Minimum & Maximum & Average \\
Distance (Meters) & 14427 & 1.43 & 2112.66 \\
\hline
\end{tabular}

Figure 4-28: Evacuation route and decision during hurricane Ivan

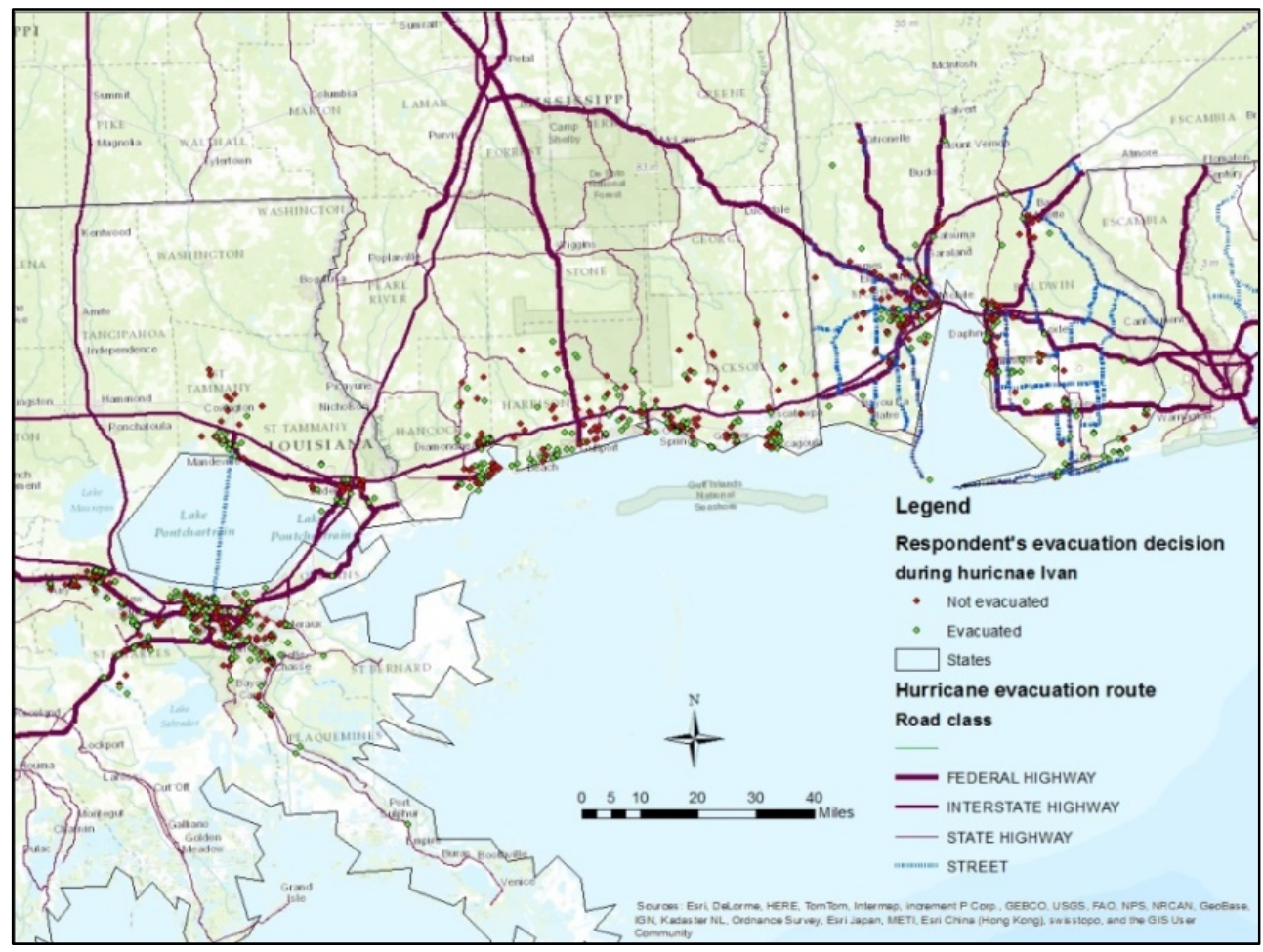


Figure 4-29: Evacuation route and decision during hurricane Katrina

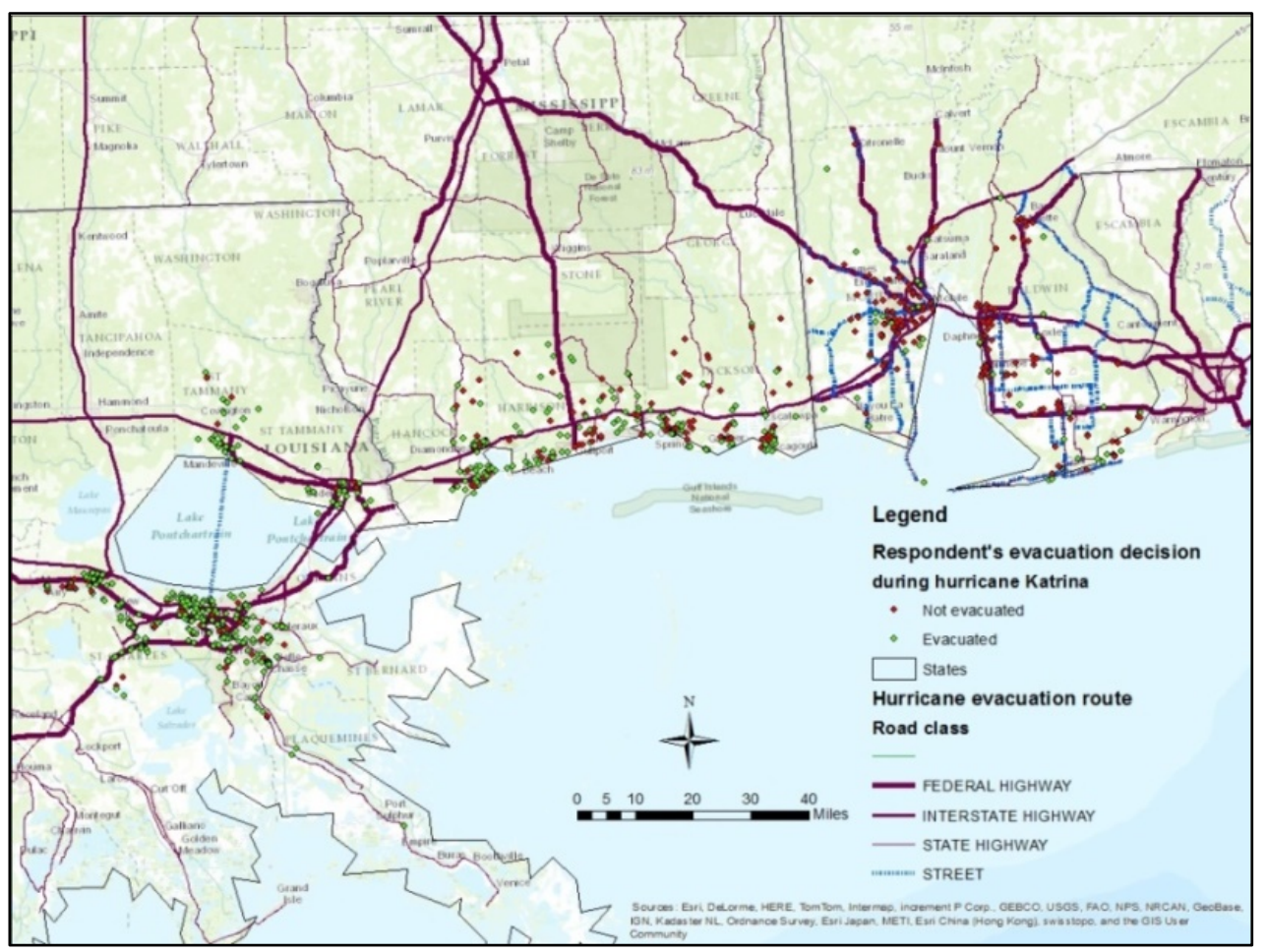

\subsection{Summary}

This chapter explained the development of the spatial dataset with reference to the household location information obtained from the household survey. The next chapter of the thesis provides the method of the empirical models to analyze the role of geo-spatial factors in hurricane risk perception and evacuation behavior. 


\section{CHAPTER 5: $\quad$ EMPIRICAL SPECIFICATIONS}

The model is based on the assumption that the evacuation decision made by household during an extreme event is endogenously related with household risk perception about hurricane threat. In the context of hurricane risk, risk perception is adaptive, dynamic and context sensitive (Meyer, 2013). Evacuation order, household preparation, influence of other people and hazard specific phenomena can act as intervention mechanism to influence people's risk perception towards hurricane and lead towards protective measures to reduce the risk. Evacuation in the face of hurricane contingencies may have uncertain consequences and expenses. In this complex evacuation decision making process under uncertainty, decisions are more likely to be made based on heuristics and judgment based on prior beliefs (Kahneman and Tversky, 1985). Not only just past events, but current socioeconomic and hazard specific consequences may also influence the risk perception. Once the respondent has perceived a risk, the evacuation decision can be influenced by other factors (e.g., resources needed following evacuation, household special needs such as presence of elderly, children or disable person etc.).

The subjective context of belief structure is explained by incorporating some spatial variables that can capture the objective risk on household. Specifically, if the respondent's latent level of hurricane risk perception crosses some benchmark, the household become prompted to evacuate. To begin modeling household evacuation behavior in terms of risk perception, we first postulate that the risk perception (No risk perception ' 0 ' and risk perception ' 1 ') is affected by a number of factors, we are especially interested to look how geospatial phenomena such as living inside evacuation 
zone, wind and rainfall exposure, proximity from shoreline, nearness from track, elevation are affecting peoples risk perception. Control variables such as education, income, ethnicity and some context specific variables such as household protective measures, past hurricane experience, home ownership, past experience of hurricane damage, duration of living in current household, and receipt of evacuation notice were considered in the model.

Next, this endogenous risk perception variable enters into the evacuation decision equation as an explanatory variable. Additional explanatory variables used to explain the evacuation decision such as income, education, ethnic background, number of household members, marital status, and receipt of evacuation notice.

\subsection{Model Specification (Bivariate Probit Model)}

To implement the second analytical approach, bivariate probit model were used, which jointly estimates the influence of household risk perception and hurricane Ivan evacuation decision. Another similar bivariate probit model jointly estimated influence of hurricane Ivan evacuation decision on the following hurricane (Katrina) evacuation decision. The bivariate probit model estimates two equations for the two binary dependent variables where the iid (independent and identically distributed) errors in each equations are correlated (Greene 2003) with zero mean vector and a non-zero variancecovariance matrix.

The bivariate system can be described as follows:

$$
\begin{aligned}
& \gamma_{1 \mathrm{i}}^{*}{ }^{*}=\alpha x_{\mathrm{i}}+\varepsilon_{1 \mathrm{i}} \\
& \gamma^{*}{ }_{2 \mathrm{i}}=\beta z_{\mathrm{i}}+\gamma y_{1 \mathrm{i}}+\varepsilon_{1 \mathrm{i}}
\end{aligned}
$$


Here, $\gamma^{*}{ }_{1 \mathrm{i}}$ and $\gamma^{*}{ }_{2 \mathrm{i}}$ are latent variables and $\gamma^{*}{ }_{1 \mathrm{i}}$ (hurricane risk perception) and $\gamma_{2 \mathrm{i}}^{*}$ (hurricane Ivan evacuation decision) are dichotomous variables that observed according to the following rule. For the next bivariate model, two latent variables are hurricane Ivan evacuation decision and hurricane Katrina evacuation decision.

$\left\{\begin{array}{lll}\gamma_{\mathrm{li}}^{*}=1 & \text { if } \quad \gamma_{1 \mathrm{i}}^{*}>0 \\ \gamma_{\mathrm{li}=0}^{*} & \text { if } \quad \gamma_{1 \mathrm{i}}^{*} \leq 0\end{array}\right.$

$$
\text { Where } 1=1,2
$$

Here $\mathrm{x}_{\mathrm{i}}$ and $\mathrm{z}_{\mathrm{i}}$ are vectors of explanatory variables and $\alpha, \beta$ and $\gamma$ represent the conformable vectors of relevant coefficients of the model. The error terms are assumed to be independently and identically distributed as bivariate normal with zero mean vectors and a non-zero variance-covariance matrix. I used the 'biprobit' option in STATA 12 to estimate the model parameters.

First bivariate probit model, analyzed the role of risk perception on evacuation decision. The first equation estimates the risk perception (risk perception $=1$, no risk perception $=0$ ) which is affected by a number of factors. This binary endogenous risk perception variable enters into the second equation (evacuation decision) as an explanatory variable. The bivariate probit model is a joint estimation technique where risk perception and evacuation decisions were estimated together.

Second and a similar bivariate probit model, analyzed the role of hurricane Ivan evacuation decision on the consecutive hurricane Katrina evacuation decision. First equation estimate that the Ivan evacuation decision (evacuated: $Y e s=1$, not evacuated $=0$ ) is affected by a number of factors. This binary endogenous variable (Ivan evacuation) enters into the second equation (Katrina evacuation decision) as an explanatory variable. 
The bivariate probit model is a joint estimation technique where two evacuation decisions were estimated together.

The Likelihood-Ratio test is used to test the null hypothesis that $\rho$ equals 0 . In the four bivariate probit models, we cannot reject the null hypothesis that $\rho$ equals zero, which indicates that the four models consists of independent probit equations which cannot be estimated separately.

\subsection{Endogeneity Test}

\subsubsection{Likelihood Ratio and Wald Tests}

The further test statistics included in our investigation were those requiring estimation of the model under the alternative hypothesis.

The likelihood ratio test has the well-known form:

$$
\mathrm{LR}=-2\left[\stackrel{\sim}{\left(\beta_{0}\right)}-1(\hat{\beta})\right] \stackrel{\stackrel{d}{H_{0}} \chi}{\longrightarrow} \chi
$$

Wald test is the squared term of Rho ( $\rho)$. The "t-test" based on $\rho$, which is given by:

$$
\operatorname{Rho}(\rho)=\frac{\hat{\rho}}{\operatorname{se}(\hat{\rho})} \underset{H_{0}}{\longrightarrow} \mathrm{N}(0,1)
$$

It requires estimation of $\operatorname{se}(\rho)$. We use to this purpose the corresponding element of the inverse of the negative hessian matrix,

$$
\mathrm{V}=\left[\frac{-\mathrm{E}[\mathrm{a} 210(\beta)}{\mathrm{a} \beta \text { á } \beta^{\prime}}\right]
$$

\subsection{Model Fitness Test}

The Akaike Information Criterion (AIC) is one of the best possible ways to select a model from a set of competing models. This approach is based on information theory and selects a model that minimizes the Kullback-Leibler distance between the estimated and the true models. Let $\mathrm{L}$ be the likelihood function, then the AIC is defined as 
$\mathrm{AIC}=-2 \ln (\mathrm{L})+2 \mathrm{p},(4)$

$\mathrm{p}$ is the number of free parameters in the model. Generally, AIC indicates interchange between complexity and accuracy of the model. The Bayesian information criterion $\left(\mathrm{BIC}_{\text {Schwarz }}\right)$ primarily considers likelihood function. BIC is closely related to AIC.

The $\mathrm{BIC}\left(\mathrm{BIC}_{\text {Schwarz }}\right)$ is defined as

$\mathrm{BIC}_{\text {Schwarz }}=-2 \ln (\mathrm{L})+\mathrm{p} \ln (\mathrm{n}) \ldots \ldots \ldots \ldots \ldots(2)$

Adding more parameters may increase the likelihood while fitting a model, which can over fit the model. BIC introduce a penalty term for added number of parameters to reduce the over fit in the model. In both cases smaller the value, better is the model fitness (Akaike 1974; Schwartz 1978). 


\section{CHAPTER 6: $\quad$ RESULT AND ANALYSIS}

\subsection{Bivariate Probit Model of Household Overall Risk Perception}

This section presents results from Bivariate Probit models to analyze the influence of endogenous risk perception on respondent's evacuation behavior. Respondent's hurricane risk perception is reported as an overall risk perception for both flood and wind risk. Additionally, respondent's hurricane risk perception is reported separately for flood and wind. A set of four models (see tables 6-3, 6-4 and 6-5) were developed for each type of risk perception (overall risk perception, flood risk perception and wind risk perception) to analyze which factors influenced each type of risk perception and eventually how the risk perception affected evacuation behavior during hurricane Ivan. All four models were developed in a way that every following model included at least one additional explanatory variable for checking consistency of results across these models. Thus the primary purpose of four different models was to demonstrate the robustness of results with a large set of explanatory variables and with different measures of risk perception (overall, flood and wind risk perception).

Definitions and descriptive statistics of the variables used in the analyses are provided in table 6-1. Initial analysis of the data and descriptive statistics gave an idea about variability on different types of risk perception. Initial analysis suggests that resident's perception about flood risk was lower than that of perception for wind risk. While the sample mean of overall risk perception (risk) is $90 \%$, flood risk perception (flood) is $52 \%$ and wind risks perception (wind) is $78 \%$ (see table 6-2). This difference in mean proportions is significant at the $1 \%$ level. Thus, the risk perception was separately estimated for overall, flood and wind perception using structured bivariate probit model. 
The model took into account those variables, where reasonable amount of responses were available. The bivariate probit model used risk perception as an endogenous dummy variable. Bivariate probit model estimates likelihood ratio of the equations (see table 6-3). The likelihood ratio (LR) test is a measure for endogeneity in model. The endogeneity condition is described in terms of the correlation coefficient $(\rho)$ which represents the correlation between the unobservable variables of two separate equations. Greene (2003); Fabrici, Monfardini and Radice (2004) suggests that the test for exogeneity, $\rho=0$, can be performed by using a likelihood ratio, Wald or Lagrange Multiplier test. In case we cannot reject $\rho=0$, the two equations can be estimated separately.

\subsubsection{Role of Socio-Economic and Context Specific Factors on Risk Perception}

In the empirical model, evacuation decision was specified to the first equation, and it simultaneously modeled respondent's hurricane risk perception using the second equation. According to the natural hazard management literatures, people's realization about their own risk depends on couple of socio-economic and demographic factors including (a) education, (b) household income, (c) ethnicity, (d) duration of stay were found consistent across several case studies.

The risk perception equation took these factors as control variables, along with some other context specific variables such as presence of child, elderly, early experience. This function includes a concern variable which is a composite of three different concerns about meteorological threat from hurricanes- storm surge risk, flooding from rainfall and damage from tornados. Most importantly, the risk perception equation includes some geospatial variables such as location in terms of state, flood zone, evacuation zone and elevation from mean sea level. 
Table 6-1: Variable definitions and descriptive statistics of hurricane Ivan

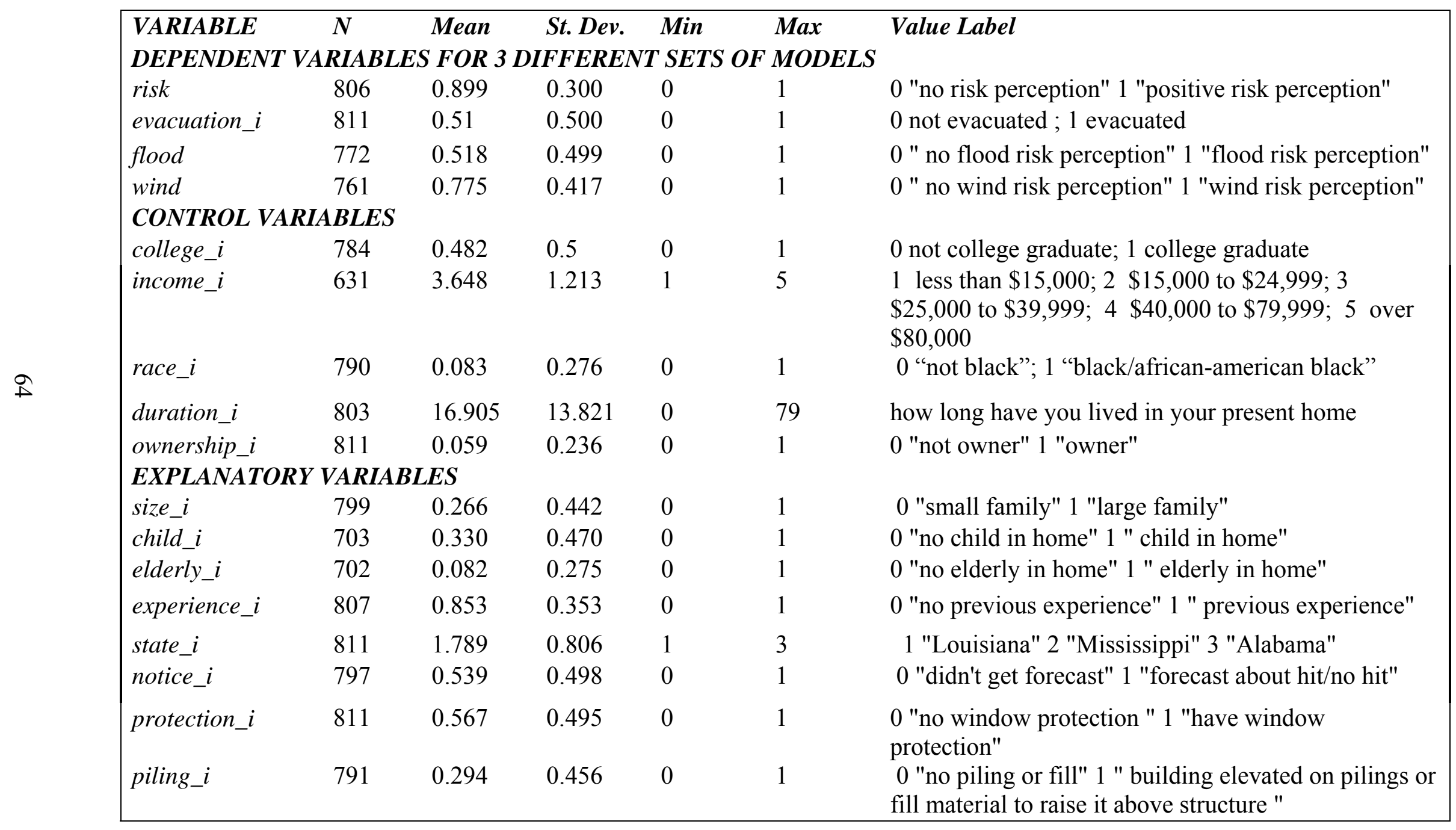




\begin{tabular}{|c|c|c|c|c|c|c|}
\hline work $\_i$ & 808 & 0.305 & 0.460 & 0 & 1 & 0 "no job requirement to stay " 1 "job required stay" \\
\hline business_i & 810 & 0.160 & 0.367 & 0 & 1 & 0 "no owner" 1 "owner" \\
\hline move_i & 800 & 0.06 & 0.237 & 0 & 1 & 0 "no plan to move" 1 "plan to move" \\
\hline map_i & 809 & 0.971 & 0.166 & 0 & 1 & $\begin{array}{l}0 \text { "no" } 1 \text { "yes" [did you see on television a map } \\
\text { showing the track the hurricane was being for] }\end{array}$ \\
\hline traffic_i & 811 & 0.059 & 0.236 & 0 & 1 & 0 "traffic concern" 1 " no concerned about traffic" \\
\hline logistic_i & 811 & 0.028 & 0.166 & 0 & 1 & 0 " shelter concern" 1 " no concern for shelter" \\
\hline \multicolumn{7}{|c|}{ GEOSPATIAL VARIABLES } \\
\hline floodzone & 811 & 0.366 & 0.482 & 0 & 1 & 0 "not in flood zone" 1 " flood zone" \\
\hline landuse & 811 & 0.254 & 0.435 & 0 & 1 & $\begin{array}{l}0 \text { "natural and open space" } 1 \text { "developed and dense } \\
\text { area" }\end{array}$ \\
\hline elevation & 811 & -13.501 & 497.078 & -2.03 & 104.61 & elevation of household from MSL \\
\hline shoreline & 811 & $\begin{array}{l}134008 . \\
3\end{array}$ & $\begin{array}{l}84624.2 \\
1\end{array}$ & 116.21 & $\begin{array}{l}257465 . \\
2\end{array}$ & distance of household from shoreline \\
\hline zone_i & 616 & 0.751 & 0.432 & 0 & 1 & 0 "not in evacuation zone" 1 "inside evacuation zone" \\
\hline route_meter & 811 & $\begin{array}{l}1981.84 \\
8\end{array}$ & $\begin{array}{l}2181.05 \\
3\end{array}$ & $\begin{array}{l}1.43354 \\
4\end{array}$ & $\begin{array}{l}14434.9 \\
4\end{array}$ & distance of household from evacuation route \\
\hline wind_i & 811 & 56.913 & 18.090 & 33.09 & 100.6 & wind exposure on household \\
\hline tract_i & 811 & $\begin{array}{l}9403.17 \\
7\end{array}$ & $\begin{array}{l}11824.1 \\
2\end{array}$ & 10.83 & $\begin{array}{l}57333.5 \\
2\end{array}$ & distance of household from evacuation tract \\
\hline rain_i & 811 & 43.392 & 42.562 & $\begin{array}{l}0.54194 \\
6\end{array}$ & 109.868 & rain exposure on household \\
\hline \multicolumn{7}{|c|}{ INTERACTION VARIABLES } \\
\hline landuse*zone_i & 616 & 0.194 & 0.396 & 0 & 1 & \\
\hline $\begin{array}{l}\text { landuse *elevatio } \\
n\end{array}$ & 811 & 2.871 & 9.566 & -1.71 & 80.18 & \\
\hline
\end{tabular}


The factors that influenced the overall risk perception were reported from a set of four models in table 6-3. In the first component (Panel A in table 6-3) shows the influence of multiple factors (geospatial, socio-economic, demographic and concern) in shaping overall risk perception (risk) that might eventually drive the respondent's hurricane evacuation behavior.

Some of the socio-economic and demographic factors significantly influenced household overall risk perception (risk). In model 1 to 4 , households that did not belong to specific ethnic group (race_i) or in other words, white people had higher risk perception. White people are mostly middle or upper middle class in terms of income group in the study area that has been observed from data analysis. Though the model did not find income to influence risk perception, but a detail summary of the income variables explained that majority of the respondents belonged to income group of $\$ 40,000$ to $\$ 80,000$. These classes of people are geographically mobile and experienced in traveling. This familiarity with moving might have contributed to the ability to plan for evacuation. In model 1 to 4 , if household belongs to white people, they showed higher risk perception. This finding is similar to previous literatures where Lachlan (2009) explained that since race and income are related, whites were more willing to evacuate than their african-american counterparts. Table 6-3 also reported the marginal effects of the corresponding coefficients in the same table. Marginal effects in the probit model refer to the impact of a corresponding variable to the risk perception of respondents conditional on the situation that a household evacuated or not (in models 1 to 4). Considering statistically significant components in tables $6-3$, being white-american household increases the hurricane risk perception by $6-12 \%$ based on different model 
specifications. Other factors such as duration of stay (duration_i) contributed positively to a household's risk perception. Duration of stay could be explained as previous experience and in such case respondents living in a house for longer time, have experienced earlier and similar natural hazards. Therefore in all models (model 1 to 4), respondents who were living since long time had higher risk perception. Among other control variables income (income_i) and presence of children (child_i) did not influence risk perception during hurricane Ivan.

Other context specific factors tend to be significant in hurricane risk perception. Presence of elderly (elderly_i) people decrease risk perception by $2 \%$ to $6 \%$ in model 1 and 3. To find a reasonable explanation for that, the research investigated the influence of previous experience (experience_i) and found that previous experience negatively influence risk perception by $20 \%$ in model 3 . Therefore the analysis indicates that there were large numbers of elderly and coastal residents who experienced storms from fringe area in past which did not hit them directly. Therefore they experience the storm but did not found that so dangerous. This gives an indication of false alarm or cry wolf phenomena in a following hurricane event. Household size (size_i) influenced household's risk perception negatively in model 1 by $18 \%$. Smaller households in the study area exhibited higher risk perception to a hurricane threat in the study area. The reason might be availability of less man power to tackle any emergencies during and after hurricanes (Model 1 to 4 in Panel A, table 6-3).

Concern about metrological threats was another factor that positively influenced hurricane risk perception. Concern was a subjective issue which includes respondents concern about three types of hurricane induced major meteorological threats such as 
flooding from storm surge and waves, flooding from rainfall or rivers and streams and damage from tornados.

\subsubsection{Geographical Dimensions of Risk Perception}

The geospatial factors exhibited strong influence on hurricane risk perception in all the four models (Model 1 to 4 in Panel A, table 6-3). The model determines if location within a particular flood zone type influenced risk perception during the evacuation process. According to the National Flood Insurance Program (NFIP), flood zone types are Zone A (100-year floodplain), Zone X-500 (500-year flood plain), and Zone X (Areas outside the 500-year floodplain). There are additional classes of flood zone including Zone AE and A1-30, Zone AH, Zone AO, Zone AR, Zone A99, Zone V, Zone VE and V1-30, one B or Zone X (shaded), Zone C or Zone X (un-shaded). These are identified as a Special Flood Hazard Area (SFHA) on the flood insurance rate map posing high, moderate and low threats. But for the convenience of analysis, the flood zone types were kept simply zone 1 (inside flood zone) and zone 2 (outside flood zone). The interaction between respondent locations within the flood zone and risk perception throughout the evacuation process was highly significant (at 1\% significance level) in all the models, model 1 to 3 . Location inside flood zone positively influenced their risk perception by $19 \%$ to $21 \%$.

For individuals during hurricane Ivan, many survey participants were noted that their risk perception to hurricane threat included geographical location of household in terms of closeness to a threat factor from natural hazard. Therefore closeness to shoreline was found to have a strong negative co-relation with risk perception. Distance from shoreline is measured in one model (model 4) because it was collinear with other 
concerned geospatial variables such as flood zone, land use. However, households located near the shoreline appeared to have experienced higher levels of risk perception during this phase than households located farther away from coastline as shown in figure 6-1.

Figure 6-1: Mapping risk perception and shoreline distance

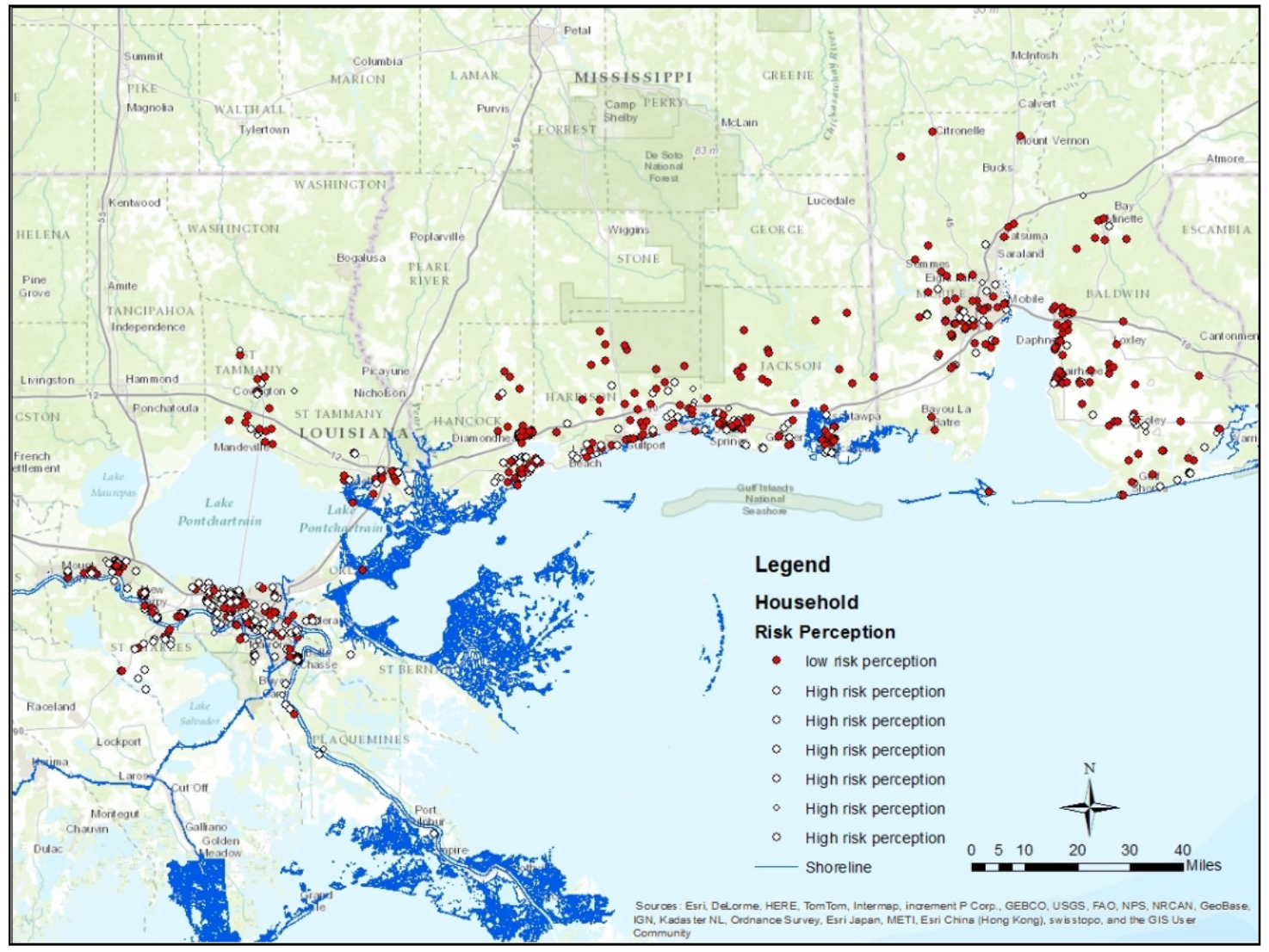

Figure 6-1 indicates that risk perception is higher in households which are closer to shoreline. This clear distance decay relation between risk perception and shoreline may reflect the notion that the location of one's home is a very important factor that influences risk perception. Determining a geographic boundary for analyzing the hurricane risk perceptions throughout the evacuation process is difficult since the nature of the hurricane threat and extent of the threat changes throughout an event. 
Table 6-2: Probability of risk perception on evacuation decision, Bivariate Probit specification and marginal effects

\begin{tabular}{|c|c|c|c|c|c|c|c|c|}
\hline \multicolumn{9}{|c|}{ Panel A: Factors Influenced People’s Risk Perception During Hurricane Ivan } \\
\hline Variable & model1 & $\begin{array}{l}\text { Marginal } \\
\text { Effect }\end{array}$ & model2 & $\begin{array}{l}\text { Marginal } \\
\text { Effect }\end{array}$ & model3 & $\begin{array}{l}\text { Marginal } \\
\text { Effect }\end{array}$ & model4 & $\begin{array}{l}\text { Marginal } \\
\text { Effect }\end{array}$ \\
\hline college_i & $\begin{array}{c}-.31^{*} \\
(0.19)\end{array}$ & 0.05 & $\begin{array}{l}-.38^{* *} \\
(0.19)\end{array}$ & 0.06 & $\begin{array}{l}-.36^{*} \\
(0.22)\end{array}$ & 0.06 & $\begin{array}{l}-.37 * \\
(0.22)\end{array}$ & 0.06 \\
\hline income_i & $\begin{array}{l}0.08 \\
(0.08)\end{array}$ & 0.03 & $\begin{array}{l}0.08 \\
(0.09)\end{array}$ & 0.04 & $\begin{array}{l}0.09 \\
(0.10)\end{array}$ & 0.04 & $\begin{array}{l}0.06 \\
(0.09)\end{array}$ & 0.04 \\
\hline race_i & $\begin{array}{l}-.51^{* * *} \\
(0.19)\end{array}$ & -0.09 & $\begin{array}{l}-.61^{* * *} \\
(0.18)\end{array}$ & -0.06 & $\begin{array}{l}-.79 * * * \\
(0.22)\end{array}$ & -0.11 & $\begin{array}{l}-.83^{* * *} \\
(0.25)\end{array}$ & -0.12 \\
\hline size_i & $\begin{array}{l}-.35^{*} \\
(0.18)\end{array}$ & -0.05 & $\begin{array}{l}-0.30 \\
(0.21)\end{array}$ & -0.02 & $\begin{array}{l}-0.25 \\
(0.25)\end{array}$ & -0.02 & $\begin{array}{l}-0.34 \\
(0.23)\end{array}$ & -0.03 \\
\hline duration_i & $\begin{array}{l}.014^{* * *} \\
(0.00)\end{array}$ & 0.00 & $\begin{array}{l}0.01 \\
(0.01)\end{array}$ & 0.00 & $\begin{array}{l}0.01 \\
(0.01)\end{array}$ & 0.00 & $\begin{array}{l}0.00 \\
(0.01)\end{array}$ & 0.00 \\
\hline child_i & $\begin{array}{l}0.24 \\
(0.19)\end{array}$ & 0.03 & $\begin{array}{l}0.23 \\
(0.20)\end{array}$ & 0.01 & $\begin{array}{l}0.03 \\
(0.23)\end{array}$ & 0.00 & $\begin{array}{l}0.18 \\
(0.24)\end{array}$ & 0.01 \\
\hline experience_i & $\begin{array}{l}-0.06 \\
(0.23)\end{array}$ & -0.01 & $\begin{array}{l}-0.22 \\
(0.23)\end{array}$ & -0.01 & $\begin{array}{l}-.4 * * \\
(0.20)\end{array}$ & -0.03 & $\begin{array}{l}-0.31 \\
(0.23)\end{array}$ & -0.02 \\
\hline floodzone & $\begin{array}{l}.58^{* * *} \\
(0.19)\end{array}$ & 0.07 & $\begin{array}{l}.45^{* *} \\
(0.19)\end{array}$ & 0.02 & $\begin{array}{l}.43^{* *} \\
(0.21)\end{array}$ & 0.03 & & \\
\hline landuse & $\begin{array}{l}-.38^{* * *} \\
(0.14)\end{array}$ & -0.06 & $\begin{array}{l}-.38 * * * \\
(0.13)\end{array}$ & -0.03 & $\begin{array}{l}-.32 * * \\
(0.16)\end{array}$ & -0.03 & & \\
\hline elevation & & & $\begin{array}{l}-.0098^{* *} \\
(0.00)\end{array}$ & 0.00 & $\begin{array}{l}-.0059 * \\
(0.00)\end{array}$ & 0.00 & $\begin{array}{l}-0.01 \\
(0.00)\end{array}$ & 0.00 \\
\hline shoreline & & & & & & & $\begin{array}{l}-0.06^{*} \\
(0.00)\end{array}$ & 0.00 \\
\hline state_i & & & & & & & $\begin{array}{l}-0.84^{*} \\
(0.47)\end{array}$ & -0.07 \\
\hline constant & $\begin{array}{l}1.2 * * * \\
(0.34)\end{array}$ & & $\begin{array}{l}1.6^{* * *} \\
(0.48)\end{array}$ & & $\begin{array}{l}0.41 \\
(0.56)\end{array}$ & & $\begin{array}{l}0.29 * * \\
(1.49)\end{array}$ & \\
\hline
\end{tabular}




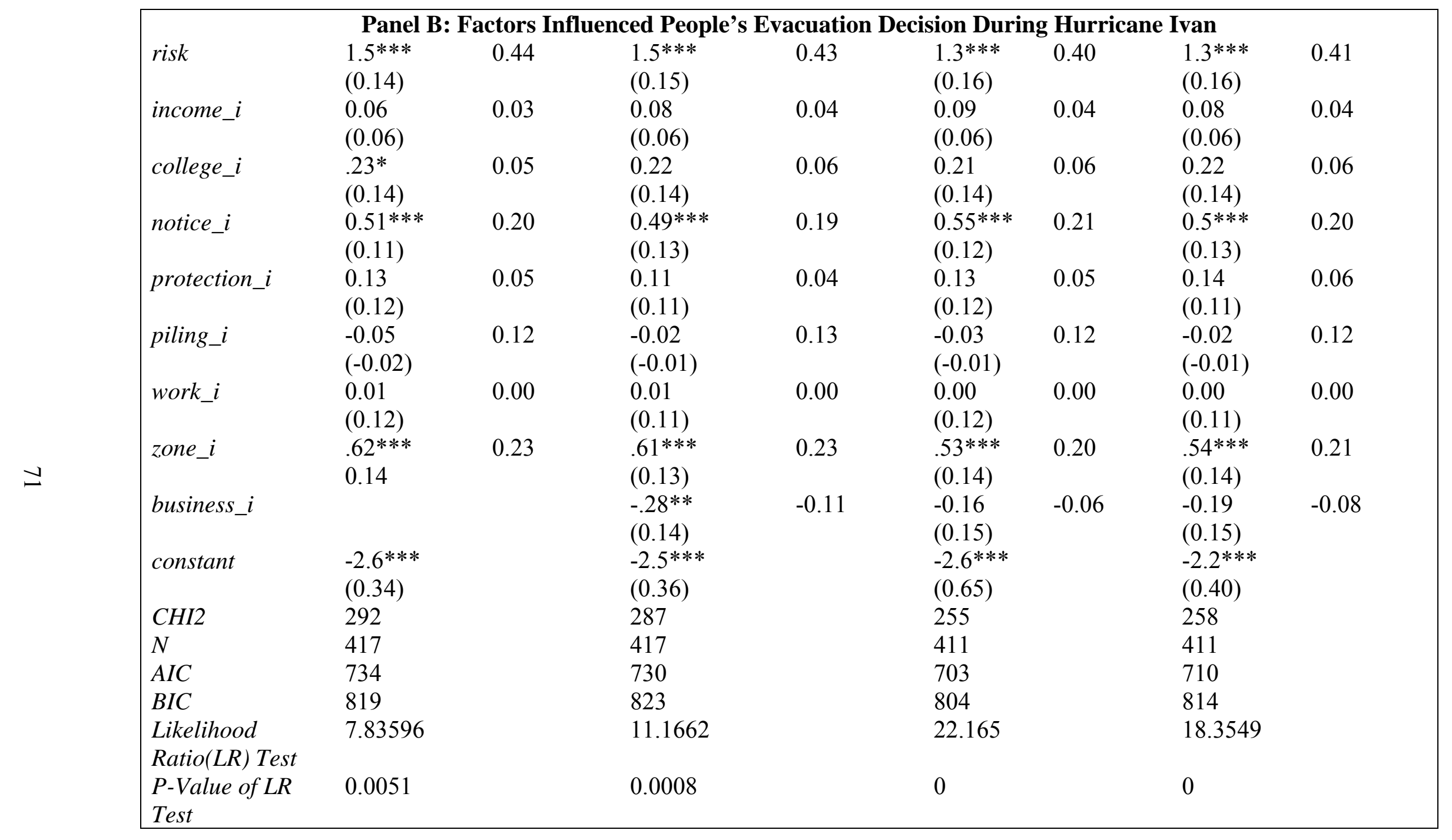

Notes: $* * *, * *, *$ imply significance at $1 \%, 5 \%, 10 \%$ levels respectively; numbers inside parenthesis are robust standard errors. 
This finding provide a unique understanding of the geographic variations in evacuee risk perception that is absent in studies of evacuees risk perception. It is important to note that these risk perception maps can assist in providing a more accurate interpretation of the statistical analyses.

The elevation of household from mean sea level was another factor which strongly influenced the risk perception (Table 6-3) in model 2 and 3. The statistically significant negative correlation implies that low elevation of household location are more exposed to impacts of storm surge such as flooding and so they perceive a higher level of risk

Household location in different states had a strong influence on respondent's hurricane risk perception. Households in Louisiana showed highest risk perception than households in Mississippi and Alabama. People living in Louisiana had 47\% higher risk perception than the rest of the household. A negative correlation value indicates that, a household from Mississippi is less likely to evacuate than Louisiana, given that everything else remains the same. Similarly, the parameter of the indicator variable for the households of Alabama suggests that being from Alabama results in a lower probability to evacuate.

Landscape pattern was found significant in respondent's hurricane risk perception in all three models from 1 to 3 . The locations of the household were classified in 15 categories. We understand that total land use types are 25 but since we are taking account only the landscape where households were located, therefore, there is no land use as water, tundra, snow etc. For the convenience of analysis, again we divide he broad classification in two groups- open landscape and highly developed landscape. The more 
developed landscape such as high, medium developed land, strong and dense evergreen forest areas showed higher risk perception. Possible reason could be fear about inland flooding after storm surge in developed areas where water removal takes time. This phenomena increase risk perception as respondents feel trapped in clogged water for long span of time which eventually might disrupt communication and utility services.

Figure 6-2: Geographic pattern of overall risk perception (wind and flood)

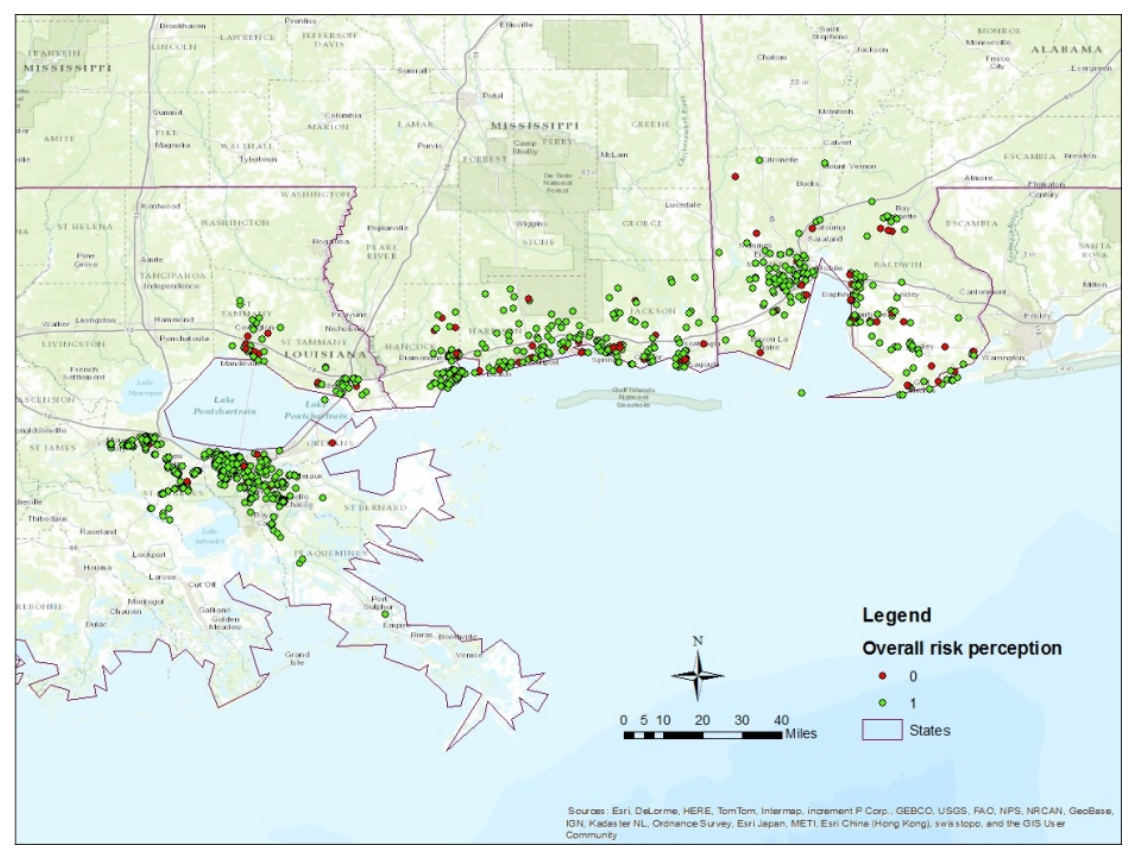

Figure 6-2 depicts that the risk perception throughout the study area follows a geographic pattern. Majority of households in Louisiana and a number of households in Mississippi exhibits highest risk perception. Louisiana has some unique features for which people living in Louisiana have higher risk perception than others. The land elevation is lower than other states. While Gulf of Mexico has an average elevation at mean sea level, New Orleans is 8 feet below sea level (U.S. Geological Survey). Also among other states, it is facing highest land loss rates. It is losing 25 to 35 square miles of wetlands per year (Barras et. al, 2003). These natural processes can bring more disastrous 
impact followed by coastal hazards. People living in these low lying areas facing land loss problems have higher risk perception than others.

\subsubsection{Geospatial and Social Dimension of Evacuation Decision in Response to}

Hurricane Risk Perception

Investigation of the second equation of evacuation decision justified significant associations with respondent's risk perception. This suggests that a respondent is more likely to evacuate when he has higher perception of risk.

In the second component (Panel B in table 6-3), the binary endogenous variable, risk perception enters into the evacuation decision equation as an explanatory variable, and is found statistically significant (in Models 1 to 4). The implication is that a higher risk perception (that one's home may be endangered by hurricane) leads to positive evacuation decision. Influence of risk perception was significant at $1 \%$ level. Respondents who have higher risk perception that hurricane may endanger their home were $40 \%$ to $44 \%$ more likely to evacuate (Models 1 to 4 , Table 6-2). It implied that a majority of people who evacuated during Ivan also had higher level of risk perception.

Figure 6-3: Evacuation decision and risk perception

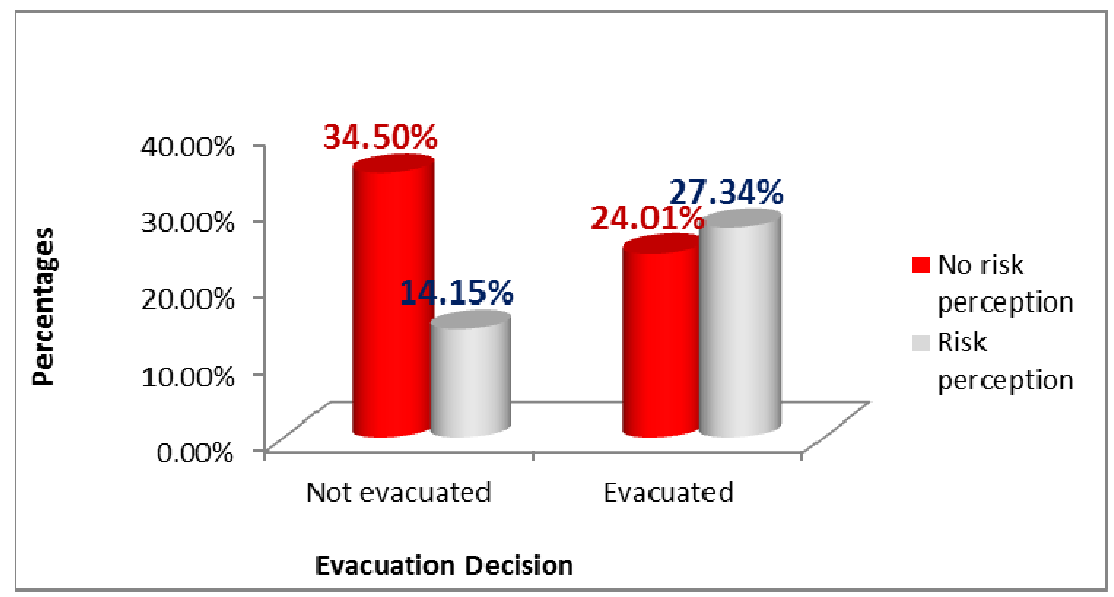


Figure 6-3 cleary depicts the joint distribution of evacuation decision and risk perception. It describes that the highest percentage of respondents $(34.50 \%)$ who did not evacuated had lower risk perception. Again the second highest percentage of respondents (27.34\%) who evacuated during hurricane Ivan, also had higher risk perception. A total of $61.84 \%(34.50 \%+27.34 \%)$ of respondents made their evacuation decision in coherence with their risk perception. This finding is similar to other studies where it was found that lower perception of risk leads to lower likelihood to evacuate (Matyas et. al, 2011).

Among the control variables, education positively influenced evacuation decision in model 1 by $5 \%$. Educated people always have better understanding about their risk and have better logistic resources. Therefore their knowledge and availability of resources helps them to take prompt evacuation decision. Income did not influence the respondents to evacuate during hurricane Ivan. Respondents receiving evacuation notice (notice_i) have influenced evacuation decision positively. Estimated coefficient is significant at $1 \%$ levels in all models in Panel B, Table 6.3. Respondents who received evacuation notice were about $20 \%$ more willing to evacuate (all models in table 6-3). Respondents who owned any kind of business evacuated less during the hurricane event (Model 1, tTable $6-2)$.

The model took into account one geospatial factor and that influenced evacuation decision significantly. Living inside evacuation zone significantly increase evacuation decision in households. Respondents who lived within evacuation zone had $20 \%$ to $23 \%$ higher risk perception. One limitation is that the evacuation zone is an indicator of areas with the potential to be impacted by storm waters during and after the flood occurring, and it may not exactly coincide with the extent and magnitude of flood damage. 


\subsubsection{Endogenous Risk Perception Result}

All four models (model 1, 2, 3 and 4) were estimated as bivariate probit with risk perception as endogenous dummy variable. Likelihood ratio (LR) estimates of the models are given in Table 6-2. LR test of two separate equation (at rho $=0$ ) gave very small $\mathrm{p}$ values, less than 0.05 . This leads to the rejection of the null hypothesis, $\mathrm{H}_{0}=$ no endogeneity in the separate equations. Therefore two equations cannot be estimated separately. Wald and likelihood ratio tests rejected the presence of endogeneity, and thus the two equations were estimated separately. To confirm the presence of endogeneity, Wald $\mathrm{chi}^{2}$ tests was also conducted on two separate equations (at rho=0). This gave similar result and fails to reject the presence of endogeneity. Therefore the two equations were finally estimated jointly by a bivariate probit model. The purpose of joint estimation of two separate functions is to remove endogeneity bias. For the purpose of removing bias, geospatial variables were added such as distance from shoreline, elevation from mean sea level (MSL), land use type, location on flood zone, and location in evacuation zone. This phenomenon implies the real risk or objective risk posed by hurricane threat. By including objective risk to the risk perception function, the endogeneity bias will be removed.

\subsection{Influence of Flood and Wind Risk Perception on Evacuation Decision}

Based on the preliminary analysis from the descriptive statistics on flood and wind risk perception, it is worth noticing that there is variability in evacuees' risk perception about flood and wind damage from a hurricane event. 
Figure 6-4: Total percentage of wind and flood risk perception

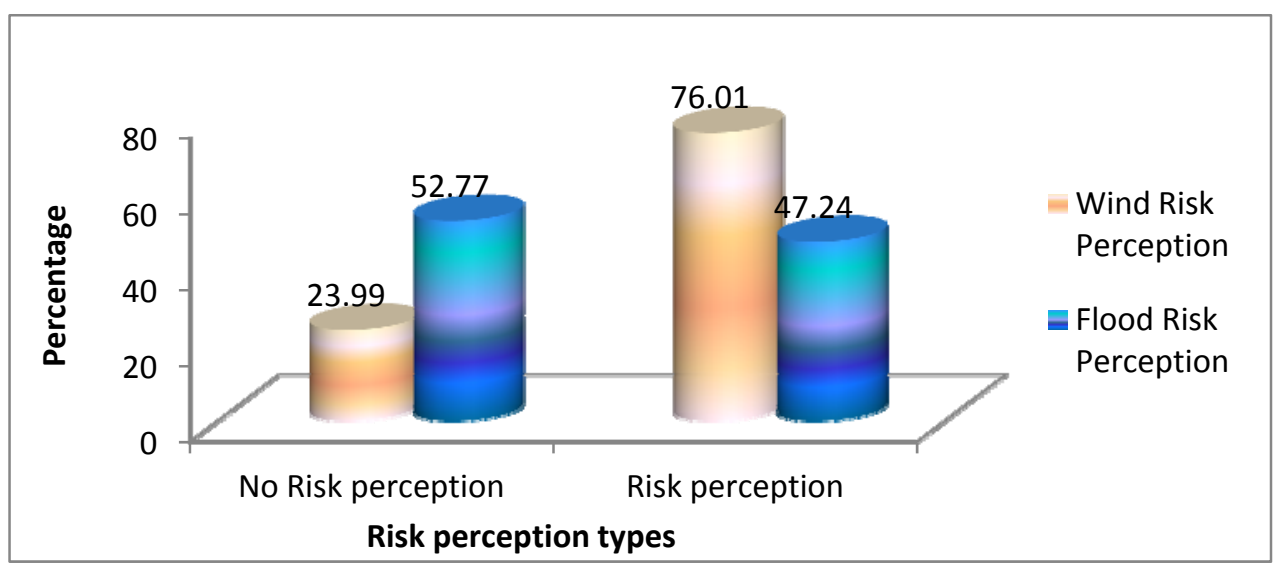

Figure 6-4 indicates that a significant percentage (76.01\%) of respondents perceive wind risk highly than the percentage of people perceive flood risk $(47.24 \%)$. While only $23.99 \%$ of respondents ignore the probability of no risk of wind damage risk at hurricane, there are $52.77 \%$ respondents who perceived no risk of flood damage at a hurricane. This priliminary analysis suggest that the perception of wind risk is higher than flood in the study area. Figure 6-5 depicts a very important message that people's risk perception in terms of flood and wind worked in a different way. While people's risk perception about flood is relatively low comparing to wind but it has a specific geographical pattern. Households in Louisiana exhibited higher flood risk perception. All these three states is the borderline of land and shoreline. Therefore the figure 6-5 also suggests that flood risk perception is higher close to shoreline and in Louisiana. This indicates that flood risk perception has strong relation with geographical pattern. On the contrary, people's wind risk perception is comparatively higher than flood risk perception but it showed no clear geographical pattern. These risk perception maps by risk perception types suggests conducting further advanced econometric analysis to gain deeper understanding about the variability of flood and wind risk perception and how this 
motivated respondents to evacuate. The following part of this section presents results of the statistical analyses conducted on evacuees' risk perception for flood and wind individually with locational influences.

Figure 6-5: Variability in risk perception for flood and wind

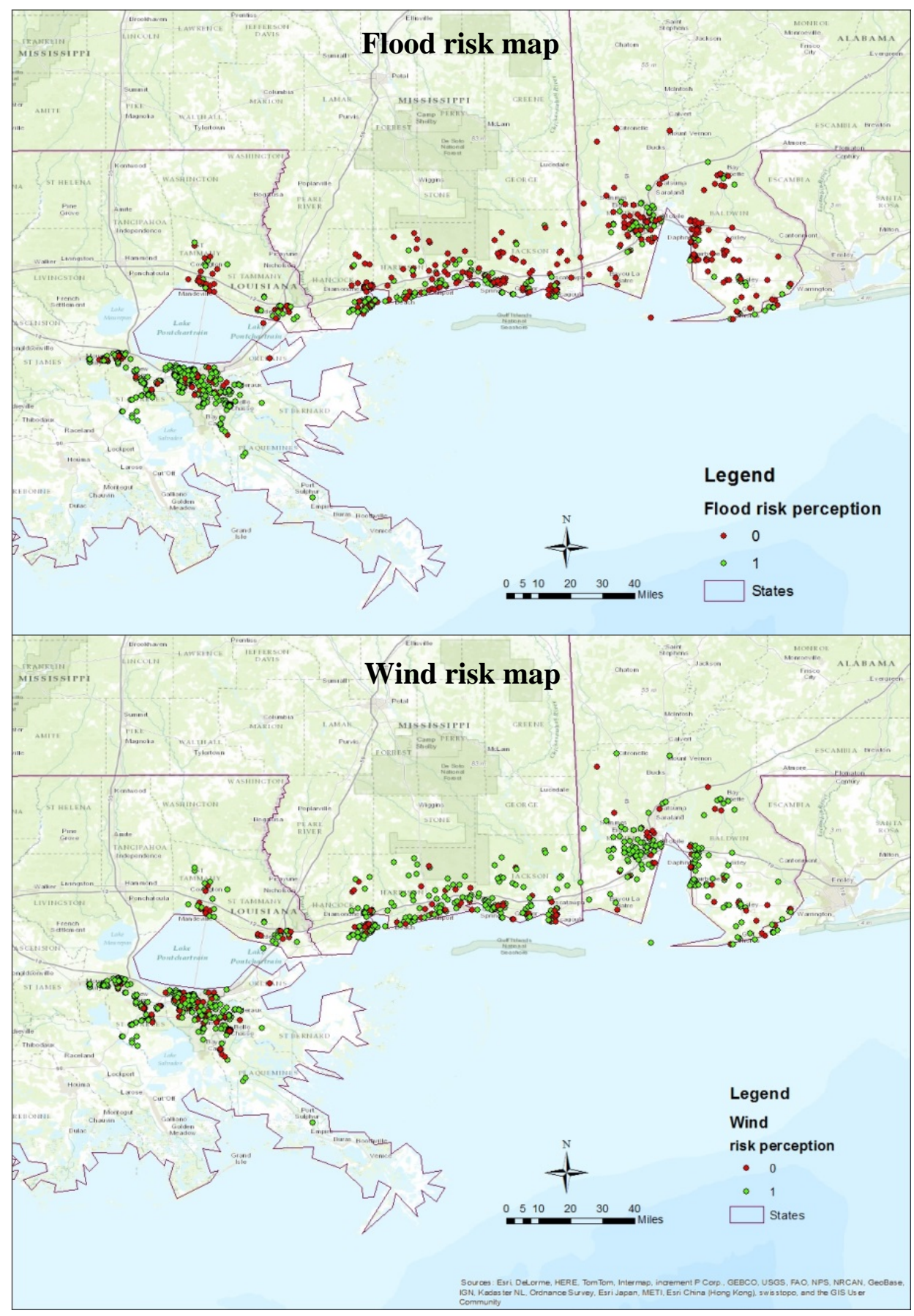




\subsection{Geospatial and Social Dimension of Household Flood Risk Perception}

Table 6-3 reports the bivariate probit estimates showing the determinants of flood risk perception and its influence on evacuation decision.

In the first component, Panel A shows the role of geo-spatial factors and other socio-economic and demographic variables that affected respondent's flood risk perception (flood) that their home may be affected by hurricane induced flooding. Panel A showed that all the seven geospatial factors except distance from route influence respondent's flood risk perception significantly. Respondents were able to realize their risk exposure towards storm surge flood if they were living inside evacuation zone or flood zone. Living inside evacuation zone (zone_i) increased respondents risk perception positively by $10 \%$. Similar finding was observed regarding living inside flood zone (floodzone) which impacted respondents in a similar way causing $8 \%$ higher risk perception than those who are not inside flood risk zone. Other geo-spatial factors such as elevation also influenced risk perception significantly and negatively. It indicates that lower elevation of household location increases respondent's risk perception regarding flood. Location in specific region significantly increased risk perception. In the study area, households inside Louisiana had higher risk perception for flood than Mississippi and Alabama. Louisiana had higher risk perception regarding flood by $17 \%$ to $19 \%$ than households in other regions. Location in different land use type also impacted respondents risk perception regarding flood risk. To understand the impact of land use, an interaction term was introduced in the risk perception decision between land use type and evacuation zone. Analysis suggests that though in the whole study area, people living in more open space tend to have higher risk perception, but maximum people evacuated 
more from evacuation zone. Therefore, focus was given on the group of people who lived inside evacuation zone. Inside evacuation zone, people had higher risk perception if they were living in densely developed regions. Respondents had higher risk perception if they were living in developed and dense areas. The reason could be better explained by another geospatial variable- distance from shoreline. Open space is composed of bare soil of grass which is good at water percolation and flood water do not stand longer in this type of region. Therefore people living in country side or agricultural land has less perception about risk of flood during a hurricane event. But respondents living in developed area are more concerned about storm surge water because water stands in such area after a natural flood event for long time. Therefore they are afraid of being trapped in clogged water which might eventually bring stress to their movement, communication and utility services also. To better understand the situation, Distance from shoreline was analyzed and it was found to affect the risk perception positively. The positive affect implies that inland respondents had higher risk perception about flood than coastal residents which is similar to previous concept as inland developed areas are much dense than coastal areas. Though coastal areas could be much hazardous for wind or surge water but for several hurricanes, it cause severe rainfall which subsequently cause inland flooding. Therefore, inland respondents were much concerned about rainfall flooding. In the next equation, two new meteorological hazards, rainfall and wind were added to elaborate on the high risk perception about inland flooding among respondents. Control variables such as education, duration of stay in household, income were included in the model but were found not significant in forming flood risk perception. In spite of no significance, the control variables were kept to control bias in model output. Among 
other socio-economic explanatory variables, ethnicity of household influenced respondent's risk perception (estimated coefficient is highly significant in all models, in table 6-4). In model 1 to 4 , if household belong to african-american black, they showed higher risk perception. Again black people are generally less solvent than whites and higher income white people live close to shoreline while majority black resides inland. Therefore ethnicity was found positively influenced flood risk perception. African American had around $20 \%$ higher risk perception than white people in the study area. It is therefore worth noticing that flood risk perception in the study area was better explained by geospatial phenomena rather than socio-economic and demographic factors. 
Table 6-3: Probability of flood risk perception on evacuation decision, Bivariate Probit specification and marginal effects

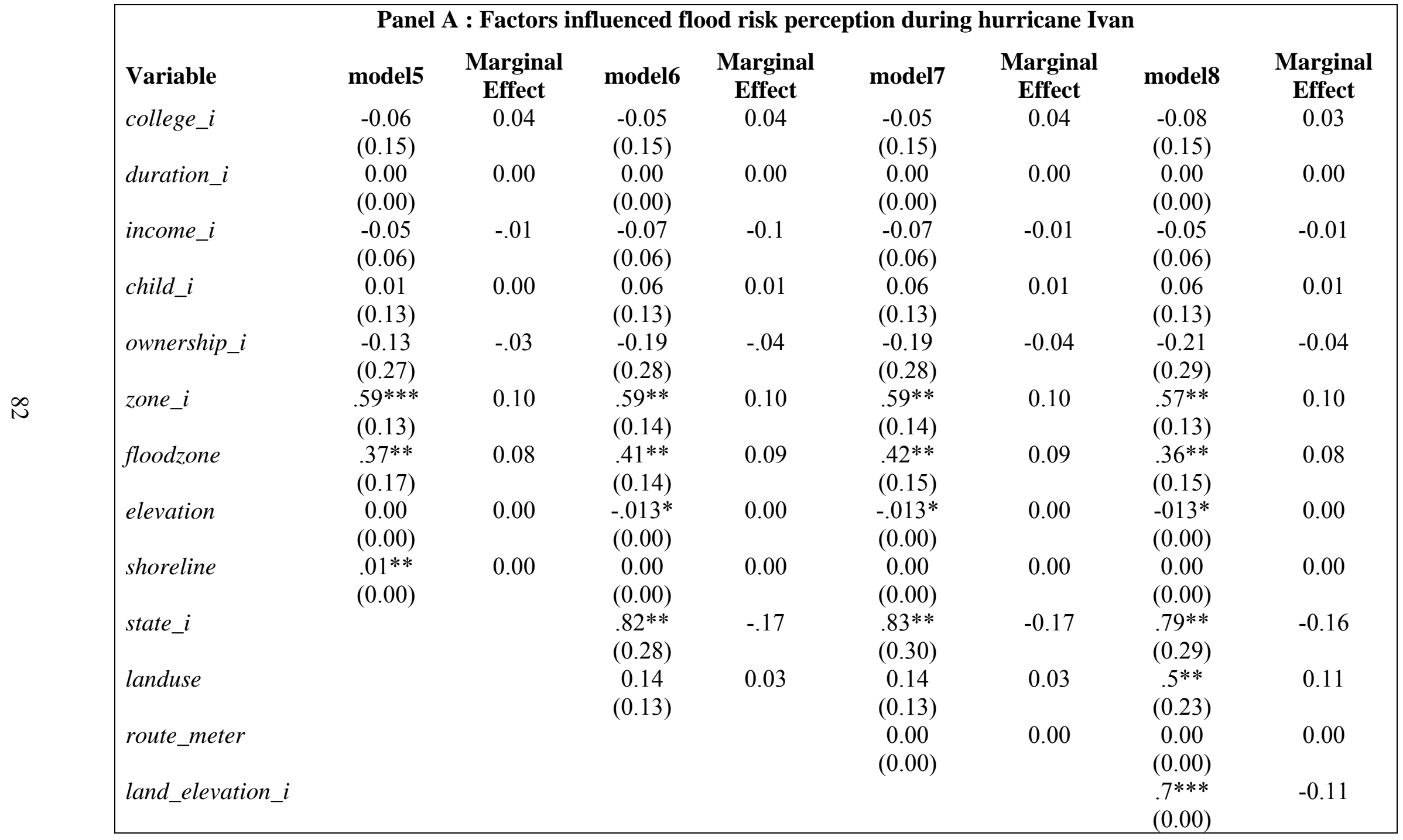




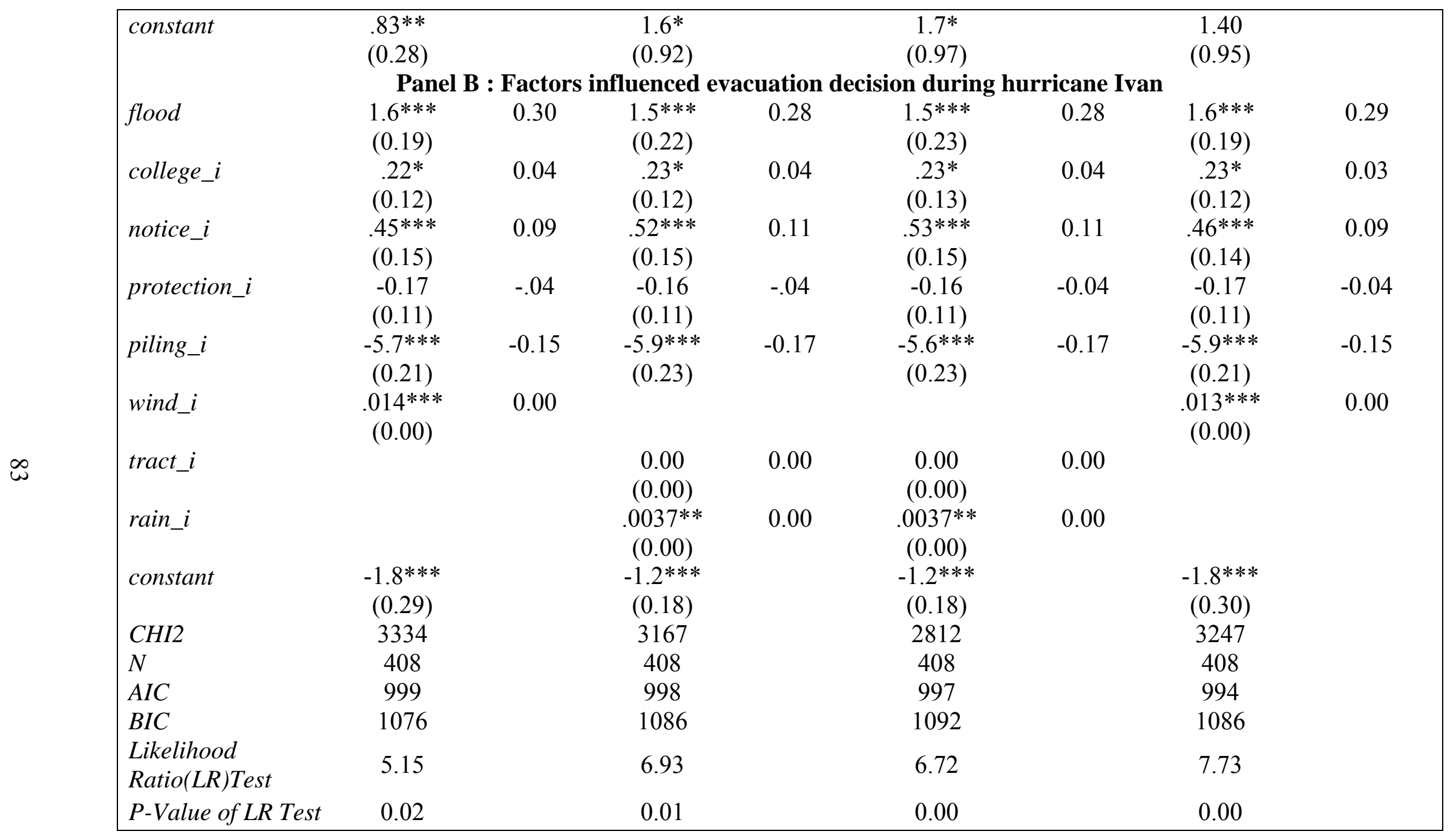

Notes: $* * *, * * *$ imply significance at $1 \%, 5 \%, 10 \%$ levels respectively; numbers inside parenthesis are robust standard errors. 
In the second component (Panel B in Table 6-3), the binary endogenous variable, flood risk perception (flood) enters into the evacuation decision equation as an explanatory variable, and was found statistically significant (in Models 5 to 8 ). The flood risk perception was found to influence the evacuation decision by $28 \%$ to $30 \%$ comparing to those who do not have the risk perception. The implication is that a higher flood risk perception led to positive evacuation. Upon receipt of evacuation notice, respondents were more likely to evacuate when they perceive high flood risk. Respondents who get evacuation notice evacuated $9 \%$ to $11 \%$ more than those who do not receive evacuation notice. The major focus here is the two meteorological hazard risks- rainfall and wind. Since rainfall and wind were found highly correlated with each other, rainfall was included in two models and in both model, rainfall was found to influence evacuation behavior positively. Wind was included in the other two models and was found to positively influence evacuation behavior. These findings implies that with increased rain and wind, people took instant decision to evacuate given they had higher risk perception about flood. The model considers time variant geospatial phenomena such as rainfall, wind in the evacuation decision function. The reason is evacuation decision is by nature very dynamic and it changes depending on situation. Inclusion of this kind of variable is quite new in disaster related researches.

\subsubsection{Endogenous Flood Risk Perception Result}

Similar to hurricane risk perception, the flood risk perception was suspected endogenous. Therefore all four models (model 5, 6,7 and 8) were estimated as bivariate probit with flood risk perception as endogenous dummy variable. Likelihood ratio (LR) and Wald test estimates of the models are given in Table 6-3. Both LR test and Wald 
test leads to the rejection of the null hypothesis $(\mathrm{H} 0=$ no endogeneity in the separate equations). Therefore the joint estimation of two equations by bivariate probit model was justified. Again, inclusion of objective risk factors in both flood risk perception function and evacuation decision function further strengthen the removal of endogeneity bias.

\subsection{Geospatial and Social Dimension of Household Wind Risk Perception}

Table 6-4 reports the bivariate probit estimates showing the determinants of wind risk perception (wind) that their home may be endangered by hurricane force wind gust before and during landfall and its influence on evacuation decision. Wind risk perception follows a different pattern than flood risk perception during hurricane Ivan. While flood risk perception positively influenced evacuation decision, wind risk perception negatively influenced evacuation decision during hurricane Ivan. This implies that respondents who had higher wind risk perception do not evacuated during hurricane Ivan. It is worth noticing that almost $50 \%$ of the respondents exhibited high wind risk perception which contributed to a negative mindset towards evacuation decision.

In the first component, Panel A shows the role of geo-spatial factors and other socio-economic and demo van. Among the six concerned geo-spatial variables, elevation and location inside evacuation zone contributed to higher wind risk perception. The risk perception is influenced by whether a respondent is living within the evacuation zone (zone_i). This factor is significant at $1 \%$ levels (Panel A, Table 6-4). Other geo-spatial factor- elevation, influence wind risk perception positively implying higher elevation increase wind risk perception that wind might damage their home and properties. 
Table 6-4: Probability of wind risk perception on evacuation decision during hurricane Ivan, Bivariate Probit specification and marginal effects

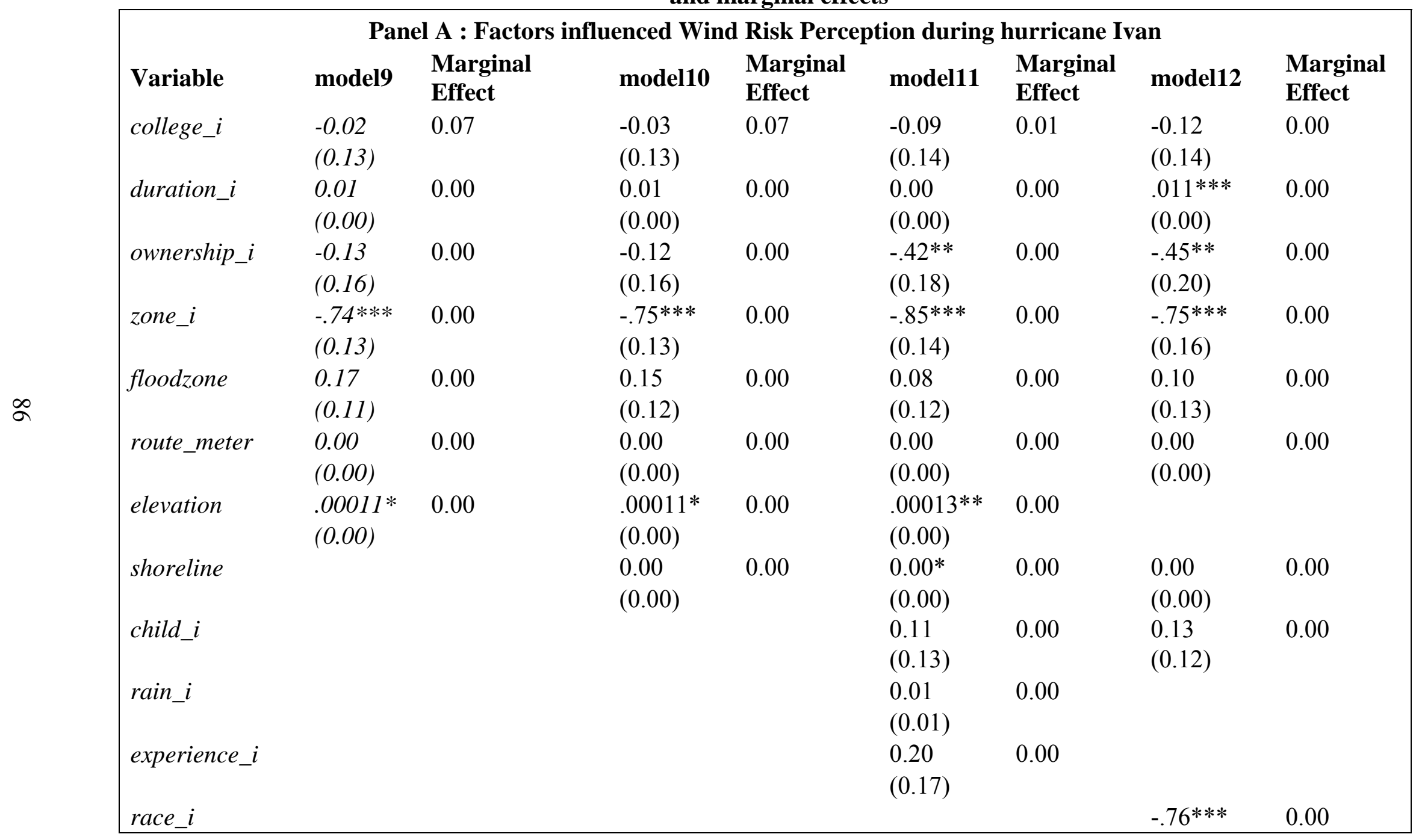




\begin{tabular}{|c|c|c|c|c|c|c|c|c|}
\hline $\begin{array}{l}\text { elderly_i } \\
\text { constant }\end{array}$ & $\begin{array}{l}1.3 * * * \\
(0.17)\end{array}$ & & $\begin{array}{l}1.3^{* * *} \\
(0.18)\end{array}$ & & $\begin{array}{l}0.22 \\
(0.67)\end{array}$ & & $\begin{array}{l}(0.22) \\
-.39^{* * *} \\
(0.15) \\
1.3 * * * \\
(0.26)\end{array}$ & 0.00 \\
\hline \multicolumn{9}{|c|}{ Panel B : Factors influenced evacuation decision during hurricane Ivan } \\
\hline $\begin{array}{l}\text { Evacuation_i } \\
\text { wind }\end{array}$ & $\begin{array}{l}-1.9^{* * *} \\
(0.11)\end{array}$ & -0.48 & $\begin{array}{l}-1.9^{* * * *} \\
(0.11)\end{array}$ & -0.50 & $\begin{array}{l}-1.9^{* * * *} \\
(0.12)\end{array}$ & -0.52 & $\begin{array}{l}-1.9^{* * * *} \\
(0.13)\end{array}$ & -0.01 \\
\hline income_i & $\begin{array}{l}0.04 \\
(0.04)\end{array}$ & 0.01 & $\begin{array}{l}0.03 \\
(0.04)\end{array}$ & 0.01 & $\begin{array}{l}.091^{* *} \\
(0.05)\end{array}$ & 0.04 & $\begin{array}{l}.14^{* * *} \\
(0.05)\end{array}$ & 0.00 \\
\hline college_i & $\begin{array}{l}0.17 \\
(0.12)\end{array}$ & 0.07 & $\begin{array}{l}0.17 \\
(0.12)\end{array}$ & 0.07 & $\begin{array}{l}0.03 \\
(0.13)\end{array}$ & 0.01 & $\begin{array}{l}-0.09 \\
(0.14)\end{array}$ & 0.00 \\
\hline notice_i & $\begin{array}{l}.4 * * * \\
(0.10)\end{array}$ & 0.16 & $\begin{array}{l}.41 * * * \\
(0.10)\end{array}$ & 0.16 & $\begin{array}{l}.52^{* * * *} \\
(0.11)\end{array}$ & 0.20 & $\begin{array}{l}.53^{* * * *} \\
(0.11)\end{array}$ & 0.00 \\
\hline protection_i & $\begin{array}{l}-.21 * * \\
(0.09)\end{array}$ & -0.08 & $\begin{array}{l}-.21^{* *} \\
(0.09)\end{array}$ & -0.08 & $\begin{array}{l}-0.10 \\
(0.10)\end{array}$ & -0.04 & $\begin{array}{l}-.19^{*} \\
(0.11)\end{array}$ & 0.00 \\
\hline piling_i $i$ & $\begin{array}{l}-6.8^{* * *} \\
(0.12)\end{array}$ & -0.55 & $\begin{array}{l}-8.1 * * * \\
(0.12)\end{array}$ & -0.55 & $\begin{array}{l}-8.4 * * * \\
(0.12)\end{array}$ & -0.54 & $\begin{array}{l}-7.4 * * * \\
(0.14)\end{array}$ & 0.00 \\
\hline tract_i & & & $\begin{array}{l}0.00 \\
(0.00)\end{array}$ & 0.00 & & & & \\
\hline work_i & & & & & $\begin{array}{l}-0.01 \\
(0.10)\end{array}$ & $\begin{array}{l}-0.01 \\
(0.10)\end{array}$ & & \\
\hline wind_i & & & & & $\begin{array}{l}0.00 \\
(0.00)\end{array}$ & $\begin{array}{l}0.00 \\
(0.00)\end{array}$ & & \\
\hline traffic_i & & & & & & & $\begin{array}{l}-1.6^{* * * *} \\
(0.40)\end{array}$ & 0.00 \\
\hline logistic_i & & & & & & & $-157 * * *$ & -0.73 \\
\hline
\end{tabular}




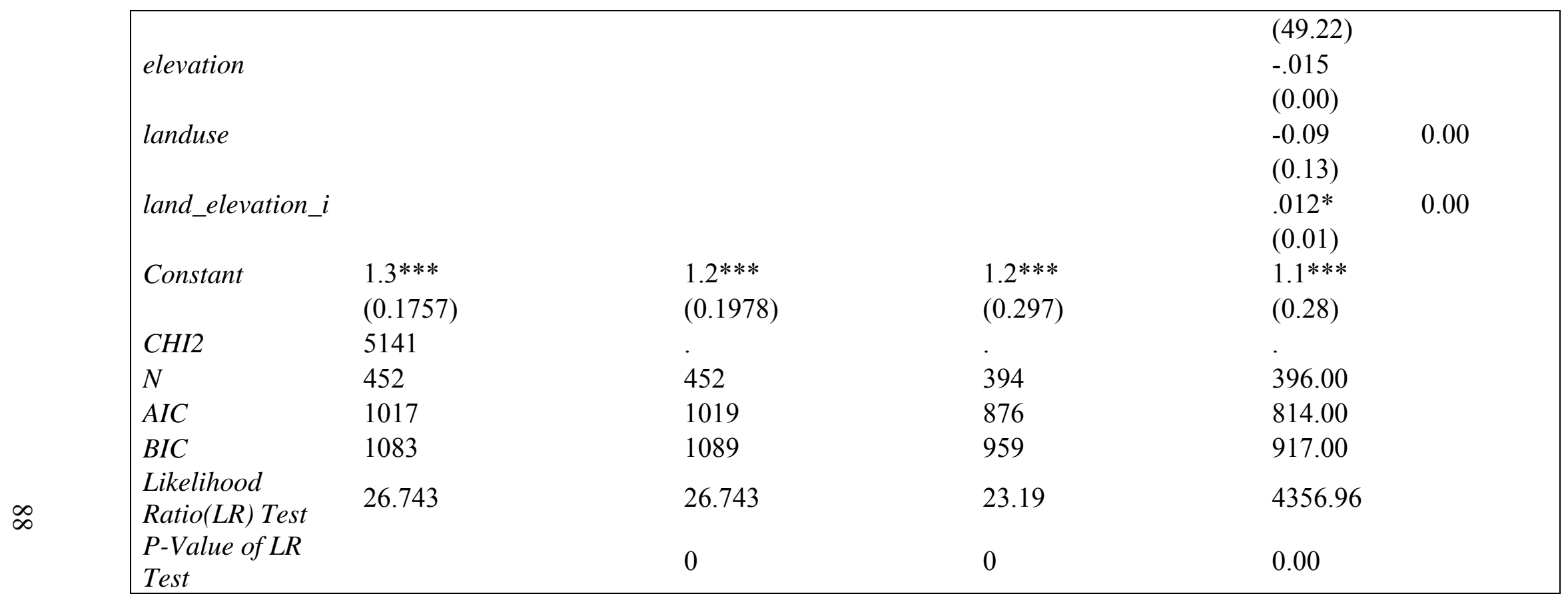

Notes: $* * *, * *, *$ imply significance at $1 \%, 5 \%, 10 \%$ levels respectively; numbers inside parenthesis are robust standard errors. 
Therefore that may be reason why tract was not found significant. We investigated other socio-economic and demographic factors. It was observed that instead of geospatial variables, social variables influenced people's risk perception for wind. Among the control variables, race and presence of elderly people in home influence towards low wind risk perception. This implies white people have less wind risk perception than African-American black people. Among other socio-economic variables, duration of living in present home positively influenced wind risk perception in a similar way to overall risk perception. Ownership negatively influenced evacuation decision. This implies respondents who were not owner had higher wind risk perception.

In the second component, (Panel B, table 6.5), a higher risk perception about wind that one's home may be endangered by hurricane wind leads not to evacuate (Models 9 to 12 ). Model 11 and 12 indicates that high rainfall (rain_i) and wind (wind_i) during hurricane Ivan influenced respondent's not to evacuate but the effect was not significant. Elevation played significant role in the evacuation decision exhibiting high evacuation of respondents from low lying areas. To understand the influence of land use on evacuation decision, an interaction term was introduced. It was found that respondents, who lived in more open areas though living in high elevated areas, evacuated more. Among control variables, income influenced evacuation decision. Higher income group evacuated more than lower income group. Respondents were found to evacuate around $20 \%$ more if they got evacuation notice (notice_i). Among other explanatory variables, availability of window protection influenced evacuation decision. Respondents evacuated more if they did not have window protection. Similar observation was found for households those were not built on elevated structure or that have no piling (piling_i). Traffic concern 
(traffic_i), logistics concern (logistics_i) significantly influenced respondents evacuation decision (Models 9 to 12 in Panel B, Table 6-4). This implies that respondents who did not have concern for traffic and logistic issues, evacuated more than others.

\subsubsection{Endogenous Wind Risk Perception Result}

Likelihood ratio (LR) and wald test statistics rejects the null hypothesis of no endogeneity. Therefore the joint estimation of two equations by bivariate probit model was justified. Objective risk factors inclusion removed further endogeneity bias.

In terms of overall fit, all models reported in Table 6-2, Table 6-3 and Table 6-4 are highly significant based on Wald Test Statistics of the joint models. This implies strong relevance of the variables used in the analysis. AIC value went lower from model 1 to 4 which indicates models were improved by adding more variables. Also BIC values indicated that later models were better than earlier models.

\subsection{Hurricane Katrina: Evidence of Near -Miss Phenomena}

One year after hurricane Ivan, hurricane Katrina made landfall in Louisiana. Hurricane Katrina impacted almost similar areas as did during hurricane Ivan. Analysis was conducted with the second part of the longitudinal household survey which was consisted of 812 common respondents from hurricane Ivan survey.

\subsubsection{Modeling Hurricane Katrina}

We report the descriptive statistics of the variables in table 6-6. Preliminary analysis based on difference in proportions tests (without controlling for any other factors) shows that while $51 \%$ household evacuated during hurricane Ivan, $62 \%$ household evacuated in the following year during hurricane Katrina. To examine more about the relationship between binary response variables, evacuation during Katrina 
(evacuation_k) and binary explanatory variables, evacuation during Ivan (evacuation_i), a $2 \times 2$ contingency table (table 6-8) was developed. Odds ratios were estimated and pvalue was determined (corresponding to chi-square statistics). Out of the 812 respondents, around $70 \%$ made the same decision in both cases (336 evacuated and 227 stayed). It suggests that citizens are most likely to make the same evacuation decisions in subsequent hurricanes as they did for earlier hurricanes. It is to be noted that 77 evacuated during Ivan but did not evacuated during hurricane Katrina. Again a comparatively higher portion of respondents (170) remained in home during Ivan but they evacuated during Katrina. Table 6-5 found an odds ratio of 5.827, which was highly significant $(\mathrm{p}<.0001)$. It indicates that the odds of a person evacuating during Katrina if he or she had evacuated during Ivan were nearly six times more those who stayed in home during Ivan.

Table 6-5: Evacuation decision during hurricane Ivan and hurricane Katrina

\begin{tabular}{|llcc|}
\hline Evacuation During Ivan & \multicolumn{3}{l|}{ Evacuation During Katrina } \\
& Stayed & Evacuated & Total \\
Stayed & 227 & 170 & 397 \\
Evacuated & 77 & 336 & 413 \\
Total & 304 & 506 & 810 \\
Odds Ratio & 5.83 & & \\
P Value & 0 & & \\
\hline
\end{tabular}

This gave an insight that people positively updated their evacuation behavior at Katrina. In the light of this understanding, we firstly assessed the factors which influenced people's evacuation decision during hurricane Katrina. Next, we analyzed the influence of hurricane Ivan evacuation decision on the following hurricane Katrina evacuation decision. The positive influence of earlier hurricane suggests no evidence for cry-wolf phenomena at the subsequent hurricane Katrina. 
Table 6-6: Descriptive statistics of the variables during hurricane Katrina

\begin{tabular}{|c|c|c|c|c|}
\hline Variable & Observation & Mean & St. Dev & Value Label \\
\hline Evacuation_k & 810 & 0.625 & 0.485 & 0 not evacuated ; 1 evacuated \\
\hline evacuation_i & 811 & 0.510 & 0.500 & 0 not evacuated ; 1 evacuated \\
\hline college_k & 385 & 0.481 & 0.500 & $\begin{array}{l}0 \text { not college graduate; } 1 \\
\text { college graduate }\end{array}$ \\
\hline income_k & 541 & 4.484 & 1.438 & $\begin{array}{l}1 \text { under } \$ 10,000 ; 2 \$ 10,000- \\
\$ 20,000 ; 3 \$ 20,000- \\
\$ 30,000 ; 4 \$ 30,000-\$ 50,000 \\
5 \$ 50,000-\$ 80,000 ; 6 \text { over } \\
\$ 80,000\end{array}$ \\
\hline size_i & 799 & 0.267 & 0.442 & $\begin{array}{l}1 \text { "large family"; } 0 \text { "small } \\
\text { family less than 4" }\end{array}$ \\
\hline size_k & 698 & 0.241 & 0.428 & $\begin{array}{l}1 \text { "large family"; } 0 \text { "small } \\
\text { family less than 4" }\end{array}$ \\
\hline house_k & 696 & 2.293 & 0.858 & $\begin{array}{l}0 \text { " no concern for house" } . . . . \\
3 \text { " most concerned" }\end{array}$ \\
\hline marital_k & 696 & 0.730 & 0.444 & $\begin{array}{l}1 \text { "married" } 0 \\
\text { "unmarried/widow/single" }\end{array}$ \\
\hline race_k & 688 & 0.084 & 0.278 & 0 "black" 1 "not black" \\
\hline damage_i & 808 & 0.165 & 0.371 & 0 "no damage" 1 "damage" \\
\hline traffic_k & 811 & 0.027 & 0.163 & $\begin{array}{l}0 \text { " no concern for traffic" } 1 \text { " } \\
\text { concern" }\end{array}$ \\
\hline elderly_k & 811 & 0.046 & 0.209 & 0 "no elderly" , 1 "elderly" \\
\hline watch_k & 811 & 0.538 & 0.499 & $\begin{array}{l}\text { 0"did not watch hurricane" } 1 \\
\text { "watch hurricane" }\end{array}$ \\
\hline ownership_k & 697 & 0.943 & 0.233 & $\begin{array}{l}0 \text { "rent or other" } 1 \text { "own mobile } \\
\text { home/own permanent home", } \\
\text { replace }\end{array}$ \\
\hline pet_i & 806 & 0.520 & 0.489 & 0 "no pet" 1 "have pet" \\
\hline pet_k & 694 & 1.702 & 1.185 & $\begin{array}{l}0 \text { "No concern for pet"... } 3 \\
\text { "most concerned for pet" }\end{array}$ \\
\hline medical_k & 697 & 0.782 & 0.413 & $\begin{array}{l}0 \text { "no medical issue" } 1 \\
\text { "medical issue" }\end{array}$ \\
\hline work_i & 808 & 0.306 & 0.461 & $\begin{array}{l}0 \text { "no job requirement' } 1 \text { "job } \\
\text { requirement" }\end{array}$ \\
\hline forecast_i & 811 & 0.186 & 0.390 & 0 "no forecast" 1 "forecast" \\
\hline forecast_k & 695 & 2.138 & 1.120 & $\begin{array}{l}0 \text { "no concern for forecast" } \\
\ldots \ldots \ldots \ldots 3 \text { "most concerned } \\
\text { about forecast" }\end{array}$ \\
\hline protection_i & 811 & 0.567 & 0.496 & $\begin{array}{l}0 \text { "no protection measure in } \\
\text { home" } 1 \text { "protection measure } \\
\text { in home" }\end{array}$ \\
\hline protection_k & 810 & 0.580 & 0.494 & 0 "no protection measure in \\
\hline
\end{tabular}




\begin{tabular}{|c|c|c|c|c|}
\hline & & & & $\begin{array}{l}\text { home" } 1 \text { "protection measure } \\
\text { in home" }\end{array}$ \\
\hline experience_i & 807 & 0.854 & 0.354 & $\begin{array}{l}1 \text { " Experience" } 0 \text { "No } \\
\text { experience" }\end{array}$ \\
\hline notice_i & 797 & 0.540 & 0.499 & $\begin{array}{l}1 \text { "got evacuation notice" } 0 \\
\text { "did not get " }\end{array}$ \\
\hline notice_k & 797 & 0.740 & 0.439 & $\begin{array}{l}1 \text { "got evacuation notice" } 0 \\
\text { "did not get " }\end{array}$ \\
\hline zone_i & 616 & 0.752 & 0.432 & 0 not in zone ; 1 in zone \\
\hline zone_k & 634 & 0.713 & 0.453 & 0 not in zone; 1 in zone \\
\hline shoreline & 811 & $\begin{array}{c}134008 . \\
300\end{array}$ & $\begin{array}{c}84624.21 \\
0\end{array}$ & Continuous variable \\
\hline rain_k & 811 & 60.752 & 17.842 & Rain exposure on household \\
\hline tract_k & 811 & $\begin{array}{c}81642.9 \\
80\end{array}$ & $\begin{array}{c}49573.88 \\
0\end{array}$ & $\begin{array}{l}\text { Distance of household from } \\
\text { hurricane tract }\end{array}$ \\
\hline wind_k & 811 & 76.826 & 13.371 & Wind exposure on household \\
\hline elevation & 811 & -13.501 & 497.078 & Elevation of household \\
\hline landuse & 811 & 0.254 & 0.436 & $\begin{array}{l}\text { Land use type in household } \\
\text { location }\end{array}$ \\
\hline land*elevation & 811 & 2.871 & 9.566 & Interaction variable \\
\hline land*zone_i & 616 & 0.195 & 0.396 & Interaction variable \\
\hline
\end{tabular}

\subsubsection{Socio-Economic Factors Influencing Evacuation Decision}

Evacuation responses differ by various sample characteristics in our model. We report the locational and social factors determining evacuation behavior from a set of models in table 6.8. We include evacuation during hurricane Ivan as an independent variable in our probit model. Evacuation behavior itself is again an endogenous variable (Nelson et. al, 1989). Therefore to account for the biasness in the result, we developed another bivariate probit model which includes the binary endogenous variable, "evacuation behavior during Ivan" both as a dependent and an independent variable in the model.

We found that home ownership positively influenced evacuation decision at Katrina and was significant at 1 percent level in all the four models (Table 6.8, model 13 
to model 16). This implies that households who were owners were more willing to evacuate than renters. It is worth noticing that those homeowners in Florida and some other states showed lower evacuation rate than renters (Solis, Thomas and Letson, 2009). One possible reason could be the new building code which made the home much safer in Florida. Therefore owners feel less risk living in home during the disaster time. But in the study area (Louisiana, Mississippi and Alabama), there were no such building codes for the households. Again homeowners were wealthier than renters. In our study area 55\% homeowners have yearly income within range 50000 to 80000 . Since they had the ability to repair their households, they are more willing to evacuate to reduce probability of personal injury. Among other explanatory variables, marital status showed negative and significant (5\% significance level) influence on evacuation behavior. This indicates that single or unmarried were more willing to evacuate during hurricane Katrina. One possible reason could be higher risk perception when a person lives alone instead of living in a family. Also single person has less logical constrains. But when a family is evacuating, they need to consider needs for every single members including age, sickness or any other emergency needs. All these constraints have negative influence on evacuation decision. In similarity with previous studies, we found that pet ownership had positive and significant influence on evacuation decision during hurricane Katrina. Income, educations were kept in the models as control variables. The household survey had limited response about education during Katrina which significantly reduced total model response numbers. Similar finding was observed regarding evacuation notice were it was found that upon receipt of evacuation notice, household tends to evacuate more than those who did not get evacuation notice. Households who were less concerned about 
traffic were more willing to evacuate during that time. Another interesting thing in this context is to observe is the timing of evacuation.

Figure 6-6: Comparison of evacuation timing during hurricane Ivan and hurricane Katrina

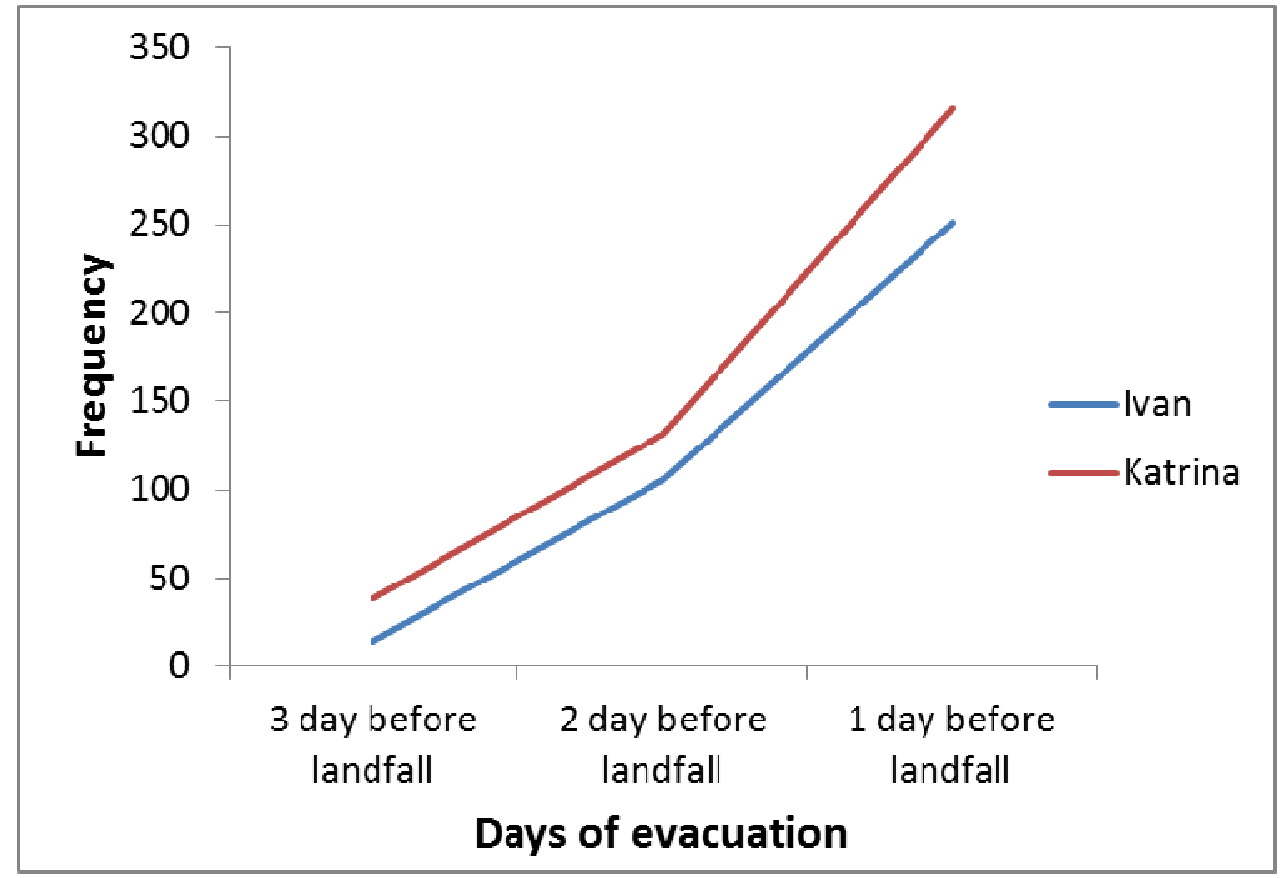


Table 6-7: Determinants of evacuation decision during hurricane Katrina

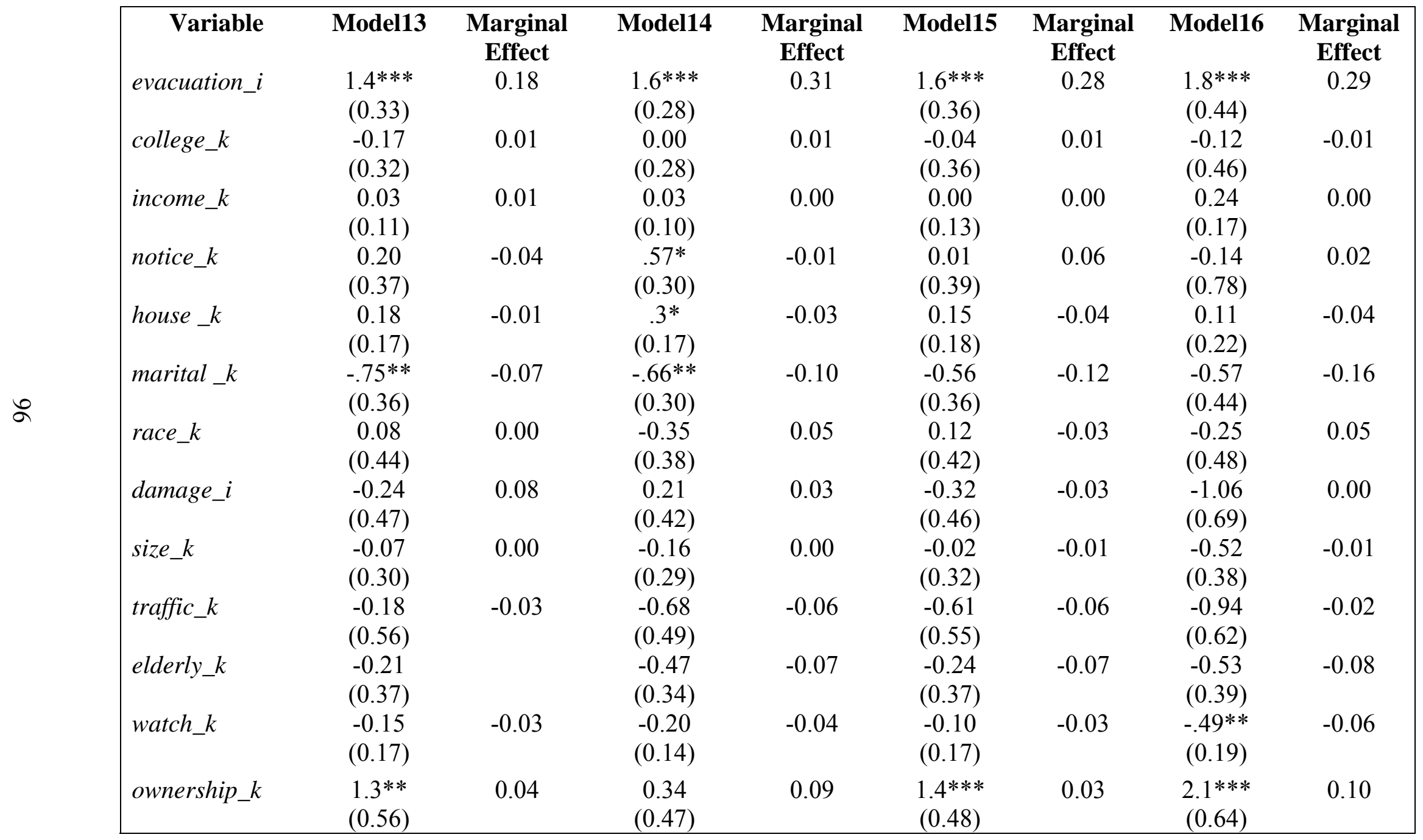




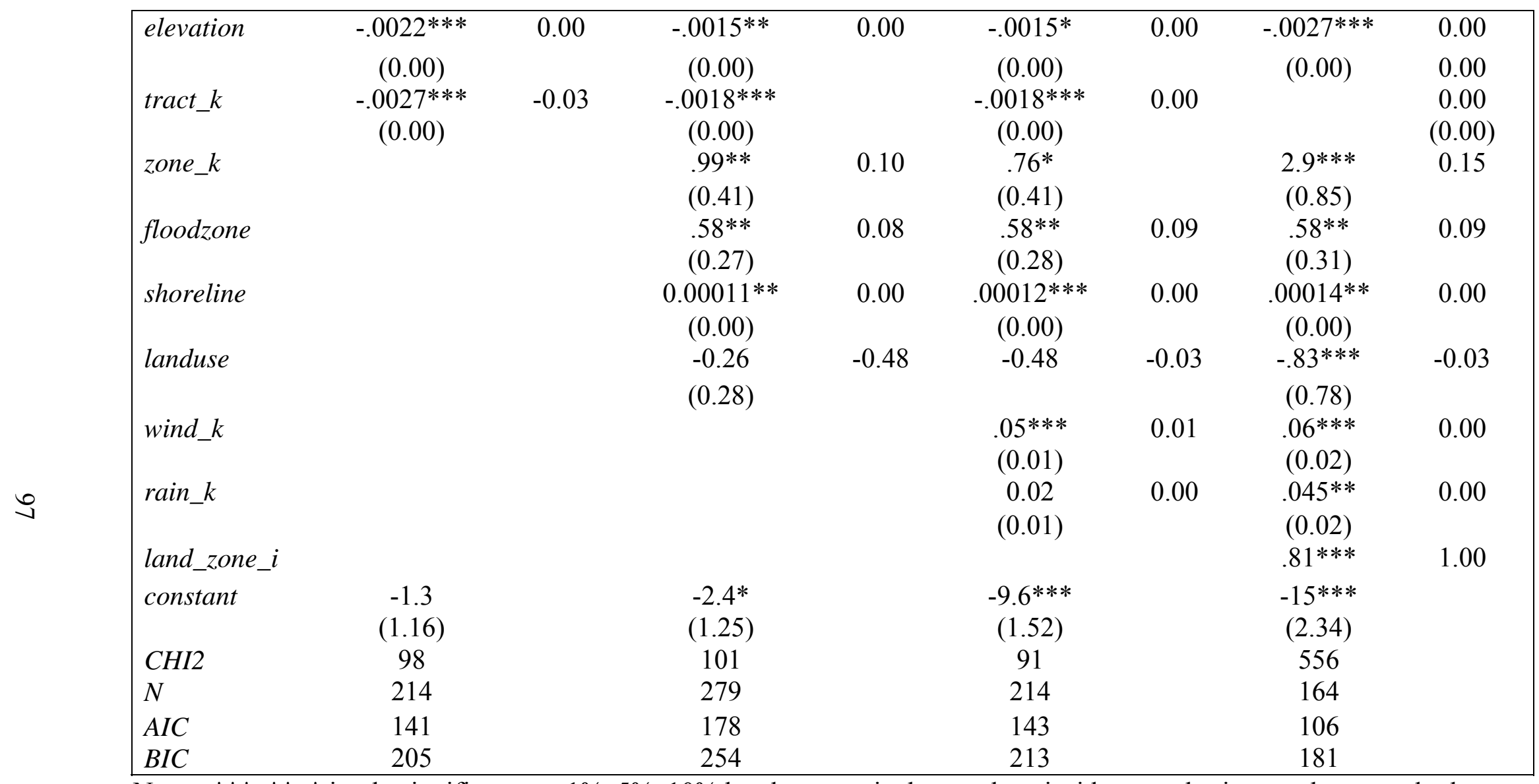

Notes: ***,**,* imply significance at $1 \%, 5 \%, 10 \%$ levels respectively; numbers inside parenthesis are robust standard errors. 
Figure 6-6 suggests that during both of the hurricanes maximum people evacuated 1 day before landfall. Though the number of evacuees increased at Katrina from Ivan, but the evacuation timing followed the similar pattern. During hurricane Ivan, the mandatory evacuation order came out Tuesday which was two days before landfall. Hurricane Ivan made landfall to the west of Gulf Shores, Alabama around 3:00 in the morning on Thursday, September $16^{\text {th }}$. Therefore, the huge percentage of people started evacuation some hours later the mandatory evacuation order on $15^{\text {th }}$ (Gillette, 2004). Again during hurricane Katrina, many said that mandatory evacuation orders came too late (Russell, 2005). Mayor Nagin ordered the mandatory evacuation order on Sunday which was one day before landfall. On such a short notice, it was not easy to evacuate for elderly or sick or disabled person or to find a shelter. President Bush issued a Presidential emergency declaration during hurricane Katrina. This type of declaration is extremely rare. Since 1990, only one such incident, Hurricane Floyd in 1999, resulted in declarations before landfall (Menzel, D. C. (2006). In spite of late evacuation order, the evacuation order type might influence those huge populations to evacuate the day before landfall.

Table 6-8: Contingency Tables: Timing of Evacuation during Ivan or Timing of Evacuation during Katrina

\begin{tabular}{|lcccc|}
\hline $\begin{array}{l}\text { Day of evacuation } \\
\text { during hurricane } \\
\text { Ivan }\end{array}$ & $\begin{array}{c}\text { Day of evacuation during hurricane Katrina } \\
\text { 1 day before } \\
\text { landfall }\end{array}$ & $\begin{array}{c}2 \text { day before } \\
\text { landfall }\end{array}$ & $\begin{array}{c}3 \text { day before } \\
\text { landfall }\end{array}$ & Total \\
\hline $\begin{array}{l}\text { 1 day before } \\
\text { landfall } \\
2 \text { day before }\end{array}$ & 5 & 5 & 5 & 15 \\
$\begin{array}{l}\text { landfall } \\
3 \text { day before }\end{array}$ & 10 & 26 & 42 & 78 \\
$\begin{array}{l}\text { landfall } \\
\text { P value } \\
\text { Odds-ratio }\end{array}$ & 11 & 58 & 130 & 199 \\
\hline
\end{tabular}


Table 6-8 indicates that the timing of both of the hurricane were similar. Though hurricane Katrina was stronger hurricane than hurricane Ivan, again maximum people evacuated just 1 day before landfall. The odds ratio suggests that almost all the people who evacuated in 1, 2 or 3 days before landfall had almost similar probability (1.87 times) of taking the similar decision about the timing to evacuate during hurricane Katrina.

Factors such as education, income, ethnic group did not influence much of the evacuation behavior during Katrina. Evan though, we kept all these control variables to control biasness of the model.

\subsubsection{Geospatial Factors Influencing Evacuation Decision}

Evacuation decision is dynamic in the sense that people change evacuation decision based on changing environmental condition. Therefore, we include some novel geospatial and time variant parameters in the probit model that might influence evacuation behavior. In addition to geospatial factors such as distance from shoreline, location within evacuation zone and elevation of property, we included wind exposure, precipitation exposure. Wind and rainfall is directly related with damage from hurricane such as wind damage or flooding. Again some of the geospatial phenomenon directly related with the most probable areas towards hurricane impacts such as evacuation zone, shoreline proximity and elevation of the properties. One thing to be noted is that, often these geospatial phenomena are highly correlated. Following is the correlation matrix between geospatial variables. 
Table 6-9: Correlation matrix between geospatial variables

\begin{tabular}{|lccllllll|}
\hline & Elevation & Wind & Shoreline & Rain & Landuse & Tract & Route & Floodzone \\
Elevation & 1.00 & & & & & & & \\
Wind & 0.06 & 1.00 & & & & & & \\
Shoreline & 0.06 & $\mathbf{0 . 2 1}$ & 1.00 & & & & & \\
Rain & 0.02 & $\mathbf{0 . 4 2}$ & $\mathbf{0 . 6 1}$ & 1.00 & & & & \\
Landuse & 0.03 & 0.02 & -0.02 & -0.04 & 1.00 & & & \\
Tract & -0.09 & $\mathbf{- 0 . 7 9}$ & $\mathbf{- 0 . 7 3}$ & $\mathbf{- 0 . 7 2}$ & 0.01 & 1.00 & & \\
Route & -0.01 & $\mathbf{0 . 2 1}$ & -0.12 & -0.07 & -0.04 & -0.05 & 1.00 & \\
Floodzone & 0.03 & $\mathbf{0 . 2 9}$ & 0.16 & 0.17 & -0.01 & $\mathbf{- 0 . 2 6}$ & $\mathbf{0 . 2 0}$ & 1.00 \\
\hline
\end{tabular}

Table 6-9 indicates that there was strong correlation between wind exposure and tract distance during hurricane Ivan. Therefore we did not include these two variables together in any of the probit models. Also there was strong correlation between tract distance and shoreline. Therefore we did not include these two variables together in any of the probit models either.

Elevation of the households (elevation) were found significant (1\% level) and the coefficient was negative in all the four (4) models. This implies that low elevated households evacuated more than high elevated households. We analyzed influence of wind exposure at Katrina (wind_k) on evacuation behavior in two models (model 15 and model 16) and the variable was found significant and positive. This indicates that people could connect their risk exposure towards hurricane threat based on weather condition and made their evacuation decision accordingly. Though during Ivan, we did not see much influence of hurricane tract, during Katrina, respondent's evacuation decision depends negatively on hurricane tract which implies that respondents evacuated more from closer distance from hurricane tract. Shoreline had a very little positive influence 
which implied that inland respondents were still more willing to evacuate during Katrina. Respondents living inside flood zone, evacuated more than those who were living outside flood zone. Living in evacuation zone (zone_k) was found to influence evacuation behavior positively and significant (1\% level) in all the four models (table 6-7: model 13, 14, 15 and 16). Households living inside evacuation zone were more likely to evacuate than those living outside evacuation zone.

\subsection{Near-Miss Evidence from Hurricane Katrina}

We recorded the influence of evacuation during Ivan on the evacuation at hurricane Katrina in table 6-11. Table 6-1 1 reports the bivariate probit estimates for the determinant of evacuation during Katrina. We included evacuation decision during the earlier hurricane Ivan (evacuation_i) in the probit model as another dependent variable. By including this dependent variable as a joint function with subsequent evacuation decision, we are removing the influence of endogeneity of the model.

In the first component (Panel A, table 6-11), variables that affect the respondent's evacuation decision during Ivan (evacuation_i) were recorded. In the second component, (Panel B, table 6-8), variables that affect the respondent's evacuation decision during Katrina (evacuation_k) were recorded. Also in the second component (Panel B in Table 6.8), the binary endogenous variable, evacuation during Ivan (evacuation_i) enters into the models second equation as an explanatory variable and was found statistically significant with a positive co-efficient. This suggests that people positively update their evacuation behavior from Ivan to Katrina. Therefore, this incident fails to reject the hypothesis of no cry-wolf phenomenon during hurricane Katrina. 
Table 6-11 again gives a platform to compare the influence of some common and uncommon variables that influenced evacuation behavior during both evacuation processes. Evacuation notice influenced evacuation decision positively at both hurricanes. Also education was found significantly influencing evacuation decision at both hurricanes. This indicates that educated household evacuated more than rest of the households during both hurricanes. Window protection played important role during Ivan, implying household who had window protection evacuated less than those household who did not have window protection but it did not influence the evacuation decision at hurricane Katrina. Household size did not impact evacuation decision during Ivan but it did using the following event. It may be due to the reason that evacuation preparation is different depending on size of home. Also people's evacuation decision complies with forecast in the following event significantly.

Both panel A and panel B, suggests that locational variables played significant role in evacuation decision. During hurricane Ivan, inland respondents were more willing to evacuate than coastline respondents. Elevation negatively influenced evacuation decision in both of these hurricanes. Living inside evacuation zone or flood zone played positive and significant role in households' evacuation which implies that households lining inside evacuation zone or flood zone were more likely to evacuate than the rest of the households.

This bivariate probit model suggests that a lot of similarity was observed in the evacuation behavior during both hurricanes. Also evacuation experience at hurricane Ivan positively influenced evacuation decision during Katrina. In spite of traffic and other problems reported by citizens (Russel, 2005) and late evacuation order, more people 
evacuated during hurricane Katrina as people become more conscious regarding hurricane threat experiencing huge loss of hurricane Ivan. This analysis clearly suggests that a big hurricane in spite of management problem will positively influence people's evacuation decision. People experiencing that disaster will leave no chance of being in the same disaster again in a similar following situation. This phenomenon suggests nearmiss phenomena of human behavior in a disaster event. 
Table 6-11: Determinants of evacuation decision during hurricane Katrina, Bivariate Probit Approach

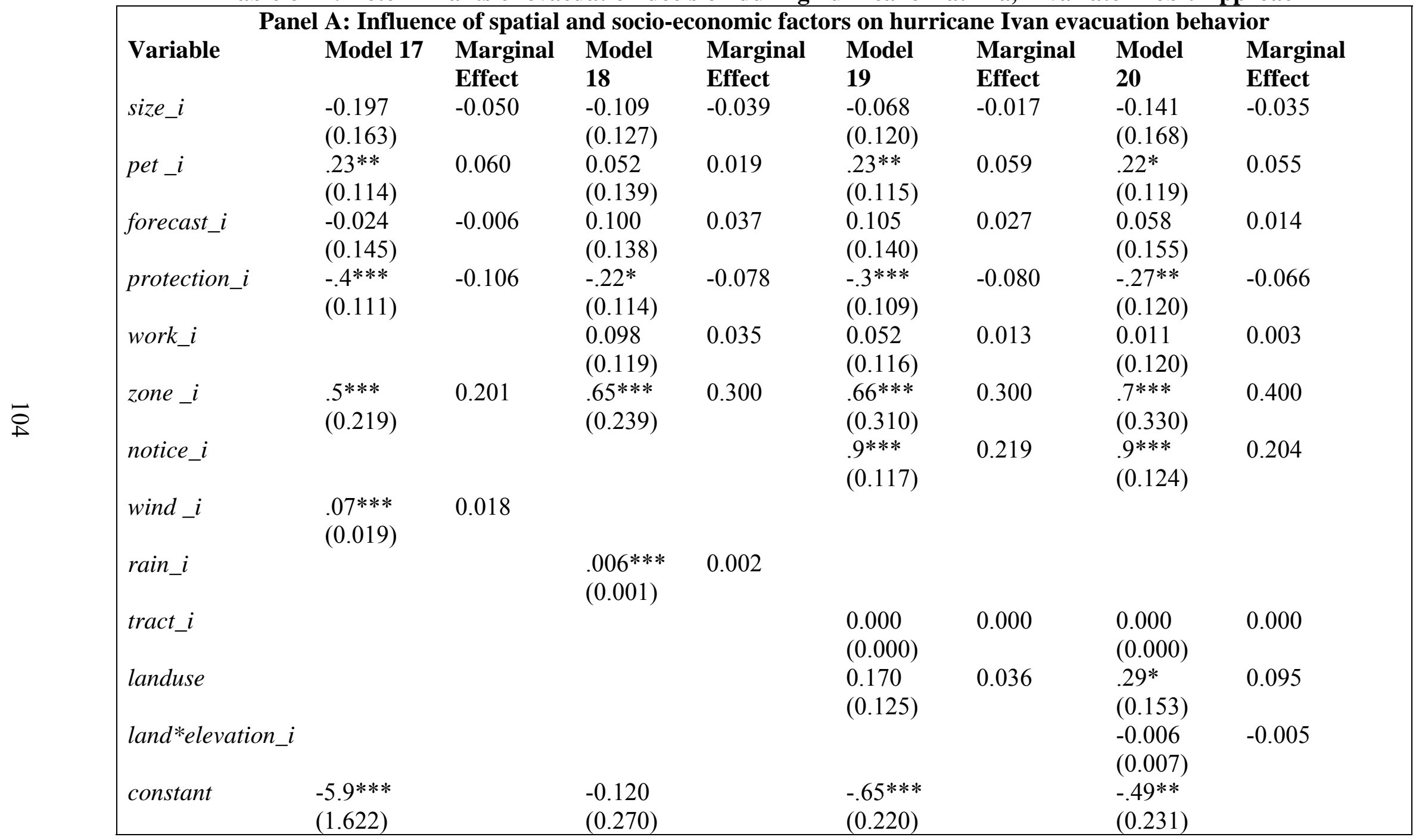




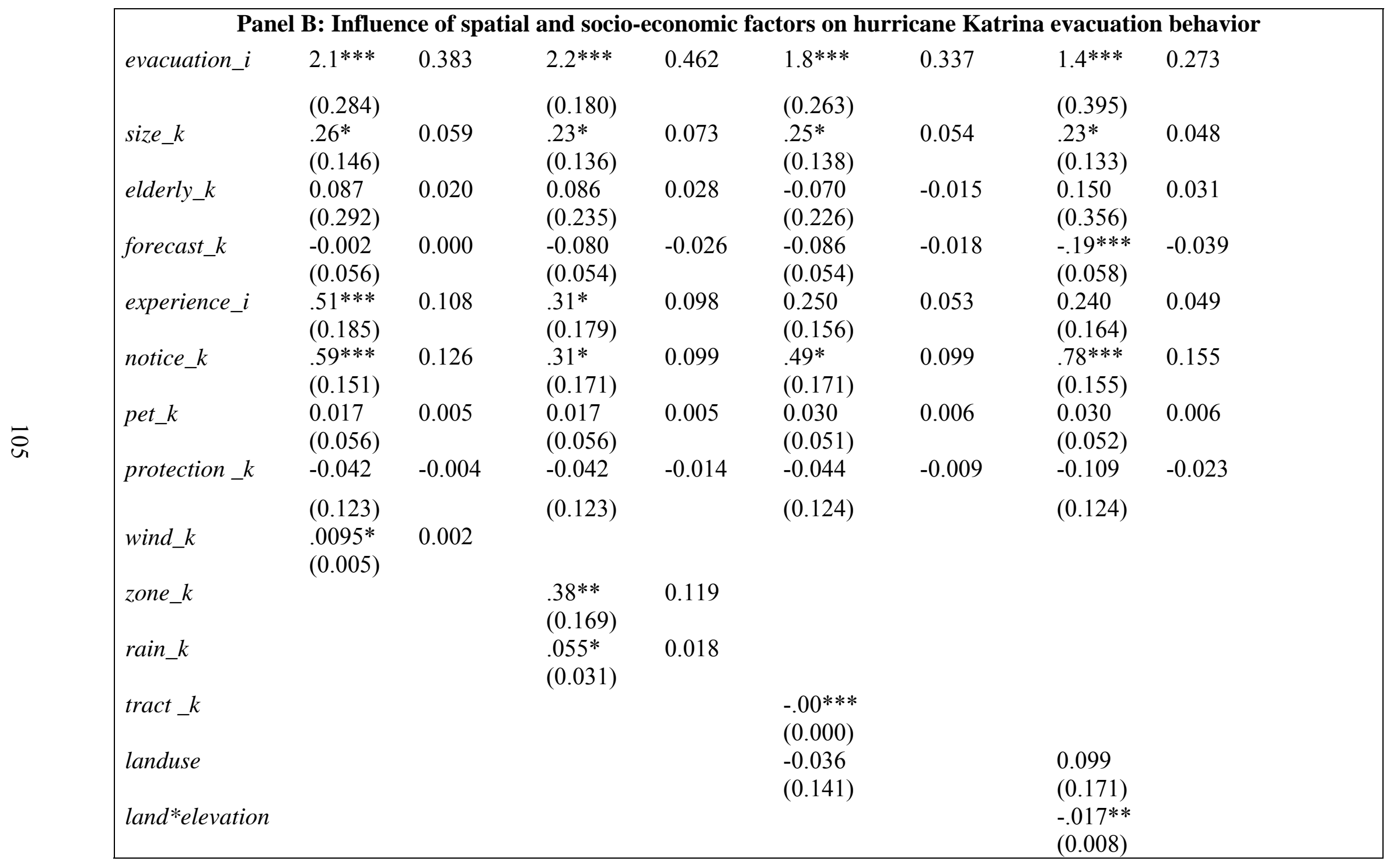




\begin{tabular}{|lllll|}
\hline constant & $-3.6^{* * *}$ & $-3.1^{* * *}$ & 0.360 & $-.91^{* * *}$ \\
& $(0.49)$ & $(0.62)$ & $(0.34)$ & $(0.33)$ \\
\hline CHI2 & 345 & 327 & 332 & 248 \\
$N$ & 585 & 360 & 580 & 569 \\
$A I C$ & 1243 & 817 & 1297 & 1340 \\
BIC & 1335 & 906 & 1397 & 1449 \\
\hline
\end{tabular}

Notes: ***,**, * imply significance at $1 \%, 5 \%, 10 \%$ levels respectively; numbers inside the parenthesis are robust standard errors. 


\section{CHAPTER 7: $\quad$ CONCLUSION}

A longitudinal analysis was performed to investigate evacuation behavior during two major hurricane events, hurricane Ivan and hurricane Katrina. A panel dataset was used for this purpose which was collected from surveys in two consecutive years (2005 and 2006) following the two major hurricane events. The longitudinal survey data analysis was supported by a geospatial database which was developed with respect to survey respondents household and was added with the survey database. The purpose of the spatial database was to extract geospatial information of the survey respondents and to explore possible relationship with evacuation behavior.

The first part of the study analyzed evacuation behavior and risk perception

during hurricane Ivan from the panel data. The analyses identified the factors influencing people's hurricane risk perception in that event and the subsequent evacuation behavior. A previous literature suggests that risk perception is an endogenous variable (Shaw and Baker, 2010). Therefore to account for the endogeneity, a structural Bivariate (BP) model was used. The BP model was developed on the hypothesis that higher risk perception about hurricane threat drives towards positive evacuation behavior. The analysis found that in addition to socio-economic variables, geospatial factors such as household location from shoreline, household distance from hurricane tract, elevation of property, rainfall and wind exposure during disaster event, and time and location inside evacuation zone influenced people risk perception significantly. The analysis also found that wind intensity affects the risk perception more than flood hazard affects risk perception. In general, the whole area exhibited higher risk perception for wind. Respondents close to shoreline had higher risk perception for flood while respondents 
located inland had higher risk perception for wind. Finally, the BP model suggests that people made evacuation decision in coherence with their risk perception about hurricane threat.

The second part of the study focused on exploring the influence of geo-spatial factors in people's evacuation decision. When consistent influence of some geospatial factors over the time period was observed, it could be asserted with more certainty about the role of those specific variables. Significant relation was found for all geospatial factors on respondent's evacuation behavior. In hurricane Ivan, Alabama residents evacuated more due to proximity to hurricane Ivan tract. During Katrina, Louisiana residents evacuated more due to proximity to and from hurricane Katrina tract. Again in both of these hurricanes, people who lived close to shoreline evacuated more than people who lived farther inland. Also elevation played a significant role in shaping the evacuation decision. People living in low lying areas evacuated more than people living in relatively higher grounds. Respondents who experienced higher hurricane wind gust and more rainfall evacuated in larger proportion than those who experienced less.

As this panel dataset analyzed people's actual evacuation decision and not just their intention for future event, it actually examined whether people updated their risk perception and evacuation behavior in the consecutive hurricanes or not. A large number of evacuees reported long traffic delays during hurricane Ivan which eventually did not hit the area (Laska, 2008). Such experiences can be seen as a precursor of the "cry wolf" phenomenon that could have negatively affected evacuation behavior during hurricane Katrina in 2005. However, longitudinal survey analysis of hurricane Ivan and Katrina did not support the "cry wolf" phenomena in hurricane Katrina evacuation behavior. In spite 
of many constraints, more people evacuated during Katrina than during Ivan. The analysis indicated that people who evacuated during Ivan were 5 times more likely to evacuate during Katrina than those who stayed home during hurricane Ivan. The analysis also provided information about the timing of evacuation for majority of people. During both hurricanes, it was found that maximum people evacuated one day before landfall.

\subsection{Implications of Results on Emergency Management Practices}

The finding suggests that once the evacuation order is given, respondent's evacuation followed a pattern which depends much on their location specific hurricane risk exposure. People close to shoreline evacuated more than people inland. Also people living in low lying areas evacuated more than people located in higher ground. Therefore, people who are most exposed to risk have inherent understanding about the risk and therefore more likely to evacuate. But then again hurricanes can cause damage to inland by intense winds, rains, and tornadoes (Forbes 2006). Also people living in higher ground might be impacted by surge depending on the severity of a storm surge. Therefore, such group of people who lived in higher grounds, perceived low risk and did not evacuate, even though they were exposed to higher risk level. Evacuation notice played a vital role in developing risk perception. Therefore, evacuation notice can be conveyed to this group of people with precise risk information so that they do not underestimate their risk exposure for incoming hurricanes.

In general, people perceive higher risk for wind than flood in the study area. But in fact there are several low lying flood prone areas even though they perceived higher wind risk than flood. Therefore, these people need to be communicated about the level of 
flood risk. This can be done by effective risk communication process (e.g., visual aid showing map or cone of tract).

During hurricane evacuation, the major focus is on the rapid movement of people to safer areas. As maximum people had the intention to avoid unnecessary evacuation, they follow hurricane prediction closely and evacuate on the last day when the location of hurricane landfall is quite certain. One way to reduce pressure on primary evacuation route is to create alternative routes and direct some evacuees to use those routes which are not free flowing. This can be done by opening temporary shelters in closest safe areas from evacuation zone and connecting them with alternative evacuation routes. In that way, even though on the last day, maximum people will be evacuating, a lot of them can use alternative routes to reach to the temporary shelters. As people evacuating last moment know that there is a chance of getting stuck in the road, a lot of them will be using alternative routes to reach to temporary shelters.

\subsection{Future Research}

There is still much to be understood about the influence of geospatial factors on people's hurricane risk perception and evacuation behavior. It is important to know the physical extent of influence of geospatial factors up to which people do not perceive risk and the evacuation process do not work. This will help to manage the evacuation more efficiently. There is room for further analysis whether the geospatial factors affect the evacuation behavior in all regions similarly or not. If the influence of geospatial factors in different regions can be determined, it will be possible to manage evacuation for specific regions more precisely. Future research can focus on determining which factors influence risk perception and evacuation decision. The models constructed for this research 
identified many geospatial factors that have been found to influence risk perception and evacuation decision. However, these factors proved to be reasonable predictors of risk perception and evacuation decision. Identification of factors, which influence risk perception and evacuation decision, are very important to grasp a better understanding of evacuee behavior in a disaster event. In addition, knowledge about these factors could assist in designing better evacuation plans and ensures maximum compliance with evacuation orders in disaster prone areas. 


\section{LIST OF REFERENCES}

1. Akaike, H. (1974). A new look at the statistical model identification. Automatic Control, IEEE Transactions on, 19(6), 716-723.

2. Baker, E. J. (1991). Hurricane evacuation behavior. International Journal of Mass Emergencies and Disasters, 9(2), 287-310.

3. Barras, J., Beville, S., Britsch, D., Hartley, S., Hawes, S., Johnston \& Suhayda, J. (2003). Historical and Projected Coastal Louisiana Land Changes: 1978-2050 (p. 39p). United States Geological Survey.

4. Bateman, J. M., \& Edwards, B. (2002). Gender and evacuation: A closer look at why women are more likely to evacuate for hurricanes. Natural Hazards Review,3(3), 107-117.

5. Botzen, W. J. W., Aerts, J. C. J. H., \& Van Den Bergh, J. C. J. M. (2009). Dependence of flood risk perceptions on socioeconomic and objective risk factors. Water Resources Research, 45(10). W10440. DOI: 10.1029/2009WR007743.

6. Brommer, D. M., \& Senkbeil, J. C. (2010). Pre-landfall evacuee perception of the meteorological hazards associated with Hurricane Gustav. Natural Hazards, 55(2), 353-369.

7. Burnside, R., Miller, D. S., \& Rivera, J. D. (2007). The impact of information and risk perception on the hurricane evacuation decision-making of greater New Orleans residents. Sociological Spectrum, 27(6), 727-740.

8. Cutter, S. L., Emrich, C. T., Bowser, G., Angelo, D., \& Mitchell, J. T. (2011). 2011 South Carolina Hurricane Evacuation Behavioral Study.

9. Czajkowski, J. (2011). Is it time to go yet? Understanding household hurricane evacuation decisions from a dynamic perspective. Natural Hazards Review, 12(2), 72-84.

10. Dash, N., \& Gladwin, H. (2007). Evacuation decision making and behavioral responses: Individual and household. Natural Hazards Review, 8(3), 69-77.

11. Douglass, S. L., Hughes, S. A., Rogers, S., and Chen, Q. (2004). The impact of Hurricane Ivan on the coastal roads of Florida and Alabama: a preliminary report. Report to Coastal Transportation Engineering Research and Education Center, Univ. of South Alabama, Mobile, Alabama. 
12. Dow, K. and Cutter, S. L. (1998). Crying wolf: Repeat responses to hurricane evacuation orders. Coastal Management, 26 (4), 237-252. DOI: 10.1080/08920759809362356.

13. Eckel, C. C. and Grossman, P. J. (2008a). Differences in the economic decisions of men and women: Experimental evidence. Handbook of Experimental Economics Results, 1, 509-519.

14. Eckel, C. C. and Grossman, P. J. (2008b). Men, women and risk aversion: Experimental evidence. Handbook of Experimental Economics Results, 1(7), 106173.

15. Eckel, C. C. and Grossman, P. J. (2008c). Forecasting risk attitudes: An experimental study using actual and forecast gamble choices. Journal of Economic Behavior \& Organization, 68(1), 1-17.

16. Eckel, C. C., \& Grossman, P. J. (2002). Sex differences and statistical stereotyping in attitudes toward financial risk. Evolution and Human Behavior, 23(4), 281-295.

17. Elliott, J. R., \& Pais, J. (2006). Race, class, and Hurricane Katrina: Social differences in human responses to disaster. Social Science Research, 35(2), 295-321.

18. Elsner, J. B., Kossin, J. P., \& Jagger, T. H. (2008). The increasing intensity of the strongest tropical cyclones. Nature, 455(7209), 92-95.

19. Emanuel, K. (2005). Increasing destructiveness of tropical cyclones over the past 30 years. Nature, 436(7051), 686-688.

20. ESRI (2011). ArcGIS Desktop: Release 10. Redlands, CA: Environmental Systems Research Institute.

21. Federal Emergency Management Agency, (2013). Fema flood zones. Retrieved from http://www.fema.gov/floodplain-management/flood-zones.

22. Fischer, H. W., Stine, G. F., Stoker, B. L., Trowbridge, M. L., \& Drain, E. M. (1995). Evacuation behavior: why do some evacuate, while others do not? A case study of the Ephrata, Pennsylvania (USA) evacuation. Disaster Prevention and Management, 4(4), 30-36.

23. Forbes, G., (2006). Inland Hurricane Threats, URL: http://www.weather.com/blog/ weather/8_9543.html on 13th may, 2014.

24. Gabe, T., Falk, G., McCarty, M., \& Mason, V. W. (2005). Hurricane Katrina: socialdemographic characteristics of impacted areas. Washington DC: Congressional Research Service, Library of Congress. 
25. Gillette, B. (2004). Stay or flee? Lessons from Hurricane Ivan evacuation. Mississippi Business Journal. Retrieved from http://msbusiness.com/blog/2004/10/25 /stay-or-flee-lessons-from-hurricane-ivan-evacuation/

26. Gladwin, C. H., Gladwin, H., \& Peacock, W. G. (2001). Modeling hurricane evacuation decisions with ethnographic methods. International Journal of Mass Emergencies and Disasters, 19(2), 117-143.

27. Gudishala, R., \& Wilmot, C. (2010). Development of a time-dependent, audio-visual, stated-choice method of data collection of hurricane evacuation behavior. Journal of Transportation Safety \& Security, 2(2), 171-183.

28. Greene, W. H. (2003). Econometric analysis. Pearson Education India.

29. Hasan, S., Ukkusuri, S., Gladwin, H., \& Murray-Tuite, P. (2010). Behavioral model to understand household-level hurricane evacuation decision making. Journal of Transportation Engineering, 137(5), 341-348.

30. Henk, R. H., Ballard, A. J., Robideau, R. L., Peacock, W. G., Maghelal, P., Lindell, M. K., ... \& Boxil, S. (2007). Disaster preparedness in Texas. College Station, Texas. Technical Memorandum for the Texas Department of Transportation, Texas Transportation Institute.

31. Hodge, D., Sharp, V., \& Marts, M. (1979). Contemporary responses to volcanism: case studies from the Cascade and Hawaii. In Volcanic activity and human ecology (pp. 221-48). Academic Press.

32. Holt, C. A., \& Laury, S. K. (2002). Risk aversion and incentive effects. American Economic Review, 92(5), 1644-1655.

33. Kates, R. W. (1971). Natural hazard in human ecological perspective: hypotheses and models. Economic Geography, 47(3), 438-451.

34. Kim, Y. C., \& Kang, J. (2010). Communication, neighbourhood belonging and household hurricane preparedness. Disasters, 34(2), 470-488.

35. Knabb, R. D., Rhome, J. R., \& Brown, D. P. (2005). Tropical cyclone report: Hurricane Katrina, 23-30 August 2005. National Hurricane Center.

36. Lara-Chavez, A., \& Alexander, C. (2006). The effects of hurricane Katrina on corn, wheat and soybean futures prices and basis. In Proceedings of the NCCC-134 Conference on Applied Commodity Price Analysis, Forecasting, and Market Risk Management. St. Louis, MO. 
37. Laska, S. (2008). What If Hurricane Ivan Had Not Missed New Orleans? Sociological Inquiry, 78(2), 174-178.

38. Lazo, J. K., \& Morrow, B. H. (2013). Survey of Coastal US Public's Perspective on Extra Tropical-Tropical Cyclone Storm Surge Information.

39. Letson, D., Sutter, D. S., \& Lazo, J. K. (2007). Economic value of hurricane forecasts: An overview and research needs. Natural Hazards Review, 8(3), 78-86.

40. Lindell, M. K., Lu, J. C., \& Prater, C. S. (2005). Household decision making and evacuation in response to Hurricane Lili. Natural Hazards Review, 6(4), 171-179.

41. Lindell, M. K., Perry, R. W., Prater, C., \& Nicholson, W. C. (2006). Fundamentals of emergency management. FEMA.

42. Lindell, M. K., Prater, C. S., \& Peacock, W. G. (2007). Organizational communication and decision making for hurricane emergencies. Natural Hazards Review, 8(3), 50-60.

43. Lybbert, T. J., Barrett, C. B., McPeak, J. G., \& Luseno, W. K. (2007). Bayesian herders: Updating of rainfall beliefs in response to external forecasts. World Development, 35(3), 480-497.

44. Major, A. M. (1999). Gender differences in risk and communication behabior: Responses in the New Madrid earthquake prediction. International Journal of Mass Emergencies and Disasters, 17(3), 313-38.

45. Matyas, C., Srinivasan, S., Cahyanto, I., Thapa, B., Pennington-Gray, L., \& Villegas, J. (2011). Risk perception and evacuation decisions of Florida tourists under hurricane threats: a stated preference analysis. Natural Hazards, 59(2), 871-890

46. Menzel, D. C. (2006). The Katrina aftermath: A failure of federalism or leadership? Public Administration Review, 66(6), 808-812.

47. Meyer, R. J., Baker, J., Broad, K., Czajkowski, J., \& Orlove, B. (2014). The dynamics of hurricane risk perception: Real-Time Evidence from the 2012 Atlantic Hurricane Season. Bulletin of the American Meteorological Society. DOI: http://dx.doi.org/10.1175/BAMS-D-12-00218.1

48. Monfardini, C., \& Radice, R. (2008). Testing exogeneity in the bivariate probit model: A monte carlo study. Oxford Bulletin of Economics and Statistics, 70(2), 271282. 
49. Morrow, B. H., \& Gladwin, H. (2005). Hurricane Ivan behavioral analysis, 2004 hurricane assessments. US Army Corps of Engineers.

50. Murray-Tuite, P., Yin, W., Ukkusuri, S. V., \& Gladwin, H. (2012). Changes in evacuation decisions between Hurricanes Ivan and Katrina. Transportation Research Record: Journal of the Transportation Research Board, 2312(1), 98-107.

51. Nelson, C. E., Coovert, M. D., Kurtz, A., Fritzche, B., Crumley, C., \& Powell, A. (1989). Models of hurricane evacuation behavior. Dept. of Psychology, Univ. of South Florida, Tampa, Fla.

52. NHC (National Hurricane Center), (2006). Tropical cyclone report: 2005 Atlantic hurricane season. NOAA, Washington D.C.

53. NOAA (2000). A Guide to National Shoreline Data and Term, derived from http://shoreline.noaa.gov/references.html

54. NOAA Special Publication NOS CO-OPS (2000). Tidal Datums and Their Applications. U.S. Department of Commerce. Silver Spring, MD. Accessed April 4, 2008,http://at tidesandcurrents.noaa.gov/publications/tidal_datums_and_their_applications.pdf.

55. Norris, F. H., Smith, T., \& Kaniasty, K. (1999). Revisiting the experience-behavior hypothesis: The effects of hurricane Hugo on hazard preparedness and other selfprotective acts. Basic and Applied Social Psychology, 21(1), 37-47.

56. Peacock, W. G., Brody, S. D., \& Highfield, W. (2005). Hurricane risk perceptions among Florida's single family homeowners. Landscape and Urban Planning, 73(2), $120-135$.

57. Peacock, W. G., Morrow, B. H., \& Gladwin, H. (Eds.). (1997). Hurricane Andrew: Ethnicity, gender, and the sociology of disasters. Psychology Press.

58. Perry, R. W., \& Lindell, M. K. (1991). The effects of ethnicity on evacuation decision-making. International journal of mass emergencies and disasters, 9(1), 4768.

59. Perry, R. W., and M. K. Lindell (1990), Predicting long term adjustment to volcano hazard, Int. J. Mass Emergencies Disasters, 8(2), 117-136.

60. Pfister, N. (2002). Community response to flood warnings: the case of an evacuation from Grafton, March 2001. Australian Journal of Emergency Management, 17(2), 19. 
61. Pielke Jr, R. A., Gratz, J., Landsea, C. W., Collins, D., Saunders, M. A., \& Musulin, R. (2008). Normalized hurricane damage in the United States: 1900-2005. Natural Hazards Review, 9(1), 29-42.

62. Rappaport, E. N. (2000). Loss of life in the United States associated with recent Atlantic tropical cyclones. Bulletin of the American Meteorological Society, 81(9), 2065-2073.

63. Riad, J. K., Norris, F. H., \& Ruback, R. B. (1999). Predicting evacuation in two major disasters: risk perception, social influence, and access to Resources1.Journal of Applied Social Psychology, 29(5), 918-934.

64. Russell, G. 2005. Nagin Orders First-Ever Mandatory Evacuation of New Orleans. The Times-Picayune, New Orleans, Louisiana, August 28, 2005. Available online at: http://www.nola.com/newslogs/breakingtp/index.ssf?/mtlogs/nola_Times- Picayune /archives/2005_08_28.html.

65. Sajaia, Z. (2008). Maximum likelihood estimation of a bivariate ordered probit model: implementation and Monte Carlo simulations. The Stata Journal, 4(2), 1-18.

66. Schwarz, G. (1978). Estimating the dimension of a model. The Annals of Statistics, 6(2), 461-464.

67. Shaw, W. D., \& Baker, J. (2010). Models of location choice and willingness to pay to avoid hurricane risks for Hurricane Katrina evacuees. International Journal of Mass Emergencies and Disasters, 28(1), 87-114.

68. Siebeneck, L. K. (2010). Examining the geographic dimensions of risk perception, communication, and response during the evacuation and return-entry process (Doctoral dissertation, The University of Utah).

69. Smith, G. S. (2010). Digital orthophotography and GIS. ESRI Conference. http://proceedings.esri.com/library/userconf/proc95/to150/p124.html

70. Smith, K. T. (1999). Estimating the cost of hurricane evacuation: a study of evacuation behavior and risk interpretation using combined reveal and stated preferences household data. Department of Economics, East Carolina Univ., Greenville, NC.

71. Snyder, J. P. (1997). Flattening the earth: two thousand years of map projections. University of Chicago Press.

72. Snyder, J.P. (1989). Album of Map Projections, United States Geological Survey Professional Paper. United States Government Printing Office. 1453. 
73. Solís, D., Thomas, M., \& Letson, D. (2010). An empirical evaluation of the determinants of household hurricane evacuation choice. Journal of Development and Agricultural Economics, 2(3), 188-196.

74. Stein, R. M. (2011). How risk perceptions influence evacuations from hurricanes (Doctoral dissertation, Department Of Statistics, Rice University).

75. Stein, R. M., Dueñas Osorio, L., \& Subramanian, D. (2010). Who Evacuates When Hurricanes Approach? The Role of Risk, Information, and Location. Social Science Quarterly, 91(3), 816-834.

76. Stein, R. M., Dueñas Osorio, L., \& Subramanian, D. (2010). Who Evacuates When Hurricanes Approach? The Role of Risk, Information, and Location. Social Science Quarterly, 91(3), 816-834.

77. Stein, R., Buzcu Guven, B., Dueñas Osorio, L., Subramanian, D., \& Kahle, D. (2013). How Risk Perceptions Influence Evacuations from Hurricanes and Compliance with Government Directives. Policy Studies Journal, 41(2), 319-342.

78. Stewart S (2004) Tropical cyclone report: Hurricane Ivan 2-24 September 2004. National Hurricane Center, Miami.

79. Turner, R. H., Nigg, J. M., \& Paz, D. H. (1986). Waiting for disaster: Earthquake watch in California. University of California Press.

80. Tversky, A., \& Kahneman, D. (1974). Judgment under uncertainty: Heuristics and biases. Science, 185(4157), 1124-1131.

81. U.S. Department of the Interior and U.S. Geological Survey, URL: http://nationalmap.gov/viewer.html.

82. US Geological Survey, URL: http://www.infoplease.com/ipa/A0001792.html.

83. Whitehead, J. C. (2003). One million dollars per mile? The opportunity costs of hurricane evacuation. Ocean \& Coastal management, 46(11), 1069-1083.

84. Whitehead, J. C. (2005). Environmental risk and averting behavior: Predictive validity of jointly estimated revealed and stated behavior data. Environmental and Resource Economics, 32(3), 301-316.

85. Whitehead, J. C., Edwards, B., Van Willigen, M., Maiolo, J. R., Wilson, K., \& Smith, K. T. (2000). Heading for higher ground: factors affecting real and hypothetical hurricane evacuation behavior. Global Environmental Change Part B: Environmental Hazards, 2(4), 133-142. 
86. Whitehead, J. C., Edwards, B., Van Willigen, M., Maiolo, J. R., Wilson, K., \& Smith, K. T. (2000). Heading for higher ground: factors affecting real and hypothetical hurricane evacuation behavior. Global Environmental Change Part B: Environmental Hazards, 2(4), 133-142.

87. Windham, G. O., Posey, E. I., Ross, P. J., \& Spencer, B. G. (1977). Reactions to storm threat during Hurricane Eloise. Mississippi State University Social Science Research Center. 